\title{
Transient Electromagnetic Soundings Near Great Sand Dunes National Park and Preserve, San Luis Valley, Colorado (2006 Field Season)
}

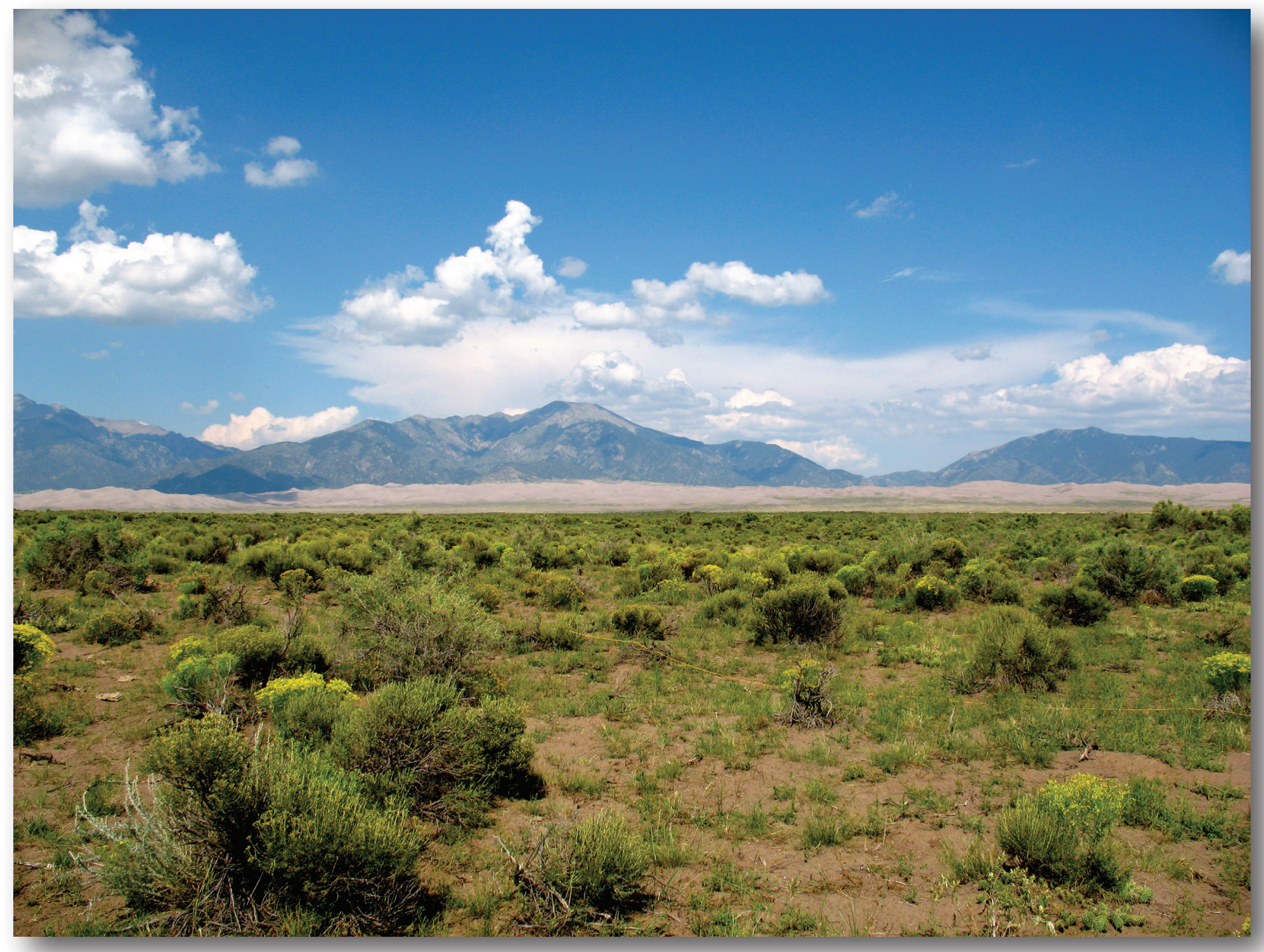

Open-File Report 2009-1051 
Cover: Near Sand Creek looking northeast toward Great Sand Dunes National Park.

The dunes form a tan ribbon sandwiched between the vegetated plain in the forground and the taller Sangre de Cristo Mountains in the background. Photo by David V. Fitterman. 


\section{Transient Electromagnetic Soundings Near Great Sand Dunes National Park and Preserve, San Luis Valley, Colorado (2006 Field Season)}

By David V. Fitterman and Oderson A. de Souza Filho

Open-File Report 2009-1051

U.S. Department of the Interior

U.S. Geological Survey 


\section{U.S. Department of the Interior KEN SALAZAR, Secretary}

\section{U.S. Geological Survey Suzette Kimball, Acting Director}

U.S. Geological Survey, Reston, Virginia 2009

For product and ordering information:

World Wide Web: http://www.usgs.gov/pubprod

Telephone: 1-888-ASK-USGS

For more information on the USGS - the Federal source for science about the Earth, its natural and living resources, natural hazards, and the environment:

World Wide Web: http://www.usgs.gov

Telephone: 1-888-ASK-USGS

Suggested citation:

Fitterman, D.V., de Souza Filho, 0.A., 2009, Transient electromagnetic soundings near Great Sand Dunes National Park and Preserve, San Luis Valley (2006 Field Season), Colorado: U.S. Geological Survey OpenFile Report 2009-1051

Any use of trade, product, or firm names is for descriptive purposes only and does not imply endorsement by the U.S. Government.

Although this report is in the public domain, permission must be secured from the individual copyright owners to reproduce any copyrighted material contained within this report. 


\section{Contents}

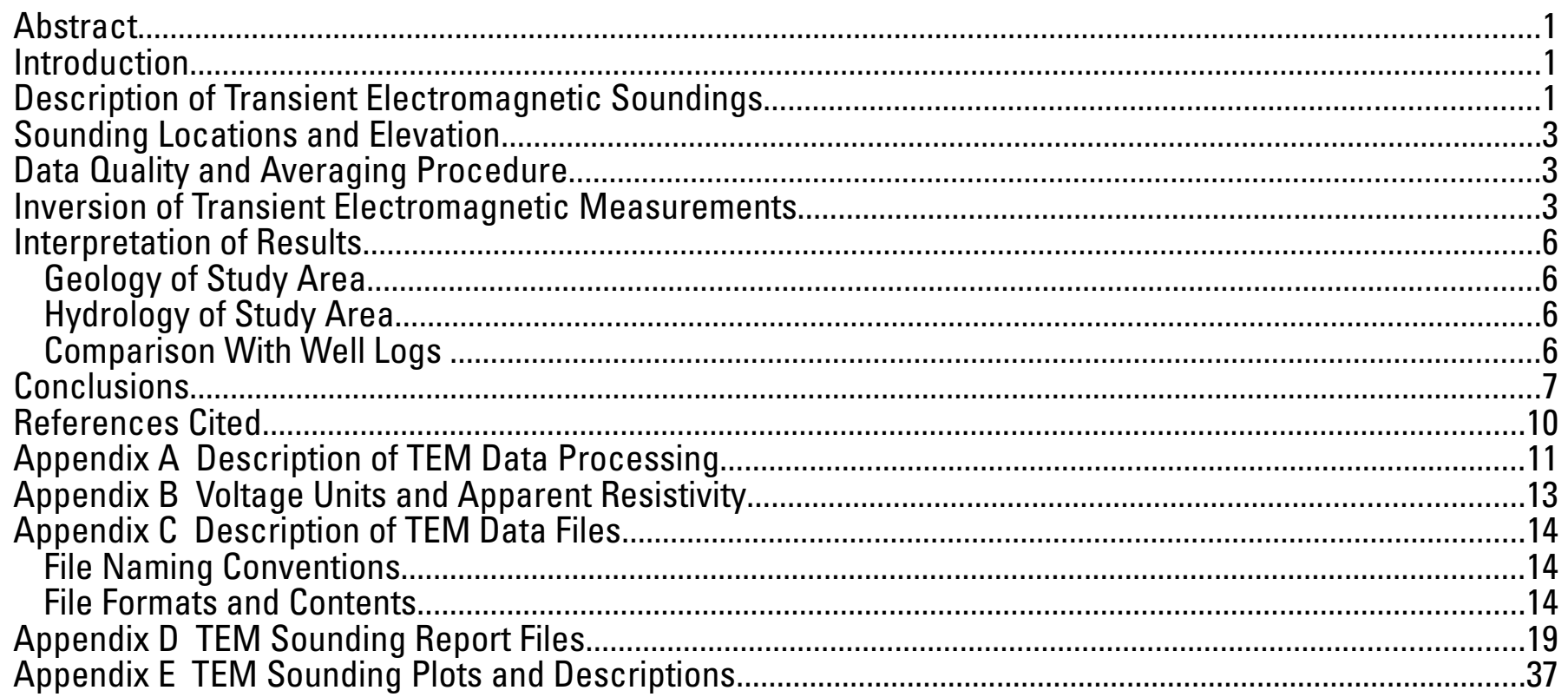

\section{Figures}

Figure 1. Location of San Luis Valley, Great Sand Dunes National Park and Preserve, and study area...........2 Figure 2. Location of TEM soundings................................................................................................. Figure 3. Comparison of interpreted resistivity-depth functions and geologic logs from nearby wells............9 Figure A-1. Data processing programs, files, and flow. Solid lines show processing flow..............................12 Figure C-1. Diagram showing contents of header records. .......................................................................

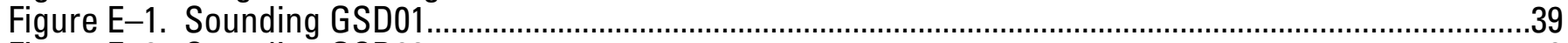

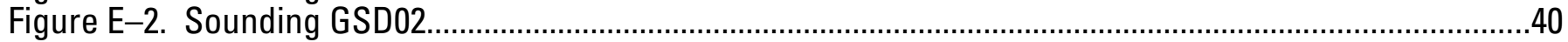

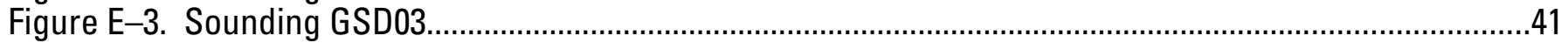

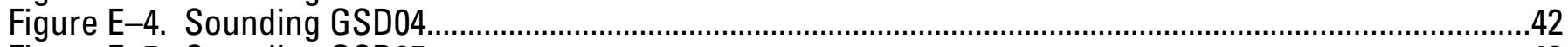

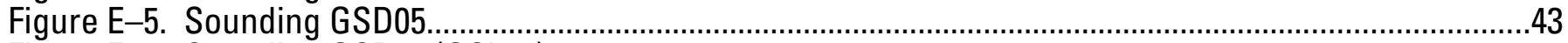

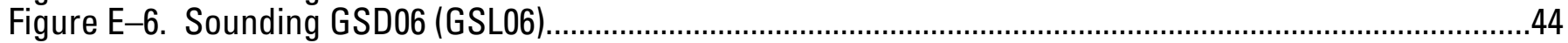

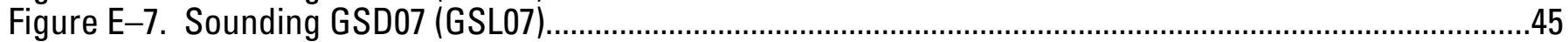

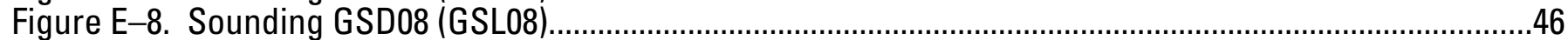

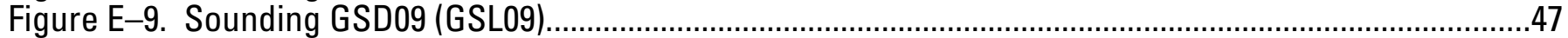

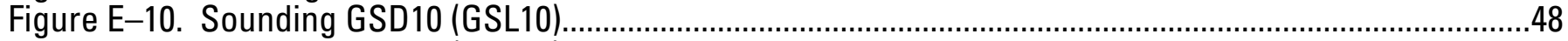

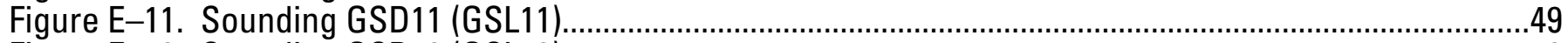

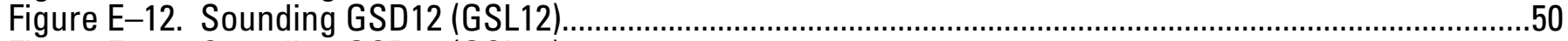

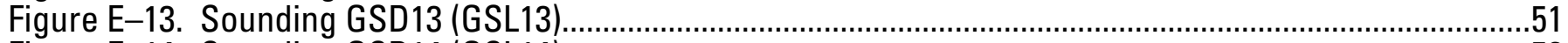

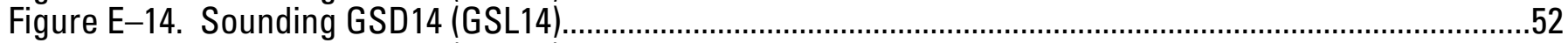

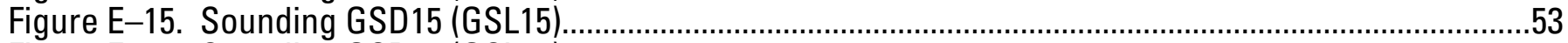

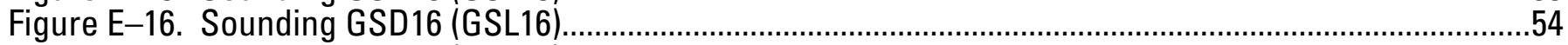

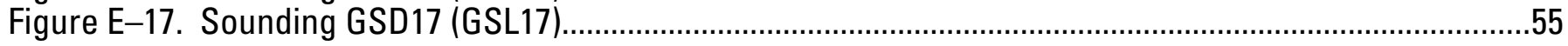




\section{Tables}

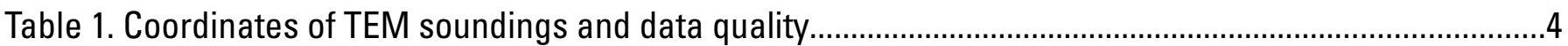

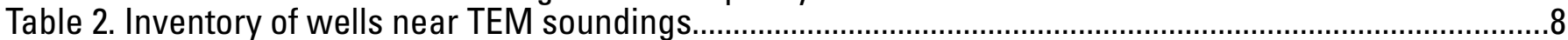

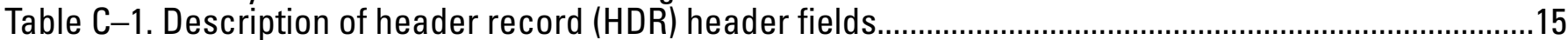

Table C-2. Description of data record (OPR) header fields..........................................................................16

Table C-3. Description of header record (HDR) data fields (gates) ..............................................................16

Table C-4. Description of data record (OPR) data fields (gates) ....................................................................16

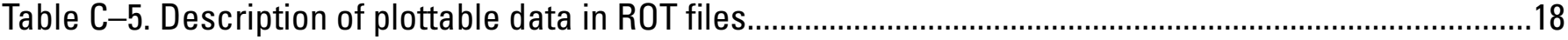




\section{Conversion Factors}

Inch/Pound to SI

\begin{tabular}{cccc}
\hline & Multiply & By & To obtain \\
\hline Length & & & \\
\hline inch (in.) & 2.54 & centimeter (cm) \\
inch (in.) & 25.4 & millimeter (mm) \\
foot (ft) & 0.3048 & meter (m) \\
mile (mi) & 1.609 & kilometer (km) \\
mile, nautical (nmi) & 1.852 & kilometer (km) \\
yard (yd) & 0.9144 & meter (m) \\
\hline
\end{tabular}

\section{SI to Inch/Pound}

\begin{tabular}{cll}
\hline \multicolumn{1}{c}{ Multiply } & \multicolumn{1}{c}{ By } & To obtain \\
\hline Length & & \\
\hline centimeter $(\mathrm{cm})$ & 0.3937 & inch (in.) \\
millimeter $(\mathrm{mm})$ & 0.03937 & inch (in.) \\
meter $(\mathrm{m})$ & 3.281 & foot (ft) \\
kilometer $(\mathrm{km})$ & 0.6214 & mile (mi) \\
kilometer $(\mathrm{km})$ & 0.5400 & mile, nautical (nmi) \\
meter $(\mathrm{m})$ & 1.094 & yard (yd)
\end{tabular}

Vertical coordinate information is referenced the National Geodetic Vertical Datum of 1929 (NGVD 29). Horizontal coordinate information is referenced to the North American Datum of 1927 (NAD 27).

Altitude, as used in this report, refers to distance above the vertical datum. 


\section{Electrical Conductivity and Electrical Resistivity}

\begin{tabular}{ccc}
\hline Multiply & By & To obtain \\
\hline Electrical conductivity & & \\
\hline siemens per meter $[\mathrm{S} / \mathrm{m}]$ & 1,000 & millisiemens per meter $[\mathrm{mS} / \mathrm{m}]$ \\
\hline siemens per meter $[\mathrm{S} / \mathrm{m}]$ & 10,000 & $\begin{array}{c}\text { microsiemens per centimeter } \\
{[\mu \mathrm{S} / \mathrm{cm}]}\end{array}$ \\
\hline Electrical resistivity & & \\
\hline ohm-meters $[\mathrm{ohm}-\mathrm{m}]$ & 0.001 & kiloohm-meters $[\mathrm{kohm}-\mathrm{m}]$ \\
\hline
\end{tabular}

Electrical conductivity $\sigma$ in siemens per meter $[\mathrm{S} / \mathrm{m}]$ can be converted to electrical resistivity $\rho$ in ohm-meters [ohm-m] as follows: $\rho=1 / \sigma$.

Electrical conductivity $\sigma$ in millisiemens per meter $[\mathrm{mS} / \mathrm{m}]$ can be converted to electrical resistivity $\rho$ in ohm-meters [ohm-m] as follows: $\rho=1,000 / \sigma$.

Electrical conductivity $\sigma$ in microsiemens per centimeter $[\mu \mathrm{S} / \mathrm{m}]$ can be converted to electrical resistivity $\rho$ in ohm-meters [ohm-m] as follows: $\rho=10,000 / \sigma$.

Electrical resistivity $\rho$ in ohm-meters [ohm-m] can be converted to electrical conductivity $\sigma$ in siemens per meter [S/m] as follows: $\sigma=1 / \rho$.

Electrical resistivity $\rho$ in ohm-meters [ohm-m] can be converted to electrical conductivity $\sigma$ in millisiemens per meter [mS/m] as follows: $\sigma=1,000 / \rho$.

Electrical resistivity $\rho$ in ohm-meters [ohm-m] can be converted to electrical conductivity $\sigma$ in microsiemens per centimeter $[\mu \mathrm{S} / \mathrm{m}]$ as follows: $\sigma=10,000 / \rho$. 


\title{
Transient Electromagnetic Soundings Near Great Sand Dunes National Park and Preserve, San Luis Valley, Colorado (2006 Field Season)
}

\author{
By David V. Fitterman ${ }^{1}$ and Oderson A. de Souza Filho ${ }^{2}$
}

\begin{abstract}
Time-domain electromagnetic (TEM) soundings were made near Great Sand Dunes National Park and Preserve in the San Luis Valley of southern Colorado to obtain subsurface information of use to hydrologic modeling. Seventeen soundings were made to the east and north of the sand dunes. Using a small loop TEM system, maximum exploration depths of about 75 to $150 \mathrm{~m}$ were obtained. In general, layered earth interpretations of the data found that resistivity decreases with depth. Comparison of soundings with geologic logs from nearby wells found that zones logged as having increased clay content usually corresponded with a significant resistivity decrease in the TEM determined model. This result supports the use of TEM soundings to map the location of the top of the clay unit deposited at the bottom of the ancient Lake Alamosa that filled the San Luis Valley from Pliocene to middle Pleistocene time.
\end{abstract}

\section{Introduction}

The supply of groundwater in the San Luis Valley of southcentral Colorado has been an on-going concern of area residents since the first wells were drilled in 1887 (Powell, 1958). Heavy reliance of agriculture on groundwatersupplied irrigation and drought conditions in recent years have intensified this concern. In addition to farming, groundwater is used to meet the requirements of the State of Colorado under the Rio Grande River Compact to furnish adequate surface-water flows to New Mexico, Texas, and Mexico. Great Sand Dunes National Park and Preserve (GSDNPP) also has an interest in the groundwater resources of the area and how they impact the national park and the National Park Service's (NPS) responsibility to preserve and protect it.

The U.S. Geological Survey (USGS) has been involved in geological, geophysical, and hydrological studies to obtain information needed to develop, verify, and refine groundwater flow models used to manage the water resources in the San Luis Valley (see Fig. 1).

Transient (or time-domain) electromagnetic (TEM) soundings were made in the San Luis Valley near GSDNPP to assess their utility in mapping the "blue clay," which separates the unconfined, near-surface aquifer from the deeper confined aquifer (Emery and others, 1973; Brendle, 2002). A second reason for making the TEM soundings was to assist in calibrating a helicopter electromagnetic (HEM) survey flown over four widely spaced lines in the area in December 2005. Data-quality problems with the HEM survey were sufficiently severe that they could not be resolved with the TEM data and will not be discussed in this report.

\section{Description of Transient Electromagnetic Soundings}

TEM soundings, which are well suited for mapping conductive targets such as saltwater intrusion and clay zones, have been used for a number of groundwater studies (Fitterman and Stewart, 1986; Fitterman,1989; Goldman

\footnotetext{
${ }^{1}$ U.S. Geological Survey

${ }^{2}$ Visiting scientist, Companhia de Pesquisa de Recursos Minerais, Brazil
} 
and others, 1991; Fitterman and others, 1999). The TEM method is described in detail by Kaufman and Keller (1983), McNeill (1990), and Fitterman and Labson (2005).

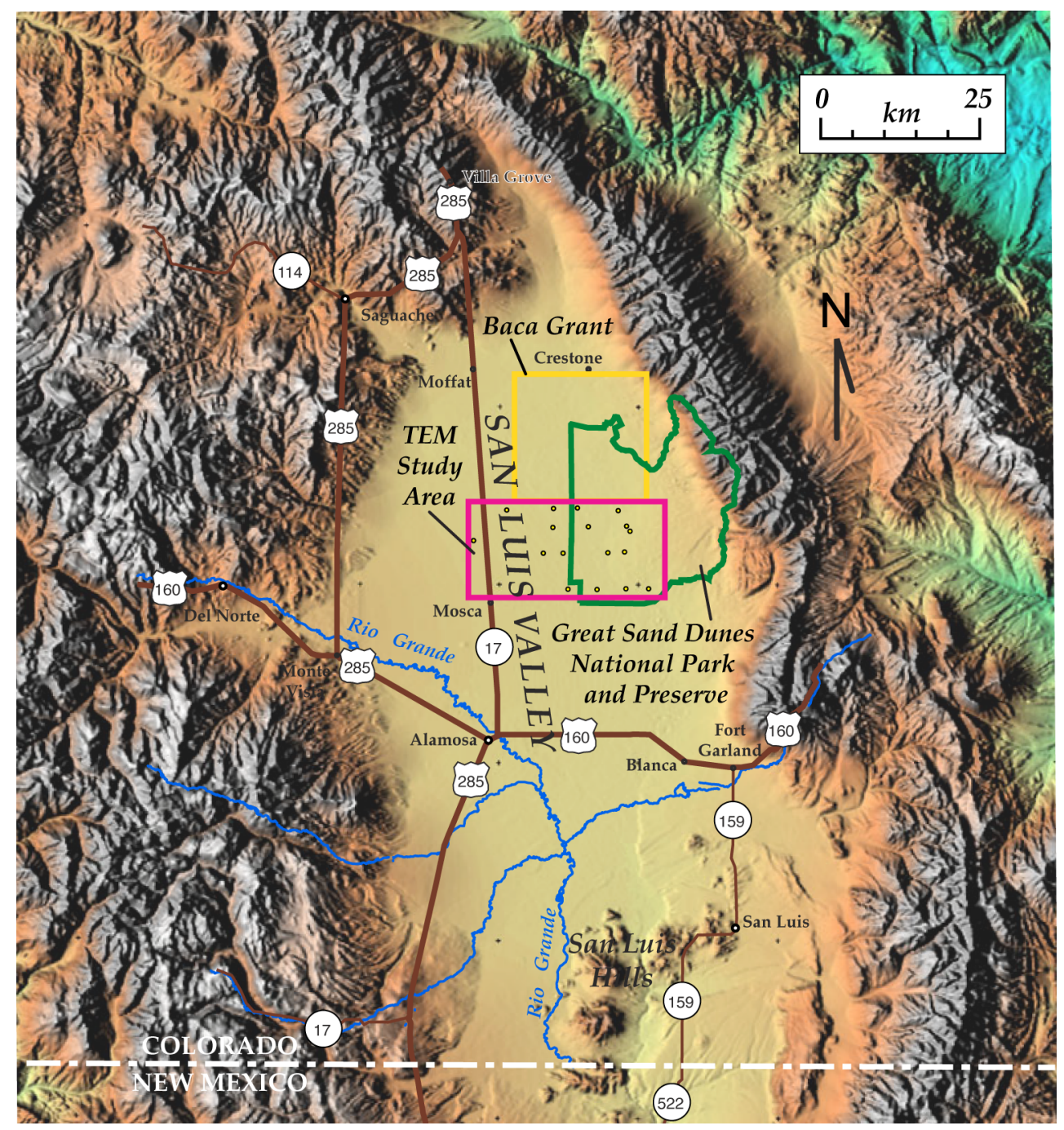

Figure 1. Location of San Luis Valley, Great Sand Dunes National Park and Preserve, and study area.

Soundings are made by passing a current through a large, square transmitter loop. The current flow generates a steady magnetic field. Abruptly cutting off the current flow disrupts the magnetic field and induces a circulating current system in the ground below the loop. The diffusion of these induced currents is controlled by the electrical conductivity of the ground. The current attenuation is small in conductive regions, and the current passes slowly through such regions. Resistive regions (low conductivity), on the other hand, attenuate the current flow. Current traverses these regions more rapidly than conductive regions. The circulating induced currents produce a secondary magnetic field that is sensed by a receiver coil located at the middle of the transmitter loop. Because of the relationship between the electrical conductivity structure of the ground, the current diffusion, and the secondary magnetic field, the voltage recorded by the receiver can be used to estimate the ground conductivity. The result is that the measured voltage-time curves, or transients, can be converted into resistivity-depth functions by a nonlinear parameter estimation process call inversion (Oldenburg and Li, 2005; Fitterman and Labson, 2005).

A Geonics PROTEM transient EM system with an analog receiver and an EM-47 battery powered transmitter were used. The transmitter loop was set up as a square with a nominal side length of $38.1 \mathrm{~m}$. Transmitter current was typically $2.5 \mathrm{~A}$. The receiver coil was a rigid loop about 1 meter in diameter with a moment of $31.4 \mathrm{~m}^{2}$. After adjusting receiver gain to an appropriate level, between five and 21 measurements were made using base-frequency repetition rates of $285 \mathrm{~Hz}$ and $30 \mathrm{~Hz}$. The base frequency controls the time range over which the transient is recorded. There are 
20 logarithmically spaced gates in the measurement associated with each base frequency. Each measurement represents a stack of several hundred individual transients. Data processing procedures are discussed in Appendix A.

\section{Sounding Locations and Elevation}

A total of 17 TEM soundings were made along four east-west lines situated west of GSDNPP (see fig. 2). Coordinates of the soundings were determined by GPS measurements and are given in table 1. Horizontal positions are referenced to NAD 27. The GPS unit reported positioning error uncertainty of between 4 to $9 \mathrm{~m}$. Elevations were obtained by using the GPS coordinates to locate the soundings on 7.5-minute topographic maps and then interpolating between the elevation contours. The vertical reference is NGVD 29.

\section{Data Quality and Averaging Procedure}

All but four of the TEM soundings were of very good quality. (Data quality is summarized in Table 1. Data plots can be found in Appendix E.) Sounding GSD10 was made next to a buried pipeline, resulting in a very linear apparent resistivity-time plot (see fig. E-10). Sounding GSD15 (fig. E-15) has very discontinuous behavior in the time range of approximately 0.1 to $1 \mathrm{~ms}$. This is likely due to coupling to nearby metallic objects, such as a fence or a buried conductor, or (less likely) from electrical noise. Sounds GSD16 and GSD17 show a pronounced discontinuous behavior, and the measurement noise is very large. This behavior is attributed to nearby electric fences used to contain a bison herd.

Anywhere from five to 21 TEM measurements were averaged for each sounding for each base frequency using program NTEMAVG to reduce and estimate measurement error. Some selective editing of the data was performed manually when it was obvious that a particular datum was significantly different from neighboring points. The average and standard deviation were calculated with the remaining measurements. The standard deviation of the apparent resistivity for the ultra high (UH) base frequency $(285 \mathrm{~Hz})$ was as low as 0.1 percent at early times. For most of the soundings the noise only increased to 1 to 3 percent at channel 20. The high (HI) base frequency data had noise levels of 0.5 percent at channel 1 often increasing to very high levels ( $>25$ percent) at the last channels. The percent standard deviation usually increases with time after transmitter turnoff because the signal due to the ground becomes small with respect to the background noise level. By the time the noise level reaches 10 percent in apparent resistivity the data are usually behaving discontinuously from one channel to the next and are not useable.

\section{Inversion of Transient Electromagnetic Measurements}

The TEM soundings were individually inverted using the simplest model that fit the data. The major features of most soundings could be adequately described with a three-layer model whose resistivities decrease with depth. After determining a preliminary model for each sounding and comparing the results with nearby soundings, additional layers were sometimes added to the models to improve the fit between the observed and computed apparent resistivities. Layers that were unresolvable because they were too thin, or their resistivity was not significantly different from adjacent layers, were eliminated from the final model. Most final models have between three and five layers. A detailed description of each sounding is given in Appendix C. 
Table 1. Coordinates of TEM soundings and data quality

\begin{tabular}{|l|c|c|c|l|}
\hline Sounding & Easting $^{\mathbf{1}}[\mathbf{m}]$ & Northing $^{\mathbf{1}}[\mathbf{m}]$ & Altitude $^{\mathbf{~}}$ [m] & \multicolumn{1}{|c|}{ Data Quality/Comments } \\
\hline GSD01 & 447883 & 4170723 & $2,342.6$ & very good \\
\hline GSD02 & 444296 & 4170718 & $2,330.8$ & very good \\
\hline GSD03 & 444939 & 4179770 & $2,336.6$ & very good \\
\hline GSD04 & 443075 & 4182999 & $2,332.5$ & very good \\
\hline GSD05 & 441451 & 4176374 & $2,327.0$ & very good \\
\hline GSD06 & 436634 & 4183430 & $2,323.9$ & very good \\
\hline GSD07 & 432845 & 4183327 & $2,319.3$ & very good \\
\hline GSD08 & 432749 & 4180343 & $2,317.6$ & very good \\
\hline GSD09 & 438358 & 4180486 & $2,327.2$ & very good \\
\hline GSD10 & 439729 & 4170606 & $2,316.2$ & not useable, near buried pipe \\
\hline GSD11 & 435143 & 4170653 & $2,313.0$ & very good \\
\hline GSD12 & 434357 & 4176316 & $2,312.8$ & very good \\
\hline GSD13 & 420246 & 4178283 & $2,308.7$ & very good \\
\hline GSD14 & 431245 & 4176318 & $2,301.0$ & very good \\
\hline GSD15 & 425482 & 4183105 & $2,307.8$ & good, near buried conductor \\
\hline GSD16 & 444081 & 4176510 & $2,338.5$ & not good, near electric fence \\
\hline GSD17 & 444403 & 4180567 & $2,350.5$ & not good, near electric fence \\
\hline
\end{tabular}

${ }^{1}$ Coordinates are in UTM Zone $13 \mathrm{~S}$ are referenced to NAD27.

${ }^{2}$ Altitude is relative to NGVD 29. Altitudes were determine by locating sounding on 1:24,000 topographic sheets, interpolating between contours, and converting the altitude to SI units. 


\section{Great Sand Dunes National Park TEM Sounding Locations}

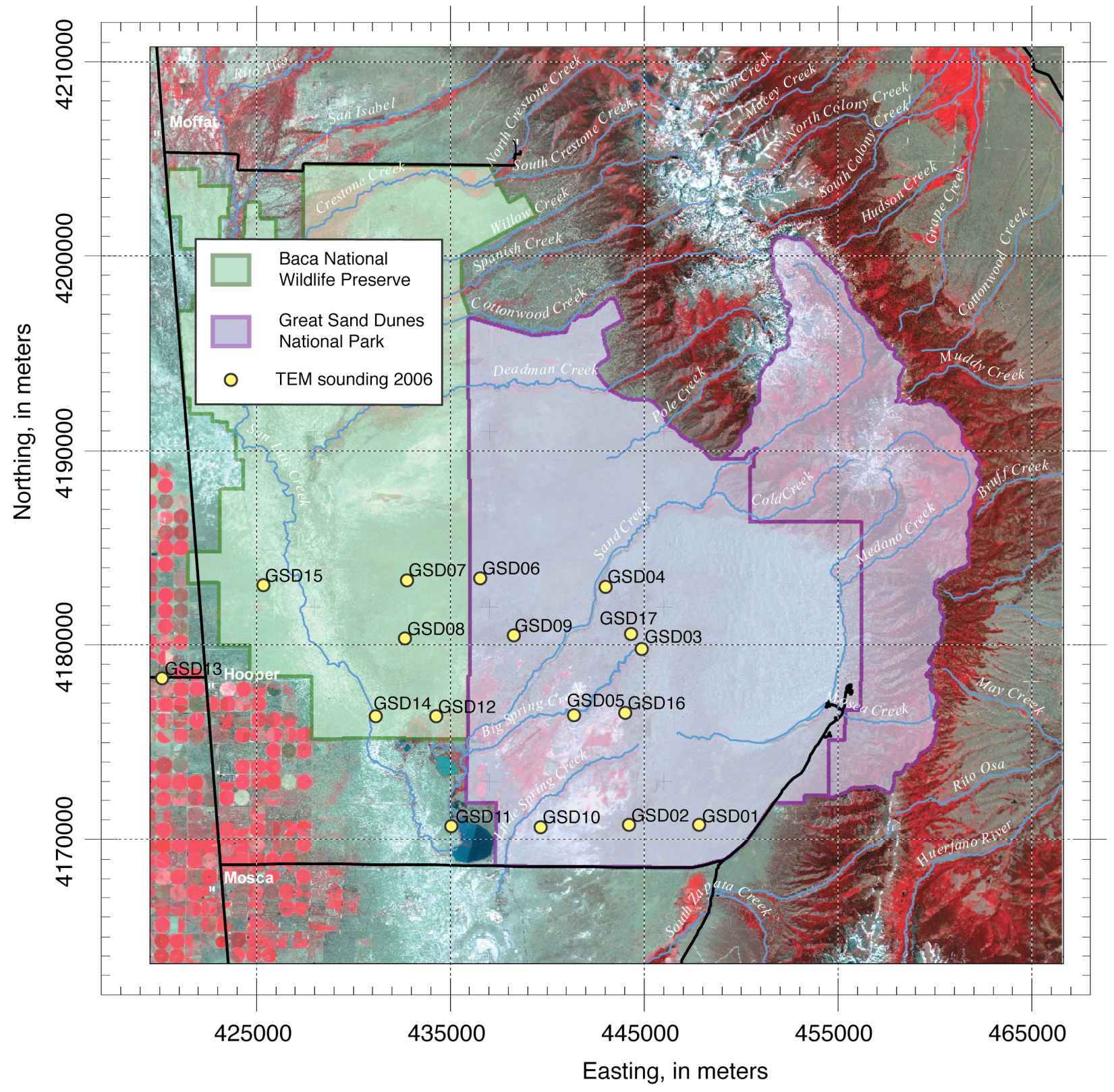

Figure 2. Location of TEM soundings 


\section{Interpretation of Results}

\section{Geology of Study Area}

Great Sand Dunes National Park is located on the eastern margin of the central portion of the San Luis Valley. The valley is a structural basin bounded by volcanic rocks of the San Juan Mountains on its western side and sedimentary and igneous rocks of the Sangre de Cristo Mountains on its eastern side (Siebenthal, 1910; Upson, 1938; Powell, 1958). The northward trending Alamosa horst divides the valley into two basins (Leonard and Watts, 1989). These depressions are filled with sediments derived from the eastern and western bounding mountain ranges.

The valley basin is filled with the Tertiary age Santa Fe Formation and the Quaternary age Alamosa Formation. The Santa Fe Formation in the San Luis Valley, as revealed in limited outcrops and well logs, consists of conglomerate, sand, gravel, clay, lava, and volcanic deposits (Powell, 1958). The upper part of the Santa Fe consists of well rounded sand and gravel indicating stream deposition. Clay layers of varying color and thickness are also present in the Santa Fe. These layers are often interfingered with sand and gravel units.

The Alamosa Formation is composed of unconsolidated gravel, sand, silt, and clay (Powell, 1958). It underlies a large portion of the valley, but exposures are limited to the southern part of the valley where the Rio Grande and other drainages have cut into it. Clay in the Alamosa Formation ranges in color from brown to green to bluish-gray.

Siebenthal (1910) hypothesized that a large lake existed in the San Luis Valley during the Pleistocene. He named the sediments deposits in this lake the Alamosa Formation (Machette and others, 2007). Recent geologic mapping by Machette (2004) provides further evidence of the existence of a large lake, which he named Lake Alamosa. Knowledge of the extent of the lake is critical to understanding the hydrology of the San Luis Valley and is discussed in the following section.

\section{Hydrology of Study Area}

The groundwater resources of the San Luis Valley have been studied for a long time because of their importance for domestic, live stock, irrigation, and other uses (Siebenthal, 1910; Powell, 1958; Harmon, 1987; Schenk and Harmon, 1999). The latter reference provides a concise discussion of the hydrology and its relationship to the various geologic units present. In general, there are three hydrologic units, which are controlled by structural and stratigraphic factors. The hydrologic units going from the surface to depth are: (1) the unconfined aquifer, (2) a confined aquifer that produces large quantities of water, and (3) a less productive, deeper confined aquifer of lower hydrologic transmissivity. During the last deep-water cycle of the lake, the blue clay that forms the aquitard between upper unconfined aquifer and the lower confined aquifer was deposited. The location and thickness of this clay is critical to modeling the hydrology of the San Luis Valley. Machette and others (2007) point out that 95 percent of all artesian wells in the basin fall inside the highest level of Lake Alamosa. They also point out that most groundwater models of the area are multilayered with little or no regard to lateral discontinuities in the blue clay caused by interfingering of lacustrine and alluvial deposits at the margins of Lake Alamosa or by structural features.

\section{Comparison With Well Logs}

A search of the USGS National Water Information System and Groundwater Site-Inventory System for wells with geologic logs near the TEM soundings found eight wells which are summarized in table 2 (K.R. Watts, written commun., 2007). Well logs for the HRS wells came from HRS Water Consultants (1999).

Figure 3 shows the interpreted TEM resistivity-depth functions for soundings that were near wells with geologic logs. The strata are categorized as sand and clay units based on the log descriptions. In general, there is a decrease in interpreted resistivity associated with thick clay zones. This behavior is seen for soundings GSD03, GDS07, GSD08, GSD13, and GSD17.

The correspondence between the depth of the clay and the resistivity decrease is good, but not perfect. This can be attributed to three factors: (1) the drill logs, if not based on cores, will have some error in depth estimates, (2) there is uncertainty in the TEM inversion results that tends to increase with depth, and (3) the distance between the well and the sounding may be sufficiently large that the geology is not the same at the two locations. Resistivity decreases can also be caused by poor water quality. This point is important only in cases where the interpreted resistivity decreases and there is no corresponding change from sand to clay, and the resistivity is less than $10 \mathrm{ohm}-\mathrm{m}$. Information about water-quality changes with depth was not considered in making this comparison. 


\section{Conclusions}

Time-domain electromagnetic soundings obtained subsurface resistivity information from depths of 75 to more than $150 \mathrm{~m}$. Layered earth models do a very good job of modeling the data. For the most part, electrical resistivity decreases with depth. This behavior is expected for the usual situation of near-surface, unsaturated sand and gravel underlain by similar, but saturated, material. At greater depth clay units are often encountered, which further decrease the resistivity. Decreases in water quality could also contribute to this general trend of resistivity decreasing with depth.

Comparison of soundings with nearby wells having geologic logs shows a fairly good correspondence between interpreted resistivity decreases and the location of clay units. This result is significant in that it supports the idea of using TEM soundings to map the top of the blue clay deposited in ancient Lake Alamosa. The location and extent of the blue clay is of great importance to groundwater flow models of the region.

No attempt was made to compare the geophysical interpretations with water-quality data, though this is a point that warrants further investigation. 
Table 2. Inventory of wells near TEM soundings

\begin{tabular}{|c|c|c|c|c|c|c|c|}
\hline $\begin{array}{c}\text { TEM } \\
\text { Sounding }\end{array}$ & $\begin{array}{l}\text { Site Number } \\
\text { Well ID }\end{array}$ & Site Name. & Easting $^{1[\mathrm{~m}]}$ & $\underset{[\mathrm{m}]}{\text { Northing }}{ }^{1}$ & $\begin{array}{c}\text { Distance } \\
\text { From } \\
\text { Sounding } \\
{[\mathrm{m}]}\end{array}$ & $\begin{array}{l}\text { Well TD } \\
\text { [ft] }\end{array}$ & Comment \\
\hline \multirow[t]{3}{*}{ GSD03 } & 374557105372901 & SC04101235ABB2 & 444975 & 4179812 & 55 & 351 & HRS Well Y²?? \\
\hline & 374558105373101 & NA04101226DCC & 444977 & 4179842 & 82 & 351 & HRS Well Y ?? \\
\hline & 374558105372801 & SC04101235ABB1 & 445000 & 4179842 & 94 & 76 & HRS Well X \\
\hline GSD04 & 374746105385203 & SC04101215CDC2 & 442986 & 4183185 & 214 & 394 & HRS Well V \\
\hline GSD07 & 374754105465201 & NA04101116CBC1 & 431231 & 4183521 & 1,626 & 200 & \\
\hline GSD08 & 374600105464301 & NA04101128CCD1 & 431422 & 4180006 & 1,370 & 200 & \\
\hline GSD12 & 374403105445201 & NA04001110AA & 434108 & 4176378 & 256 & 202 & \\
\hline GSD13 & 374502105543001 & NA04101032CCC & 419978 & 4178321 & 270 & 127 & Higgins Farm well \\
\hline GSD14 & 374355105460702 & NA04001109ACA2 & 432271 & 4176146 & 1,040 & 120 & main well ${ }^{3} ? ?$ \\
\hline GSD14 & 374355105460701 & NA04001109ACA1 & 432271 & 4176146 & 1,040 & 96 & observation well \\
\hline \multirow[t]{3}{*}{ GSD17 } & 374558105373101 & NA04101226DCC & 444977 & 4179842 & 924 & 351 & HRS Well Y ?? \\
\hline & 374558105372801 & SC04101235ABB1 & 444500 & 4179842 & 939 & 76 & HRS Well X \\
\hline & 374557105372901 & SC04101235ABB2 & 444975 & 4179812 & 948 & 351 & HRS Well Y ?? \\
\hline
\end{tabular}

${ }^{1}$ Coordinates are in UTM Zone $13 \mathrm{~S}$ are referenced to NAD27.

${ }^{2}$ Several descriptions associated with the listed site number well ID appeared to correspond to HRS Well Y, but could not be definitively confirmed. They are marked by (??)

${ }^{3}$ The well near GSD14 appears to correspond to the one called "main well" in the description. 

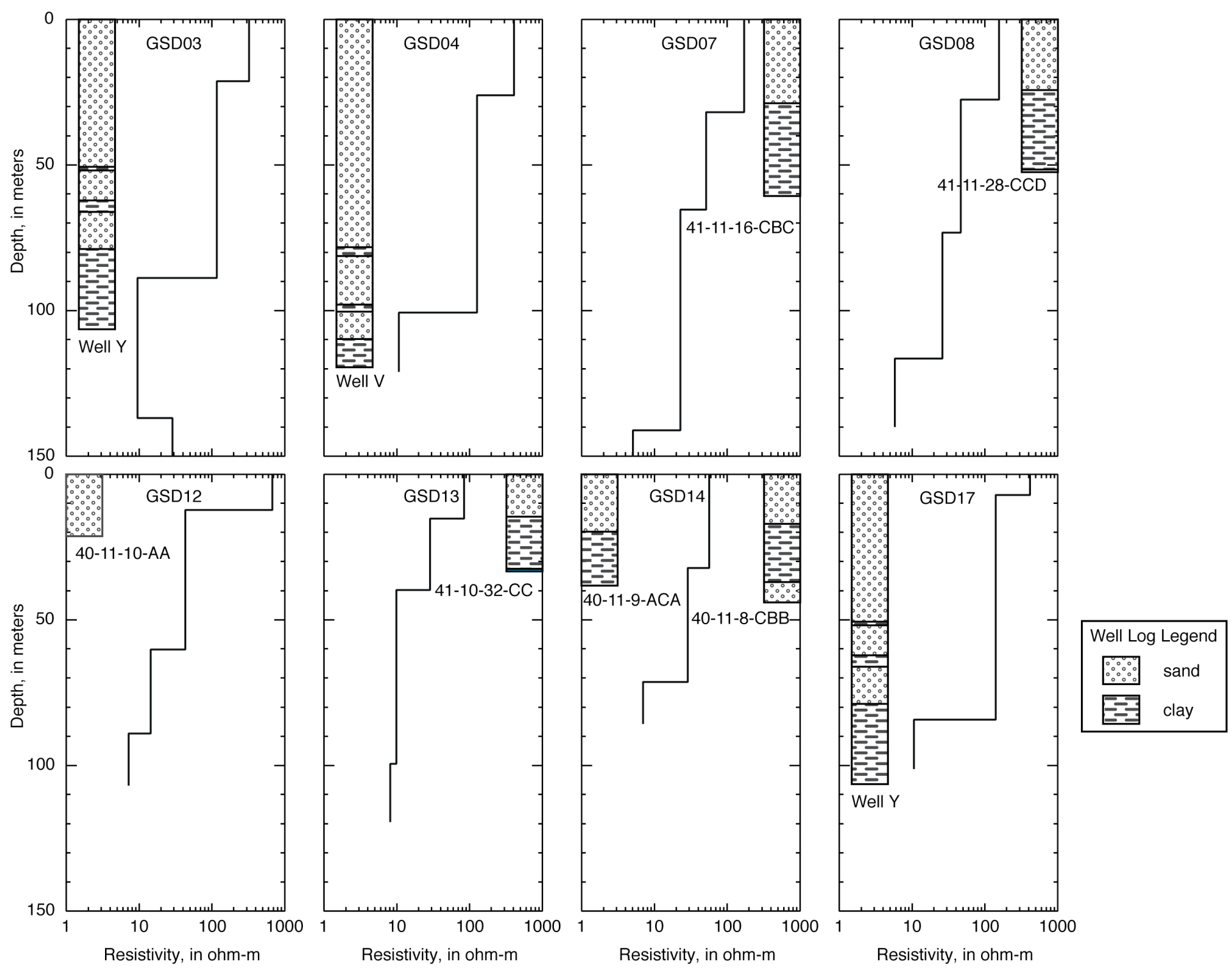

Figure 3. Comparison of interpreted resistivity-depth functions and geologic logs from nearby wells. 


\section{References Cited}

Brendle, D.L., 2002, Geophysical logging to determine construction, contributing zones, and appropriate use of water levels measured in confined-aquifer network wells, San Luis Valley, Colorado, 1998-2000: U.S. Geological Survey Water-Resources Investigations Report 02-4058, $58 \mathrm{p}$.

Emery, P.A., Snipes, R.J., Dumeyer, J.M., and Klein, J.M., 1973, Water in the San Luis Valley, south-central Colorado: Colorado Water Resources Circular 18, 27 p., 10 plates.

Fitterman, D.V., 1989, Detectability levels for central induction transient soundings: Geophysics, v. 54, p. 127-129.

Fitterman, D.V., Deszcz-Pan, M., and Stoddard, C.E., 1999, Results of time-domain electromagnetic soundings in Everglades National Park, Florida (on CD-ROM): U.S. Geological Survey Open-File Report 99-426, 152 p.

Fitterman, D., and Labson, V.F., 2005, Electromagnetic induction methods for environmental problems, in Butler, D.K., ed., Near surface geophysics, part 1 - Concepts and fundamentals: Tulsa, Society of Exploration Geophysicists, $\mathrm{p}$. 295-349.

Fitterman, D.V., and Stewart, M.T., 1986, Transient electromagnetic sounding for ground-water: Geophysics, v. 51, p. 995-1005.

Goldman, M., Gilad, D., Ronen, A., and Melloul, A., 1991, Mapping seawater intrusion into the coastal aquifer of Israel by the time domain electromagnetic method: Geoexploration, v. 28, p. 153-174.

Harmon, E., 1987, San Luis Valley confined aquifer study, Phase 1, Final report—Prepared for Colorado Water Resources and Power Development Authority: HRS Water Consultants, 138 p.

HRS Water Consultants, 1999, Hydrogeologic investigations Sand Creek and Indian Springs area, Great Sand Dunes National Monument, Colorado: Report to National Park Service 92021-04, 40 p.

Kaufman, A.A., and Keller, G.V., 1983, Frequency and transient sounding: Amsterdam, Elsevier, 685 p.

Leonard, G.J., and Watts, K.R., 1989, Hydrogeology and simulated effects of ground-water development on an unconfined aquifer in the Closed Basin Division, San Luis Valley, Colorado: U.S. Geological Survey WaterResources Investigations Report 87-4284, 41 p.

Machette, M.N., 2004, New evidence for ancient Lake Alamosa in the San Luis Basin of Colorado: Geological Society of America Abstracts with Program, v. 36, no. 5, p. 530.

Machette, M.N., Marcheti, D.W., and Thompson, R.A., 2007, Ancient Lake Alamosa and the Pliocene to middle Pleistocene evolution of the Rio Grande (Chapter G), in Machette, M.N., Coates, M-M., and Johnson M.L., 2007, Rocky Mountain Section Friends of the Pleistocene Field Trip - Quaternary geology of the San Luis Basin of Colorado and New Mexico, September 7-9, 2007: U. S. Geological Survey Open-File Report, p. 157-167.

McNeill, J.D., 1990, Use of electromagnetic methods for groundwater studies, in Ward, S.H., ed., Geotechnical and environmental geophysics: Tulsa, Society of Exploration Geophysicists, p. 191-218.

Oldenburg, D.W., and Li, Y., 2005, Inversion for applied geophysics: a tutorial, in Butler, D.K., ed., Near surface geophysics, Part 1 - Concepts and fundamentals: Tulsa, Society of Exploration Geophysicists, p. 89-150.

Powell, W.J., 1958, Ground-water Resources of the San Luis Valley, Colorado: U.S. Geological Survey Water-Supply Paper 1379, $284 \mathrm{p}$.

Schenk, A.J., and Harmon, E.J., 1999, Hydrogeology of the San Luis Valley, Colorado, in Schenk, C.J., ed., Proceedings of National Park Service Research Symposium No. 1, Hydrologic, geologic, and biologic research at Great Sand Dunes National Monument, Colorado, National Park Service, p. 74-90.

Siebenthal, C.E., 1910, Geology and water resources of the San Luis Valley, Colorado: U.S. Geological Survey WaterSupply Paper 240, 128 p.

Upson, J.E., 1938, Physiographic subdivisions of the San Luis Valley, southern Colorado: Journal of Geology, v. 47, p. $721-736$. 


\section{Appendix A. Description of TEM Data Processing}

Processing of the TEM data included the following steps: (1) downloading, (2) averaging, (3) inversion, (4) extracting results, (5) plotting results, and (6) report generation. Figure 2 summarizes the data flow and processing programs used.

The data in the Geonics PROTEM receiver are downloaded to a PC using program PROTEM, which is supplied by Geonics. Typically data from one sounding location are downloaded into a single raw data file. The format of this file is referred to as Geonics TEM File (GTF) format. Following downloading, selected data records from the raw data file are averaged using program $\mathrm{NTEMAVG}^{3}$. Data are usually selected to include measurements made with the same receiver gain and integration time, though this is not mandatory. The averaged data files are saved in GTF format. In addition to the averaged data file, a file containing a summary of the averaging process is saved.

Both the raw and averaged data files can be read into TEMIXXL, a program commercially available from Interpex Ltd., that was used for data interpretation. TEMIXXL stores a copy of the data, the model, and the calculated response of the model in a proprietary, binary database file. The database can hold a large number of soundings, so one database is usually enough for an entire survey. Sometimes it is helpful to retain several alternative models for a given data set. These are stored as separate soundings in the TEMIXXL database. Typically these alternative models have the original sounding name with up to 3 characters added at the end. For example a sounding called ABC01, might have variants ABC01L4 and ABC01L5 to indicate models with four and five layers, respectively. There are no restrictions on the extra characters added to the sounding name other than the total number of characters in the sounding name cannot exceed 8 . The results of the inversion are reported in an inversion output file.

Program TEM_EXTRACT is used to extract apparent-resistivity-time and interpreted-resistivity-depth files for plotting. After the interpretation process is complete a report file is generated using program TEM_REPORT. This file contains all of the information about the sounding parameters, the data values, the model parameters, and the model response. There is adequate information in this file to enter the data into another inversion program to verify the results.

\footnotetext{
${ }^{3}$ Programs NTEMAVG, TEM_EXTRACT, and TEM_REPORT were developed at the U.S. Geological Survey.
} 


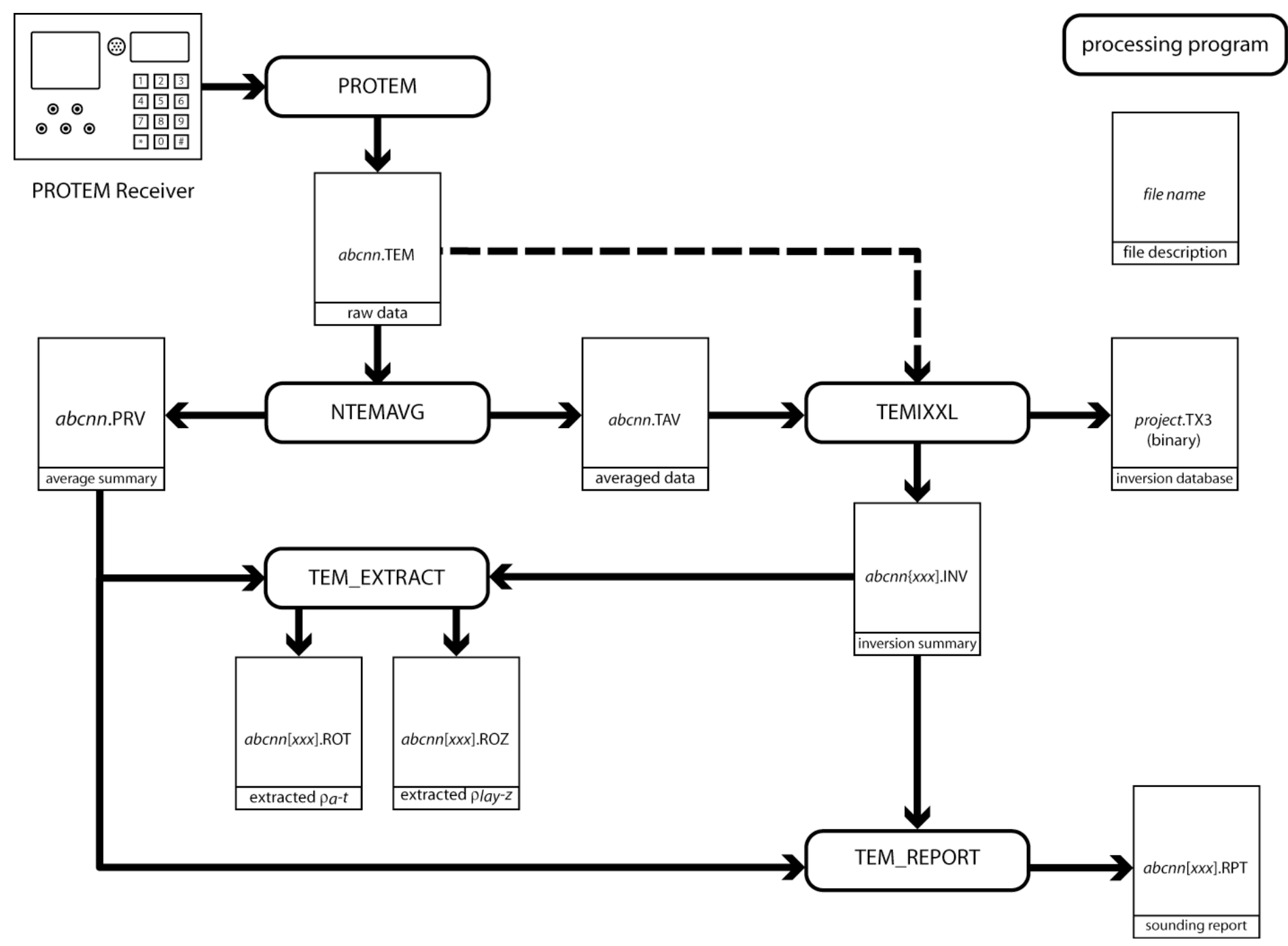

Figure A-1. Data processing programs, files, and flow. Solid lines show processing flow. Dashed arrow is alternative path. Program PROTEM is available from Geonics Limited. Program TEMIXXL is available from Interpex Limited. Programs NTEMAVG, TEM_EXTRACT, and TEM_REPORT were developed at the U.S. Geological Survey. 


\section{Appendix B. Voltage Units and Apparent Resistivity}

Measured electromagnetic transients can be reported in two different ways: either as the voltage recorded in the receiver itself, or the voltage at the receiver coil normalized by the receiver-coil moment (number of coil turns times the coil area). The voltage at the receiver coil can be determined using Faraday's Law

$$
V_{\text {coil }}=-M_{R x} \frac{d \mathbf{B} \bullet \widehat{\mathbf{n}}}{d t}=-M_{R x} \frac{d B}{d t},
$$

where $\mathbf{B}$ is the magnetic induction in units of webers per meter squared $\left[\mathrm{Wb} / \mathrm{m}^{2}\right], \widehat{\mathbf{n}}$ is the unit normal to the receiver coil (assumed to be vertical), and $M_{R x}$ is the receiver-coil moment. Rearranging gives

$$
V_{\text {coil }} / M_{R x}=-\frac{d B}{d t} .
$$

This representation of the data is convenient for comparison against background electromagnetic noise levels, which are typically $0.1-1 \mathrm{nV} / \mathrm{m}^{2}$ (Fitterman, 1989).

For the PROTEM receiver used in this study the voltage at the coil $V_{\text {coil }}$ and the voltage recorded at the receiver $V_{R x}$ are related by

$$
V_{c o i l}[\mathrm{nV}]=\frac{10^{-6} V_{R x}[\mathrm{mV}]}{52.1 \cdot 2^{G}}
$$

where $G$ is the receiver gain setting (see table $\mathrm{C}-2$ ), and the factor 52.1 accounts for additional fixed receiver gain. The magnitude of the time derivative of the magnetic induction is then

$$
\frac{d B}{d t}\left[\mathrm{nV} / \mathrm{m}^{2}\right]=V_{c o i l}[\mathrm{nV}] / M_{R x}\left[\mathrm{~m}^{2}\right]=\frac{10^{-6} V_{R x}[\mathrm{mV}]}{52.1 \cdot 2^{G} M_{R x}\left[\mathrm{~m}^{2}\right]} .
$$

The late stage apparent resistivity (Kaufman and Keller, 1983; Fitterman and Labson, 2005) is computed from the receiver voltage using

$$
\rho_{a}^{L S}=\frac{\mu_{o}}{4 \pi t} \frac{2 \mu_{o} L^{2} M_{R x} I_{T x}^{2 / 3}}{5 t V_{c o i l}}
$$

where $t$ is the time after current turn off, $L$ is the square transmitter loop side length, $I_{T x}$ is the transmitter current, $\mu_{o}=4 \pi \cdot 10^{-7}[\mathrm{H} / \mathrm{m}]$ is the magnetic permeability of free space, and all units are SI. Recasting equation into typical field units and incorporating the PROTEM gain constants gives

$$
\rho_{a}^{L S}[\mathrm{ohm}-\mathrm{m}]=\frac{10^{-4}}{t[\mathrm{~ms}]}\left\{\frac{0.16 \cdot \pi \cdot 52.1 \cdot 2^{G} L^{2}\left[\mathrm{~m}^{2}\right] M_{R x}\left[\mathrm{~m}^{2}\right] I_{T x}[\mathrm{~A}]}{t[\mathrm{~ms}] V_{R x}[\mathrm{mV}]}{ }^{2 / 3}\right.
$$

and

$$
\rho_{a}^{L S}[\mathrm{ohm}-\mathrm{m}]=\frac{0.1}{t[\mu \mathrm{s}]}\left\{\frac{160 \cdot \pi \cdot 52.1 \cdot 2^{G} L^{2}\left[\mathrm{~m}^{2}\right] M_{R x}\left[\mathrm{~m}^{2}\right] I_{T x}[\mathrm{~A}]}{t[\mu \mathrm{s}] V_{R x}[\mathrm{mV}]}{ }^{2 / 3} .\right.
$$




\section{Appendix C. Description of TEM Data Files}

The file naming conventions and formats of files generated during downloading, processing, inversion, and extraction are described below.

\section{File Naming Conventions}

The downloaded GTF format files are typically given a name of the form aaann.TEM, where aaa is a three character identifier, typically associated the survey and $n n$ is a two digit number. The sounding "name" would be considered aaann. Geonics and some software vendors give these files an extension of .RED.

Averaged data files are named aaann.TAV. These files are also in GTF format. The printed summary of the averaging process is written to a file named aaann.PRV

TEMIXXL database file are binary files in a proprietary format. They are named with suffix of .TX3. Data sets include observed data, measurement parameters, calculated model response, and inversion model parameters. A data set is identified by a name of up to 8 characters.

A summary of the inversion is written to a file name aaann $[x x x] . I N V$, where $[x x x]$ represents optional characters added to the sounding name in TEMIXXL to identify alternative models.

Extracted apparent-resistivity-time and interpreted-resistivity-depth files suitable for plotting are named aaann $[x x x]$. ROT and aaann $[x x x]$. ROZ, respectively.

\section{File Formats and Contents}

\section{Geonics TEM File (GTF) Format}

The raw data collected in the field are written in Geonics TEM file (GTF) format. GTF files consist of 256character long records, containing a 50 -character header field followed by 25 eight-character data fields. The last two characters of the record are a carriage return and a line feed. Two types of records are created during PROTEM receiver downloading. The record type is indicated by characters 19-21 of the header field: "HDR" for a header record, and "OPR" for a data record. A header record is created every time a change is made in certain measurement parameters in the PROTEM receiver. For example, changes in the sounding name, transmitter current, transmitter loop size, turnoff time, or receiver moment will produce a new header record. Figure $\mathrm{C}-1$ shows the structure of the header fields for header (HDR) and data (OPR) records; descriptions for these two types of header fields are given in tables $\mathrm{C}-1$ and $\mathrm{C}-$ 2 , respectively.

The data fields of header and data records contain 25 eight-character data fields. Geonics' documentation refers to these data fields as gates. The contents of the gates is given in Tables $\mathrm{C}-3$ and $\mathrm{C}-4$.

The raw data files from this survey can be found in directory raw_data_files on the accompanying data CD. 


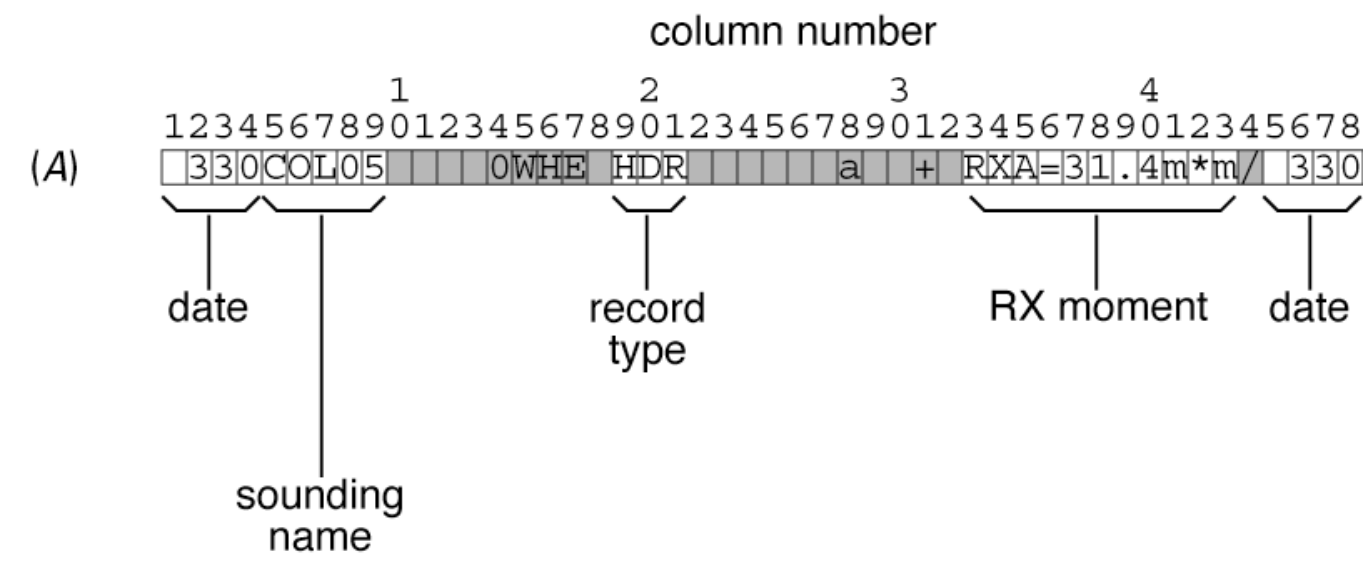

column number

1

2

3

4

123456789012345678901234567890123456789012345678

$(B)$

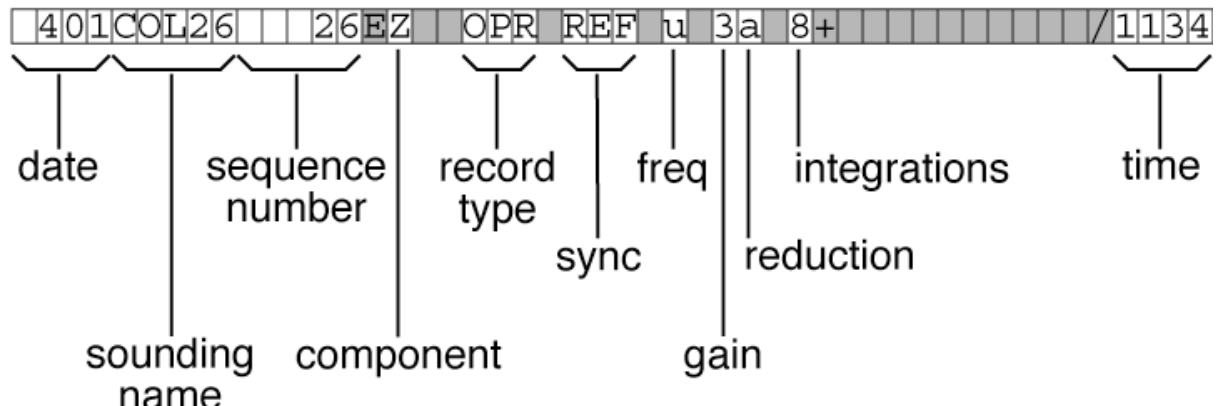

Figure C-1. Diagram showing contents of header records. $A$ Header record (HDR), header fields. $B$ Data record $(\mathrm{OPR})$, header fields. The contents of shaded cells are ignored in further processing.

Table C-1. Description of header record (HDR) header fields.

\begin{tabular}{|c|c|l|}
\hline Field & Columns & \multicolumn{1}{c|}{ Description } \\
\hline date & $1-4$ & date of measurement [mmdd] \\
\hline sounding name & $5-9$ & sounding name \\
\hline record & $19-21$ & "HDR" to indicate header record \\
\hline RX moment & $33-43$ & RX coil moment [turn- ${ }^{2}$ ] \\
\hline date & $45-48$ & date of measurement $[\mathrm{mmdd}]$ \\
\hline
\end{tabular}


Table C-2. Description of data record (OPR) header fields.

\begin{tabular}{|c|c|l|}
\hline Field & Columns & \multicolumn{1}{c|}{ Description } \\
\hline date & $1-4$ & date of measurement [mmdd] \\
\hline sounding name & $5-9$ & sounding name \\
\hline sequence number & $10-14$ & $\begin{array}{l}\text { sequence number of sounding; requires } \\
\text { operator to manually update or values will not } \\
\text { be significant }\end{array}$ \\
\hline record type & $19-21$ & "OPR" to indicate data record \\
\hline sync & $23-25$ & $\begin{array}{l}\text { synchronization method; REF indicates } \\
\text { reference cable, XTL indicates crystal } \\
\text { oscillators }\end{array}$ \\
\hline freq & 27 & $\begin{array}{l}\text { transmitter repetition frequency; determines } \\
\text { measurement times: } \\
\text { u= ultra high, v= very high, h = high, } \mathrm{m}= \\
\text { medium, l = low }\end{array}$ \\
\hline gain & 29 & additional PROTEM gain factor of 2 ${ }^{\text {gain }}(\mathrm{G})$ \\
\hline reduction & 30 & $\begin{array}{l}\text { value of "a" indicates that receiver 4x and 10x } \\
\text { gain factors have been removed }\end{array}$ \\
\hline integrations & 32 & PROTEM coded integration time setting \\
\hline time & $45-48$ & time of measurement [hhmm] \\
\hline
\end{tabular}

Table C-3. Description of header record (HDR) data fields (gates).

\begin{tabular}{|c|l|}
\hline Field (Gate) & \multicolumn{1}{|c|}{ Contents } \\
\hline 0 & date of measurement $[\mathrm{mmdd}]$ \\
\hline 2 & time of measurement $[\mathrm{hhmm}]$ \\
\hline 4 & TX current $[\mathrm{A}]$ \\
\hline 5 & TX turnoff time $[\mu \mathrm{s}]$ \\
\hline 6,7 & TX loop side length $[\mathrm{m}] \mathrm{LX}$ and LY \\
\hline 8.9 & RX coil position XR and YR relative to center of TX loop [m] \\
\hline 10 & RX coil moment [turn-m $\left.{ }^{2}\right]($ RXA) \\
\hline 11 & TX number \\
\hline 22 & logger record number for this header record \\
\hline
\end{tabular}

Table C-4. Description of data record (OPR) data fields (gates).

\begin{tabular}{|c|l|}
\hline Field (Gate) & \multicolumn{1}{c|}{ Contents } \\
\hline 0 & logger record number for this data record \\
\hline $1-20$ & channels 1-20 TEM data \\
\hline 21 & TX turnoff time [ms] \\
\hline 22 & first RX gate time [ms] \\
\hline 23 & TX current $[\mathrm{A}]$ \\
\hline 24 & TX moment [turn-m $\left.{ }^{2}\right]$, may include trailing "/" \\
\hline 25 & time of measurement $[\mathrm{hhmm}]$ \\
\hline
\end{tabular}

\section{PRV Files}

PRV files are text files that summarize the data averaging process. The first page of the file consists of a listing of all of the header record (HDR) and data record (OPR) header fields. The first line is a descriptive header indicating that the data came from a PROTEM logger. The second line usually contains HDR header fields. Subsequent 
lines are OPR header fields associated with the recorded data. Additional HDR header fields will be present whenever the operator made a change in the header information on the PROTEM receiver. The output concludes with two records whose headers contain X's to indicate the end of the data processing.

Following the summary page, a separate page is devoted to data records that were averaged together. There is usually one page for each transmitter repetition frequency used for the sounding. The first line of these pages indicates the program version used to average the data, the averaged-output file name, the record number of the averaged-output file to which this page corresponds, and the GTF format input file name.

Each data page of the PRV file contains a summary of all of the data recorded by the PROTEM receiver for a single frequency. For each measurement there is a data record number, frequency, transmitter current, receiver gain, integration value NSTK, transmitter turnoff time, and a time shift. The time shift is applied during data averaging to adjust for incorrect turnoff time settings during data recording. If no adjustment was made this value will be zero. This part of the output is followed by a list of the SI units of the various reported quantities, the TEM system used, the receiver coil moment (RXA), the transmitter loop dimensions (LX and LY), and the location of the receiver coil with respect to the center of the transmitter loop (XR and YR).

The next section of the data page gives the channel number, the voltage induced in the receiver coil in units of $\left[\mu \mathrm{V} / \mathrm{m}^{2}\right]$. The average of these voltages is computed and expressed as PROTEM receiver units $[\mathrm{mV}]$. The standard deviation as a percentage of the average data value is also reported.

The last section of the data page presents the voltages after they have been transformed to apparent resistivity. The print out includes the channel number, the receiver channel time, the square root of the time in seconds $\left[\mathrm{s}^{1 / 2}\right]$, the late stage apparent resistivity, the average of the resistivity values, and the percentage deviation of the apparent resistivity.

The PRV files from this survey can be found in directory averaged_report_files on the accompanying data CD.

\section{TAV Files}

The averaged data are contained in TAV files and use the GTF format described above. The header of the first record indicates the type of instrument the data came from, and whether the data have been averaged. The data fields of this record are all set to zero. The second record is an HDR record with header fields and data fields as described in Tables C-1 and C-3. Next comes an OPR record for each frequency average computed by program NTEMAVG. If different groups of data records were averaged, there will be multiple output records, one for each group. Following the last OPR record comes a record with "XXXXX" in the header field. The numbers in the data fields are meaningless.

The averaged data files from this survey can be found in directory averaged_data_files on the accompanying data $\mathrm{CD}$.

\section{INV Files}

This file is a report generated by TEM inversion program TEMIXGL. It provides information on the sounding location, the measurement geometry, the model misfit error, the model parameter estimates, the measured resistivity and calculated model response, and usually a resolution matrix.

Misfit error reported by the TEM inversion program (TEMIXXL) is given as percentage RMS misfit for voltage data. The apparent resistivity misfit is approximately $2 / 3$ of this value.

The inversion output files from this survey can be found in directory inversion_files on the accompanying data $\mathrm{CD}$.

\section{ROT and ROZ Files} information:

These are text files that contain data and models in a form for plotting. The ROT file contains the following

1. The sounding name.

2. Tab delimited column headings for the data that follow.

3. Tab delimited time and apparent resistivity data consisting of 6,9 , or 12 columns corresponding to 1,2 , or 3 transmitter repetition frequencies, respectively. Typically the data are given in order of decreasing repetition frequency. The contents of the columns are specified in table $\mathrm{C}-5$. 
The ROZ files contain the following information:

1. The sounding name.

2. Tab delimited titles for the data that follow: Depth (m) Resistivity (ohm-m).

3. Tab delimited data for plotting a resistivity depth plot. Depths are given as positive values below the surface. The depth sequence will be: $0, z_{1}, z_{1}, z_{2}, z_{2}, \ldots, z_{n-1}, z_{n-1}, 1.2 * z_{n-1}$. The resistivity sequence will be $\rho_{1}, \rho_{1}$, $\rho_{2}, \rho_{2}, \ldots \rho_{\mathrm{n}-1}, \rho_{\mathrm{n}-1}, \rho_{\mathrm{n}}, \rho_{\mathrm{n}}$

The extracted data files (ROT and ROZ) from this survey can be found in directory extracted_data_files on the accompanying data CD.

Table C-5. Description of plottable data in ROT files.

\begin{tabular}{|c|c|l|}
\hline Column $^{1}$ & Contents & \multicolumn{1}{c|}{ Description } \\
\hline 1 & time [msec] & time of data point after TX turnoff \\
\hline 2 & freq1_avg & averaged apparent resistivity, FREQ1 \\
\hline 3 & freq1_std & standard error in FREQ1 averaged apparent resistivity \\
\hline 4 & freq1_cal & calculated FREQ1 apparent resistivity \\
\hline 5 & freq2_avg & averaged apparent resistivity, FREQ2 \\
\hline 6 & freq2_std & standard error in FREQ2 averaged apparent resistivity \\
\hline 7 & freq2_cal & calculated FREQ2 apparent resistivity \\
\hline 8 & freq3_avg & averaged apparent resistivity, FREQ3 \\
\hline 9 & freq3_std & standard error in FREQ3 averaged apparent resistivity \\
\hline 10 & freq3_cal & calculated FREQ3 apparent resistivity \\
\hline 11 & masked & apparent resistivity of a masked data point \\
\hline 12 & m_err & standard error of a masked data point \\
\hline
\end{tabular}

${ }^{1}$ When sounding has fewer than 3 sweeps, the unnecessary columns are removed. The masked and m_err data follow immediately after the last sweep.

\section{RPT Files}

The sounding report files are presented in Appendix D and can be found in directory sounding_report_file on the accompanying data CD.

The report file contains all relevant information for the sounding and its interpretation summarized on a single sheet.

\section{TEMIXXL Database File}

The TEMIXXL database file GRSANDUN.TX3 used for interpretation of the TEM soundings can be found in directory TEMIXXL_database_file on the accompanying data CD.. 


\section{Appendix D. TEM Sounding Report Files}


Sounding: GSD01

Client: USGS/NPS

Location: Great Sand Dunes National Park

Project: San Luis Valley Blue Clay

County: Alamosa [Colorado]

TX loop size: $X[\mathrm{~m}] \quad 38.1 \quad \mathrm{Y}[\mathrm{m}] \quad 38.1$

$\begin{array}{cccc}\text { Model } & \text { Resistivity } & \text { Thickness } & \text { Elevation } \\ \text { Layer } & \text { [ohm-m] } & {[\mathrm{m}]} & {[\mathrm{m}]} \\ 1 & 248.30 & 44.4 & 2359.1 \\ 2 & 48.90 & 33.2 & 2314.6 \\ 3 & 7.37 & 15.7 & 2281.4 \\ 4 & 11.32 & -- & 2265.7\end{array}$

System: EM-47 Freq[Hz]: 285 Data Set Code: uh TX Cur[A]: 2.5 Turn Off[usec]: 2.5

$\mathrm{RX}$ Moment[turns-m^2]: 31.4 Gain Setting: 4

\begin{tabular}{|c|c|c|c|c|}
\hline $\begin{array}{l}\text { Time } \\
\text { [ms ] }\end{array}$ & $\begin{array}{l}\text { rhoa_obs } \\
\text { [ohm-m] }\end{array}$ & $\begin{array}{c}\text { obs_err } \\
{[\overline{\%}]}\end{array}$ & mask & $\begin{array}{l}\text { rhoa_cal } \\
{[\text { ohm-m] }}\end{array}$ \\
\hline 0.00680 & 232.1 & 0.3 & $\mathrm{u}$ & 232.4 \\
\hline 0.00890 & 261.9 & 0.1 & $\mathrm{~m}$ & 235.6 \\
\hline 0.01200 & 230.3 & 0.1 & $\mathrm{u}$ & 230.2 \\
\hline 0.01570 & 216.3 & 0.2 & $\mathrm{u}$ & 218.6 \\
\hline 0.02000 & 209.6 & 0.2 & $\mathrm{u}$ & 207.5 \\
\hline 0.02610 & 197.0 & 0.2 & $\mathrm{u}$ & 195.4 \\
\hline 0.03340 & 183.7 & 0.1 & $\mathrm{u}$ & 184.9 \\
\hline 0.04210 & 172.3 & 0.2 & $\mathrm{u}$ & 172.6 \\
\hline 0.05410 & 154.4 & 0.3 & $\mathrm{u}$ & 155.1 \\
\hline 0.06820 & 137.4 & 0.2 & $\mathrm{u}$ & 136.1 \\
\hline 0.08380 & 119.0 & 0.2 & $\mathrm{u}$ & 118.5 \\
\hline 0.10460 & 102.6 & 0.3 & $\mathrm{u}$ & 101.2 \\
\hline 0.13560 & 84.8 & 0.4 & $\mathrm{u}$ & 83.9 \\
\hline 0.17230 & 71.8 & 0.2 & $\mathrm{u}$ & 71.1 \\
\hline 0.21490 & 62.1 & 0.2 & $\mathrm{u}$ & 61.5 \\
\hline 0.27500 & 54.0 & 0.3 & $\mathrm{u}$ & 53.3 \\
\hline 0.34900 & 47.8 & 0.5 & $\mathrm{u}$ & 47.1 \\
\hline 0.43600 & 42.8 & 0.8 & $\mathrm{u}$ & 42.6 \\
\hline 0.55500 & 39.3 & 1.7 & $\mathrm{u}$ & 39.0 \\
\hline 0.70100 & 37.1 & 1.4 & $\mathrm{u}$ & 36.5 \\
\hline
\end{tabular}

Date: 07-JUN-06

UTM Coord: E[m] $447887.0 \quad \mathrm{~N}[\mathrm{~m}] \quad 4170723.0$

Elevation $[\mathrm{m}]: \quad 2359.1$

RX location: $\mathrm{X}[\mathrm{m}] \quad 0.0 \quad \mathrm{Y}[\mathrm{m}] \quad 0.0$

\section{Fit Error [\%]: 2.741}

System: EM-47 Freq[Hz]: 30 Data Set Code: hi TX $\operatorname{Cur}[A]: 2.5$ Turn Off[usec]: 2.5

RX Moment[turns-m^2]: 31.4 Gain Setting: 7

Time
$[\mathrm{ms}]$
0.10000
0.12100
0.15100
0.18800
0.23100
0.29100
0.36500
0.45200
0.57000
0.71200
0.87100
1.08000
1.39000
1.75000
2.18000
2.78000
3.52000
4.39000
5.56000
7.04000

rhoa_obs

[ohm-m ]

100.0

88.0
74.9

63.4

55.7

47.6

41.7

37.1

32.7

30.1

27.2

24.5

23.0

22.7

22.7

21.9
19.6

18.1

22.4

17.4

46.1 obs_err mask

[\%]

0.4 [ohm-m]

$\mathrm{u} \quad 102.5$

$\begin{array}{lll}0.5 & u & 88.8\end{array}$

$\begin{array}{lll}0.3 & u & 75.2 \\ 0.3 & u & 64.3\end{array}$

0.9 u

0.7 u $\quad 48.2$

1.0 u $\quad 42.1$

1.9 u 37.4

2.3 u 33.3

2.4 u 30.1

3.1 u $\quad 27.6$

5.4 u 25.5

6.2 u 23.4

$\begin{array}{lll}7.0 & u & 21.8\end{array}$

15.0 u $\quad 20.6$

$18.1 \mathrm{u} \quad 19.6$

$16.1 \quad \mathrm{u} \quad 18.8$

63.2

75.3

100.0 
Sounding: GSD02

Client: USGS/NPS

Location: Great Sand Dunes National Park

Project: San Luis Valley Blue Clay

County: Alamosa [Colorado]

TX loop size: $X[\mathrm{~m}] \quad 38.1 \quad \mathrm{Y}[\mathrm{m}] \quad 38.1$

$\begin{array}{cccc}\text { Model } & \text { Resistivity } & \text { Thickness } & \text { Elevation } \\ \text { Layer } & {[\text { ohm-m] }} & {[\mathrm{m}]} & {[\mathrm{m}]} \\ 1 & 170.90 & 24.5 & 2327.1 \\ 2 & 68.09 & 36.2 & 2302.5 \\ 3 & 6.99 & 51.2 & 2266.3 \\ 4 & 4.14 & -- & 2215.1\end{array}$

System: EM-47 Freq[Hz]: 285 Data Set Code: uh TX Cur[A]: 2.5 Turn Off[usec]: 2.5 $\mathrm{RX}$ Moment[turns-m^2]: 31.4 Gain Setting: 3

$\begin{array}{rrrrrr}\text { Time } & \text { rhoa_obs } & \text { obs_err } & \text { mask } & \begin{array}{c}\text { rhoa_cal } \\ \text { [ohm-m] }\end{array} \\ 1 & 0.00680 & 149.1 & 0.2 & \mathrm{u} & 148.5 \\ 2 & 0.00890 & 150.0 & 0.1 & \mathrm{~m} & 140.6 \\ 3 & 0.01200 & 138.2 & 0.1 & \mathrm{u} & 137.3 \\ 4 & 0.01570 & 133.4 & 0.1 & \mathrm{u} & 135.2 \\ 5 & 0.02000 & 135.0 & 0.2 & \mathrm{u} & 134.5 \\ 6 & 0.02610 & 132.7 & 0.1 & \mathrm{u} & 133.5 \\ 7 & 0.03340 & 129.2 & 0.1 & \mathrm{u} & 129.6 \\ 8 & 0.04210 & 123.0 & 0.2 & \mathrm{u} & 122.1 \\ 9 & 0.05410 & 110.6 & 0.4 & \mathrm{u} & 109.3 \\ 10 & 0.06820 & 97.7 & 0.3 & \mathrm{u} & 95.9 \\ 11 & 0.08380 & 84.6 & 0.1 & \mathrm{u} & 83.9 \\ 12 & 0.10460 & 73.5 & 0.1 & \mathrm{u} & 72.2 \\ 13 & 0.13560 & 61.9 & 0.1 & \mathrm{u} & 60.6 \\ 14 & 0.17230 & 53.4 & 0.2 & \mathrm{u} & 52.0 \\ 15 & 0.21490 & 46.9 & 0.3 & \mathrm{u} & 45.7 \\ 16 & 0.27500 & 41.3 & 0.3 & \mathrm{u} & 40.1 \\ 17 & 0.34900 & 36.9 & 0.5 & \mathrm{u} & 35.9 \\ 18 & 0.43600 & 33.4 & 0.5 & \mathrm{u} & 32.8 \\ 19 & 0.55500 & 30.7 & 0.9 & \mathrm{u} & 30.1 \\ 20 & 0.70100 & 29.1 & 1.4 & \mathrm{u} & 28.1\end{array}$

Date: 07-JUN-06

UTM Coord: E[m] 444289.0 N[m] 4170722.0

Elevation $[\mathrm{m}]: 2327.1$

RX location: $\mathrm{X}[\mathrm{m}] \quad 0.0 \quad \mathrm{Y}[\mathrm{m}] \quad 0.0$

Fit Error $[\%]: \quad 3.123$

System: EM-47 Freq[Hz]: 30 Data Set Code: hi TX Cur[A]: 2.5 Turn Off[usec]: 2.5

RX Moment[turns-m^2]: 31.4 Gain setting: 7

Time
$[\mathrm{ms}]$
0.10000
0.12100
0.15100
0.18800
0.23100
0.29100
0.36500
0.45200
0.57000
0.71200
0.87100
1.08000
1.39000
1.75000
2.18000
2.78000
3.52000
4.39000
5.56000
7.04000

rhoa_obs obs

obs_err mas

rhoa_cal

[ohm-m]

[\% ]

ohm-m ]

$\begin{array}{rrrr}69.7 & 0.2 & u & 73.0\end{array}$

$\begin{array}{llll}61.9 & 0.2 & \mathrm{u} & 63.8\end{array}$

$\begin{array}{llll}53.5 & 0.3 & \mathrm{u} & 54.7\end{array}$

$\begin{array}{llll}45.9 & 0.2 & \mathrm{u} & 47.2\end{array}$

$\begin{array}{llll}40.7 & 0.4 & u & 41.5\end{array}$

$\begin{array}{llll}35.4 & 0.7 & u & 36.1\end{array}$

$\begin{array}{llll}31.0 & 0.9 & \mathrm{u} & 31.8\end{array}$

$27.4 \quad 0.7 \quad \mathrm{u} \quad 28.3$

$\begin{array}{llll}24.3 & 1.6 & \mathrm{u} & 25.1\end{array}$

$22.0 \quad 2.1 \quad \mathrm{u} \quad 22.4$

$20.1 \quad 1.8 \quad \mathrm{u} \quad 20.2$

$18.2 \quad 0.6 \quad u \quad u$

$\begin{array}{llll}16.3 & 2.4 & \mathrm{u} & 16.1\end{array}$

$\begin{array}{llll}14.8 & 4.6 & \mathrm{u} & 14.6\end{array}$

$\begin{array}{llll}13.4 & 3.9 & u & 13.3\end{array}$

$12.1 \quad 6.9 \quad \mathrm{u} \quad 12$.

$11.2 \quad 16.4 \quad \mathrm{u}$

$\begin{array}{llll}10.8 & 26.7 & \mathrm{u} & 10.6\end{array}$

$\begin{array}{llll}9.9 & 23.6 & \mathrm{u} & 10.0\end{array}$ 
Sounding: GSD03

Client: USGS/NPS

Location: Great Sand Dunes National Park

Project: San Luis Valley Blue Clay

County: Saguache [Colorado]

TX loop size: $X[\mathrm{~m}] \quad 38.1 \quad \mathrm{Y}[\mathrm{m}] \quad 38.1$

$\begin{array}{cccc}\text { Model } & \text { Resistivity } & \text { Thickness } & \text { Elevation } \\ \text { Layer } & {[\text { ohm-m] }} & {[\mathrm{m}]} & {[\mathrm{m}]} \\ 1 & 326.30 & 21.3 & 2342.4 \\ 2 & 118.10 & 67.6 & 2321.0 \\ 3 & 9.55 & 48.1 & 2253.4 \\ 4 & 28.89 & -- & 2205.3\end{array}$

System: EM-47 Freq[Hz]: 285 Data Set Code: uh TX Cur[A]: 2.5 Turn off[usec]: 2.5 RX Moment[turns-m^2]: 31.4 Gain Setting: 4

$\begin{array}{rrrrrr}\text { Time } & \text { rhoa_obs } & \text { obs_err } & \text { mask } & \begin{array}{c}\text { rhoa_cal } \\ \text { [ohm-m] }\end{array} \\ 1 & 0.00680 & 183.5 & 0.1 & \mathrm{~m} & 216.3 \\ 2 & 0.00890 & 205.8 & 0.3 & \mathrm{u} & 201.8 \\ 3 & 0.01200 & 191.7 & 0.4 & \mathrm{u} & 193.2 \\ 4 & 0.01570 & 186.0 & 0.5 & \mathrm{u} & 187.6 \\ 5 & 0.02000 & 187.6 & 0.5 & \mathrm{u} & 185.4 \\ 6 & 0.02610 & 184.5 & 0.2 & \mathrm{u} & 185.9 \\ 7 & 0.03340 & 185.7 & 0.2 & \mathrm{u} & 188.2 \\ 8 & 0.04210 & 187.7 & 0.3 & \mathrm{u} & 188.5 \\ 9 & 0.05410 & 182.8 & 0.3 & \mathrm{u} & 183.5 \\ 10 & 0.06820 & 178.3 & 0.3 & \mathrm{u} & 171.7 \\ 11 & 0.08380 & 158.5 & 0.3 & \mathrm{u} & 156.3 \\ 12 & 0.10460 & 141.3 & 0.2 & \mathrm{u} & 137.1 \\ 13 & 0.13560 & 117.6 & 0.2 & \mathrm{u} & 114.5 \\ 14 & 0.17230 & 97.9 & 0.3 & \mathrm{u} & 95.8 \\ 15 & 0.21490 & 82.3 & 0.5 & \mathrm{u} & 81.2 \\ 16 & 0.27500 & 69.2 & 0.5 & \mathrm{u} & 68.0 \\ 17 & 0.34900 & 60.0 & 0.7 & \mathrm{u} & 58.3 \\ 18 & 0.43600 & 53.1 & 0.6 & \mathrm{u} & 51.6 \\ 19 & 0.55500 & 48.0 & 1.2 & \mathrm{u} & 46.4 \\ 20 & 0.70100 & 45.3 & 1.1 & \mathrm{u} & 43.0\end{array}$

Date: 08-JUN-06

UTM Coord: $\mathrm{E}[\mathrm{m}]$

Elevation $[\mathrm{m}]$ : 2342.4

$44942.0 \quad \mathrm{~N}[\mathrm{~m}] \quad 4179766.0$

$\mathrm{RX}$ location: $\mathrm{X}[\mathrm{m}]$

$0.0 \quad \mathrm{Y}[\mathrm{m}]$

0.0

Fit Error $[\%]: 3.754$

System: EM-47 Freq[Hz]: 30 Data Set Code: hi TX Cur[A]: 3.0 Turn Off[usec]: 2.5

RX Moment[turns-m^2]: 31.4 Gain setting: 7

Time
$[\mathrm{ms}]$
0.10000
0.12100
0.15100
0.18800
0.23100
0.29100
0.36500
0.45200
0.57000
0.71200
0.87100
1.08000
1.39000
1.75000
2.18000
2.78000
3.52000
4.39000
5.56000
7.04000

rhoa_obs obs_err mask rhoa_cal

rhoa_obs obs_err mask rhoa_cal

$\begin{array}{rrrr}131.8 & 0.2 & u & 137.9\end{array}$

$\begin{array}{llll}117.7 & 0.6 & \mathrm{u} & 120.6\end{array}$

$\begin{array}{llll}99.8 & 0.6 & \mathrm{u} & 101.8\end{array}$

$82.4 \quad 0.6 \quad u \quad 85.5$

$\begin{array}{llll}70.7 & 0.9 & \mathrm{u} & 72.6\end{array}$

$\begin{array}{llll}59.1 & 0.8 & u & 60.9\end{array}$

$\begin{array}{llll}50.5 & 0.5 & \mathrm{u} & 52.0\end{array}$

$44.6 \quad 1.5 \quad \mathrm{u} \quad 45.5$

$39.3 \quad 1.7 \quad \mathrm{u} \quad 40.0$

$\begin{array}{llll}35.9 & 2.3 & \mathrm{u} & 36.1\end{array}$

$\begin{array}{llll}32.9 & 3.5 & u & 33.5\end{array}$

31.3

$\begin{array}{llll}29.1 & 8.8 & \mathrm{u} & 29.4\end{array}$

$28.0 \quad 5.1 \quad$ u $\quad 28.3$

$27.4 \quad 12.7 \quad \mathrm{u} \quad 27.7$

27.4

$31.2 \quad 69.0 \quad \mathrm{~m} \quad 27.3$

23.4

$19.2 \quad 56.7$

$30.1 \quad 100.0$ 
Sounding: GSD04

Client: USGS/NPS

Location: Great Sand Dunes National Park

Project: San Luis Valley Blue Clay

County: Saguache [Colorado]

TX loop size: $X[\mathrm{~m}] \quad 38.1 \quad \mathrm{Y}[\mathrm{m}] \quad 38.1$

$\begin{array}{cccc}\text { Model } & \text { Resistivity } & \text { Thickness } & \text { Elevation } \\ \text { Layer } & {[\text { ohm-m] }} & {[\mathrm{m}]} & {[\mathrm{m}]} \\ 1 & 409.70 & 26.2 & 2347.0 \\ 2 & 127.00 & 74.6 & 2320.7 \\ 3 & 10.74 & -- & 2246.0\end{array}$

System: EM-47 Freq[Hz]: 285 Data Set Code: uh TX Cur[A]: 2.5 Turn Off[usec]: 2.5

RX Moment[turns-m^2]: 31.4 Gain Setting: 4

$\begin{array}{rrrrrr}\text { Time } & \text { rhoa_obs } & \text { obs_err } & \text { mask } & \text { rhoa_cal } \\ \text { [ohm-m] } & \text { [ohm-m] } & & \text { [o } \\ 1 & 0.00680 & 225.1 & 0.1 & \mathrm{~m} & 273.1 \\ 2 & 0.00890 & 253.9 & 0.2 & \mathrm{u} & 252.0 \\ 3 & 0.01200 & 235.2 & 0.3 & \mathrm{u} & 237.0 \\ 4 & 0.01570 & 223.3 & 0.3 & \mathrm{u} & 226.1 \\ 5 & 0.02000 & 222.6 & 0.1 & \mathrm{u} & 219.4 \\ 6 & 0.02610 & 215.8 & 0.1 & \mathrm{u} & 216.2 \\ 7 & 0.03340 & 215.0 & 0.2 & \mathrm{u} & 216.4 \\ 8 & 0.04210 & 216.0 & 0.0 & \mathrm{u} & 216.9 \\ 9 & 0.05410 & 211.5 & 0.1 & \mathrm{u} & 213.6 \\ 10 & 0.06820 & 208.2 & 0.7 & \mathrm{u} & 203.8 \\ 11 & 0.08380 & 186.4 & 0.4 & \mathrm{u} & 189.0 \\ 12 & 0.10460 & 174.1 & 0.7 & \mathrm{u} & 169.0 \\ 13 & 0.13560 & 150.5 & 0.8 & \mathrm{u} & 144.2 \\ 14 & 0.17230 & 128.5 & 1.3 & \mathrm{u} & 123.2 \\ 15 & 0.21490 & 109.2 & 1.5 & \mathrm{u} & 106.5 \\ 16 & 0.27500 & 91.8 & 2.2 & \mathrm{u} & 91.1 \\ 17 & 0.34900 & 78.7 & 2.9 & \mathrm{u} & 79.2 \\ 18 & 0.43600 & 68.0 & 3.4 & \mathrm{u} & 70.3 \\ 19 & 0.55500 & 60.7 & 4.6 & \mathrm{u} & 62.8 \\ 20 & 0.70100 & 53.4 & 5.3 & \mathrm{u} & 57.3\end{array}$

Date: $08-J U N-06$

UTM Coord: $\mathrm{E}[\mathrm{m}] \quad 443073.0 \mathrm{~N}[\mathrm{~m}] \quad 4183004.0$

Elevation [m] : 2347.0

RX location: X[m] $0.0 \quad \mathrm{Y}[\mathrm{m}] \quad 0.0$

\section{Fit Error [\%]: 4.486}

System: EM-47 Freq[Hz]: 30 Data Set Code: hi TX $\operatorname{Cur}[A]: 2.5$ Turn Off[usec]: 2.5

RX Moment[turns-m^2]: 31.4 Gain Setting: 7

Time
$[\mathrm{ms}]$
0.10000
0.12100
0.15100
0.18800
0.23100
0.29100
0.36500
0.45200
0.57000
0.71200
0.87100
1.08000
1.39000
1.75000
2.18000
2.78000
3.52000
4.39000
5.56000
7.04000

rhoa_obs [ohm-m ]

161.5

148.7

131.6

112.2

95.8

80.1

67.7

58.1

49.2

44.0

41.0

38.1

34.3

30.5

30.

34.3
34.8

42.0

81.5

14.4

12.1

\section{obs_err mask}

[\%]

0.8

1.1

0.8
1.2

1.6

2.4

3.4

2.6

2.6

4.8

9.0

6.2

11.2

14.7

15.6

37.6

100.0

100.0

100.0

100.0

$\begin{array}{cc} & \text { [ohm-m] } \\ \mathrm{u} & 169.1 \\ \mathrm{u} & 149.9 \\ \mathrm{u} & 128.8 \\ \mathrm{u} & 109.9 \\ \mathrm{u} & 94.7 \\ \mathrm{u} & 80.4 \\ \mathrm{u} & 68.8 \\ \mathrm{u} & 59.8 \\ \mathrm{u} & 51.7 \\ \mathrm{u} & 45.4 \\ \mathrm{u} & 40.6 \\ \mathrm{u} & 36.4 \\ \mathrm{u} & 32.4 \\ \mathrm{u} & 29.4 \\ \mathrm{~m} & 27.0 \\ \mathrm{~m} & 25.0 \\ \mathrm{~d} & - \\ \mathrm{d} & - \\ \mathrm{d} & - \\ \mathrm{d} & -\end{array}$


Sounding: GSD05

Client: USGS/NPS

Location: Great Sand Dunes National Park

Project: San Luis Valley Blue Clay

County: Alamosa [Colorado]

TX loop size: $X[\mathrm{~m}] \quad 38.1 \quad \mathrm{Y}[\mathrm{m}] \quad 38.1$

$\begin{array}{cccc}\text { Model } & \text { Resistivity } & \text { Thickness } & \text { Elevation } \\ \text { Layer } & {[\text { ohm-m] }} & {[\mathrm{m}]} & {[\mathrm{m}]} \\ 1 & 132.80 & 28.4 & 2311.9 \\ 2 & 49.53 & 30.3 & 2283.4 \\ 3 & 10.72 & 39.9 & 2253.1 \\ 4 & 5.13 & -- & 2213.1\end{array}$

System: EM-47 Freq[Hz]: 285 Data Set Code: uh TX Cur[A]: 2.5 Turn Off[usec]: 2.5 $\mathrm{RX}$ Moment[turns-m^2]: 31.4 Gain Setting: 3

$\begin{array}{rrrrrr}\text { Time } & \text { rhoa_obs } & \text { obs_err } & \text { mask } \\ {\left[\begin{array}{c}\text { [ms] } \\ \text { [ohm] }\end{array}\right.} & \begin{array}{c}\text { rhoa_cal } \\ \text { [ohm-m] }\end{array} \\ 1 & 0.00680 & 123.6 & 0.1 & \mathrm{u} & 125.2 \\ 2 & 0.00890 & 125.0 & 0.3 & \mathrm{u} & 121.9 \\ 3 & 0.01200 & 118.8 & 0.4 & \mathrm{u} & 119.4 \\ 4 & 0.01570 & 114.0 & 0.3 & \mathrm{u} & 115.9 \\ 5 & 0.02000 & 113.7 & 0.3 & \mathrm{u} & 112.5 \\ 6 & 0.02610 & 109.0 & 0.2 & \mathrm{u} & 108.8 \\ 7 & 0.03340 & 103.7 & 0.3 & \mathrm{u} & 104.2 \\ 8 & 0.04210 & 98.3 & 0.4 & \mathrm{u} & 98.2 \\ 9 & 0.05410 & 89.8 & 0.6 & \mathrm{u} & 89.8 \\ 10 & 0.06820 & 82.5 & 0.7 & \mathrm{u} & 81.0 \\ 11 & 0.08380 & 73.7 & 0.1 & \mathrm{u} & 73.4 \\ 12 & 0.10460 & 67.4 & 0.1 & \mathrm{u} & 65.7 \\ 13 & 0.13560 & 59.9 & 0.2 & \mathrm{u} & 58.1 \\ 14 & 0.17230 & 53.8 & 0.1 & \mathrm{u} & 52.1 \\ 15 & 0.21490 & 48.6 & 0.2 & \mathrm{u} & 47.5 \\ 16 & 0.27500 & 43.9 & 0.3 & \mathrm{u} & 42.9 \\ 17 & 0.34900 & 39.8 & 0.6 & \mathrm{u} & 39.1 \\ 18 & 0.43600 & 36.5 & 1.2 & \mathrm{u} & 35.9 \\ 19 & 0.55500 & 33.7 & 1.2 & \mathrm{u} & 32.9 \\ 20 & 0.70100 & 31.9 & 2.3 & \mathrm{u} & 30.6\end{array}$

Date: 08-JUN-06

UTM Coord: E[m] $441449.0 \quad \mathrm{~N}[\mathrm{~m}] \quad 4176374.0$

Elevation [m] : 2311.9

RX location: $\mathrm{X}[\mathrm{m}] \quad 0.0 \quad \mathrm{Y}[\mathrm{m}] \quad 0.0$

Fit Error $[\%]: \quad 3.339$

System: EM-47 Freq[Hz]: 30 Data Set Code: hi TX Cur[A]: 2.5 Turn Off[usec]: 2.5

RX Moment[turns-m^2]: 31.4 Gain setting: 7

Time
$[\mathrm{ms}]$
0.10000
0.12100
0.15100
0.18800
0.23100
0.29100
0.36500
0.45200
0.57000
0.71200
0.87100
1.08000
1.39000
1.75000
2.18000
2.78000
3.52000
4.39000
5.56000
7.04000

obs

mask

rhoa cal

[ohm-m] [ [\% ]

62.9

[\%]

0.2
0.3

58.6

53.0

0.4

47.1

42.8

37.9

33.6

30.0

26.4

24.1

21.9

19.7

17.8

15.8

14.5

12.9

13.0

14.2

10.6

0.5

0.4

0.6

0.8

1.5

1.4

1.3

1.1

3.3

7.0

10.4

17.7

16.3

18.5

72.6 [ohm-m ]

66.2

60.0

53.7

48.2

43.6

38.9

34.6

30.9

27.4

24.3

21.9

19.7

17.5

15.8

14.5

13.3

12.4

11.8

11.3 
Sounding: GSL06

Client: USGS/NPS

Location: Great Sand Dunes National Park

Project: San Luis Valley Blue Clay

County: Saguache [Colorado]

TX loop size: $X[\mathrm{~m}] \quad 38.1 \quad \mathrm{Y}[\mathrm{m}] \quad 38.1$

$\begin{array}{cccc}\text { Model } & \text { Resistivity } & \text { Thickness } & \text { Elevation } \\ \text { Layer } & {[\text { ohm-m] }} & {[\mathrm{m}]} & {[\mathrm{m}]} \\ 1 & 652.20 & 16.1 & 2322.6 \\ 2 & 137.10 & 75.0 & 2306.4 \\ 3 & 30.42 & 68.3 & 2231.3 \\ 4 & 6.84 & -- & 2163.0\end{array}$

System: EM-47 Freq[Hz]: 285 Data Set Code: uh TX Cur[A]: 2.5 Turn off[usec]: 2.5 RX Moment[turns-m^2]: 31.4 Gain Setting: 4

$\begin{array}{rrrrrr}\text { Time } & \text { rhoa_obs } & \text { obs_err } & \text { mask } & \begin{array}{c}\text { rhoa_cal } \\ \text { [ohm-m] }\end{array} \\ 1 & 0.00680 & 193.3 & 0.3 & \mathrm{~m} & 237.9 \\ 2 & 0.00890 & 223.3 & 0.1 & \mathrm{u} & 221.0 \\ 3 & 0.01200 & 211.5 & 0.3 & \mathrm{u} & 211.5 \\ 4 & 0.01570 & 204.3 & 0.3 & \mathrm{u} & 205.2 \\ 5 & 0.02000 & 204.5 & 0.0 & \mathrm{u} & 201.3 \\ 6 & 0.02610 & 196.6 & 0.1 & \mathrm{u} & 198.4 \\ 7 & 0.03340 & 193.2 & 0.2 & \mathrm{u} & 195.7 \\ 8 & 0.04210 & 190.9 & 0.3 & \mathrm{u} & 191.1 \\ 9 & 0.05410 & 183.4 & 0.5 & \mathrm{u} & 182.6 \\ 10 & 0.06820 & 177.8 & 0.8 & \mathrm{u} & 171.7 \\ 11 & 0.08380 & 158.6 & 1.7 & \mathrm{u} & 160.7 \\ 12 & 0.10460 & 153.4 & 1.0 & \mathrm{u} & 149.1 \\ 13 & 0.13560 & 142.4 & 0.2 & \mathrm{u} & 137.3 \\ 14 & 0.17230 & 133.7 & 0.7 & \mathrm{u} & 128.5 \\ 15 & 0.21490 & 125.4 & 1.1 & \mathrm{u} & 121.6 \\ 16 & 0.27500 & 116.4 & 1.2 & \mathrm{u} & 114.3 \\ 17 & 0.34900 & 111.5 & 2.4 & \mathrm{u} & 106.9 \\ 18 & 0.43600 & 99.0 & 2.1 & \mathrm{u} & 99.3 \\ 19 & 0.55500 & 91.4 & 1.8 & \mathrm{u} & 91.2 \\ 20 & 0.70100 & 80.6 & 7.9 & \mathrm{u} & 83.6\end{array}$

Date: 09-JUN-06

UTM Coord: $\mathrm{E}[\mathrm{m}] \quad 436634.0 \mathrm{~N}[\mathrm{~m}] \quad 4183429.0$

Elevation $[\mathrm{m}]: 2322.6$

$\mathrm{RX}$ location: $\mathrm{X}[\mathrm{m}] \quad 0.0 \quad \mathrm{Y}[\mathrm{m}] \quad 0.0$

\section{Fit Error [\%]: 5.051}

System: EM-47 Freq[Hz]: 30 Data Set Code: hi TX $\operatorname{Cur}[A]: 2.5$ Turn Off [usec] : 2.5 RX Moment[turns-m^2]: 31.4 Gain setting: 7

Time
$[\mathrm{ms}]$
0.10000
0.12100
0.15100
0.18800
0.23100
0.29100
0.36500
0.45200
0.57000
0.71200
0.87100
1.08000
1.39000
1.75000
2.18000
2.78000
3.52000
4.39000
5.56000
7.04000

rhoa_obs
[ohm-m]
140.6
134.9
128.0
119.0
111.0
101.9
89.4
80.3
69.3
64.2
56.2
52.1
41.6
39.8
32.1
27.4
24.4
25.7
23.1
12.4

obs_err mask

rhoa_cal

$[\%]$

ohm-m ]

$\begin{array}{rr}1 & 0.10000 \\ 2 & 0.12100 \\ 3 & 0.15100 \\ 4 & 0.18800 \\ 5 & 0.23100 \\ 6 & 0.29100 \\ 7 & 0.36500 \\ 8 & 0.45200 \\ 9 & 0.57000 \\ 10 & 0.71200 \\ 11 & 0.87100 \\ 12 & 1.08000 \\ 13 & 1.39000 \\ 14 & 1.75000 \\ 15 & 2.18000 \\ 16 & 2.78000 \\ 17 & 3.52000 \\ 18 & 4.39000 \\ 19 & 5.56000 \\ 20 & 7.04000\end{array}$

$0.8 \quad$

$0.6 \quad u$

1.4

1.3

2.3

3.2

3.9

4.3

8.4

10.3

15.1

14.5

22.5

20.8

29.3

44.7

63.6

85.0

69.9 
Sounding: GSL07

Client: USGS/NPS

Location: Great Sand Dunes National Park

Project: San Luis Valley Blue Clay

County: Saguache [Colorado]

TX loop size: $X[\mathrm{~m}] \quad 38.1 \quad \mathrm{Y}[\mathrm{m}] \quad 38.1$

$\begin{array}{cccc}\text { Model } & \text { Resistivity } & \text { Thickness } & \text { Elevation } \\ \text { Layer } & \text { [ohm-m] } & {[\mathrm{m}]} & {[\mathrm{m}]} \\ 1 & 172.30 & 32.0 & 2307.3 \\ 2 & 51.61 & 33.4 & 2275.2 \\ 3 & 22.91 & 75.8 & 2241.7 \\ 4 & 5.10 & -- & 2165.9\end{array}$

System: EM-47 Freq[Hz]: 285 Data Set Code: uh TX Cur[A]: 2.5 Turn Off[usec]: 2.5 $\mathrm{RX}$ Moment[turns-m^2]: 31.4 Gain Setting: 3

\begin{tabular}{|c|c|c|c|c|c|}
\hline & $\begin{array}{l}\text { Time } \\
\text { [ms ] }\end{array}$ & $\begin{array}{l}\text { rhoa_obs } \\
\text { [ohm-m] }\end{array}$ & $\begin{array}{c}\text { obs_err } \\
{\left[\frac{\%}{\%}\right]}\end{array}$ & mask & $\begin{array}{l}\text { rhoa_cal } \\
\text { [ohm-m] }\end{array}$ \\
\hline 1 & 0.00680 & 150.3 & 0.3 & $\mathrm{~m}$ & 160.6 \\
\hline 2 & 0.00890 & 158.0 & 0.1 & $\mathrm{u}$ & 155.7 \\
\hline 3 & 0.01200 & 147.8 & 0.2 & $\mathrm{u}$ & 149.8 \\
\hline 4 & 0.01570 & 139.9 & 0.2 & $\mathrm{u}$ & 141.7 \\
\hline 5 & 0.02000 & 135.7 & 0.2 & $\mathrm{u}$ & 133.7 \\
\hline 6 & 0.02610 & 126.1 & 0.1 & $\mathrm{u}$ & 125.1 \\
\hline 7 & 0.03340 & 117.1 & 0.1 & $\mathrm{u}$ & 117.0 \\
\hline 8 & 0.04210 & 109.6 & 0.1 & $\mathrm{u}$ & 109.3 \\
\hline 9 & 0.05410 & 99.9 & 0.1 & $\mathrm{u}$ & 100.5 \\
\hline 10 & 0.06820 & 92.5 & 0.2 & $\mathrm{u}$ & 92.3 \\
\hline 11 & 0.08380 & 84.4 & 0.3 & $\mathrm{u}$ & 85.3 \\
\hline 12 & 0.10460 & 79.1 & 0.2 & $\mathrm{u}$ & 78.3 \\
\hline 13 & 0.13560 & 73.5 & 0.1 & $\mathrm{u}$ & 71.6 \\
\hline 14 & 0.17230 & 70.2 & 0.4 & $\mathrm{u}$ & 66.7 \\
\hline 15 & 0.21490 & 66.8 & 0.4 & $\mathrm{u}$ & 63.5 \\
\hline 16 & 0.27500 & 63.0 & 0.4 & $\mathrm{u}$ & 60.9 \\
\hline 17 & 0.34900 & 60.0 & 0.7 & $\mathrm{u}$ & 59.1 \\
\hline 18 & 0.43600 & 57.3 & 0.7 & $\mathrm{u}$ & 57.5 \\
\hline 19 & 0.55500 & 54.2 & 1.6 & $\mathrm{u}$ & 55.5 \\
\hline 20 & 0.70100 & 53.7 & 2.8 & $\mathrm{u}$ & 53.3 \\
\hline
\end{tabular}

Date: 09-JUN-06

UTM Coord: $\mathrm{E}[\mathrm{m}] \quad 432848.0 \mathrm{~N}[\mathrm{~m}] \quad 4183329.0$

Elevation $[\mathrm{m}]: 2307.3$

$\mathrm{RX}$ location: $\mathrm{X}[\mathrm{m}] \quad 0.0 \quad \mathrm{Y}[\mathrm{m}] \quad 0.0$

\section{Fit Error [\%]: 4.360}

System: EM-47 Freq[Hz]: 30 Data Set Code: hi TX Cur[A]: 2.5 Turn Off[usec]: 2.5

RX Moment[turns-m^2]: 31.4 Gain setting: 7

Time
$[\mathrm{ms}]$
0.10000
0.12100
0.15100
0.18800
0.23100
0.29100
0.36500
0.45200
0.57000
0.71200
0.87100
1.08000
1.39000
1.75000
2.18000
2.78000
3.52000
4.39000
5.56000
7.04000

rhoa_obs obs

obs err mas

rhoa_cal

ohm-m ]

[\%]

ohm-m ]

0.6 u

63.6

$\begin{array}{llll}60.8 & 1.0 & \mathrm{u} & 60.3\end{array}$

$\begin{array}{llll}56.7 & 1.1 & u & 57.0\end{array}$

$\begin{array}{llll}52.5 & 1.4 & \mathrm{u} & 53.8\end{array}$

$\begin{array}{llll}47.9 & 1.6 & \mathrm{u} & 50.4\end{array}$

$\begin{array}{llll}44.1 & 3.6 & \mathrm{u} & 46.3\end{array}$

$\begin{array}{llll}41.2 & 5.2 & \mathrm{u} & 41.9\end{array}$

$\begin{array}{llll}38.2 & 6.5 & \mathrm{u} & 37.9\end{array}$

$\begin{array}{llll}33.7 & 8.7 & \mathrm{u} & 33.8\end{array}$

$\begin{array}{llll}30.7 & 6.6 & u & 29.4\end{array}$

$\begin{array}{llll}27.2 & 8.7 & u & 26.0\end{array}$

$\begin{array}{llll}24.6 & 13.4 & u & 23.3\end{array}$

$\begin{array}{llll}20.8 & 25.1 & \mathrm{u} & 20.7\end{array}$

$\begin{array}{lll}18.0 & 27.3 & \mathrm{u}\end{array}$

$\begin{array}{llll}16.6 & 47.1 & u & 17.3\end{array}$

12.438 .3

$14.5 \quad 65.3$ 
Sounding: GSL08

Client: USGS/NPS

Location: Great Sand Dunes National Park

Project: San Luis Valley Blue Clay

County: Saguache [Colorado]

TX loop size: $X[\mathrm{~m}] \quad 38.1 \quad \mathrm{Y}[\mathrm{m}] \quad 38.1$

$\begin{array}{cccc}\text { Model } & \text { Resistivity } & \text { Thickness } & \text { Elevation } \\ \text { Layer } & \text { [ohm-m] } & {[\mathrm{m}]} & {[\mathrm{m}]} \\ 1 & 158.20 & 27.6 & 2305.8 \\ 2 & 46.69 & 45.7 & 2278.1 \\ 3 & 26.27 & 43.3 & 2232.4 \\ 4 & 5.83 & -- & 2189.0\end{array}$

System: EM-47 Freq[Hz]: 285 Data Set Code: uh TX Cur[A]: 2.5 Turn Off[usec]: 2.5 $\mathrm{RX}$ Moment[turns-m^2]: 31.4 Gain Setting: 3

$\begin{array}{rrrrrr}\text { Time } & \text { rhoa_obs } & \text { obs_err } & \text { mask } & \begin{array}{c}\text { rhoa_cal } \\ \text { [ohm-m] }\end{array} \\ 1 & 0.00680 & 142.7 & 0.1 & \mathrm{u} & 145.6 \\ 2 & 0.00890 & 143.3 & 0.2 & \mathrm{u} & 137.9 \\ 3 & 0.01200 & 129.0 & 0.3 & \mathrm{u} & 129.7 \\ 4 & 0.01570 & 118.8 & 0.2 & \mathrm{u} & 120.5 \\ 5 & 0.02000 & 112.8 & 0.2 & \mathrm{u} & 112.1 \\ 6 & 0.02610 & 103.9 & 0.2 & \mathrm{u} & 103.8 \\ 7 & 0.03340 & 96.4 & 0.2 & \mathrm{u} & 97.2 \\ 8 & 0.04210 & 91.6 & 0.3 & \mathrm{u} & 91.8 \\ 9 & 0.05410 & 86.3 & 0.4 & \mathrm{u} & 86.4 \\ 10 & 0.06820 & 83.6 & 0.6 & \mathrm{u} & 82.0 \\ 11 & 0.08380 & 79.7 & 0.2 & \mathrm{u} & 78.5 \\ 12 & 0.10460 & 77.4 & 0.1 & \mathrm{u} & 75.5 \\ 13 & 0.13560 & 74.3 & 0.2 & \mathrm{u} & 72.7 \\ 14 & 0.17230 & 72.5 & 0.2 & \mathrm{u} & 70.4 \\ 15 & 0.21490 & 69.7 & 0.5 & \mathrm{u} & 68.0 \\ 16 & 0.27500 & 65.4 & 0.3 & \mathrm{u} & 64.8 \\ 17 & 0.34900 & 61.6 & 0.9 & \mathrm{u} & 60.7 \\ 18 & 0.43600 & 57.5 & 1.1 & \mathrm{u} & 56.5 \\ 19 & 0.55500 & 52.1 & 0.7 & \mathrm{u} & 51.9 \\ 20 & 0.70100 & 49.2 & 1.6 & \mathrm{u} & 47.9\end{array}$

Date: 09-JUN-06

UTM Coord: $\mathrm{E}[\mathrm{m}] \quad 432749.0 \mathrm{~N}[\mathrm{~m}] \quad 4180346.0$

Elevation $[\mathrm{m}]$ : 2305.8

$\mathrm{RX}$ location: $\mathrm{X}[\mathrm{m}] \quad 0.0 \quad \mathrm{Y}[\mathrm{m}] \quad 0.0$

\section{Fit Error [\%]: 2.979}

System: EM-47 Freq[Hz]: 30 Data Set Code: hi TX $\operatorname{Cur}[A]: 2.5$ Turn Off [usec] : 2.5

RX Moment[turns-m^2]: 31.4 Gain setting: 7

Time
$[\mathrm{ms}]$
0.10000
0.12100
0.15100
0.18800
0.23100
0.29100
0.36500
0.45200
0.57000
0.71200
0.87100
1.08000
1.39000
1.75000
2.18000
2.78000
3.52000
4.39000
5.56000
7.04000

rhoa_obs obs

obs_err mask rhoa_cal

ohm-m] [\%]

$\begin{array}{llll}71.7 & 0.4 & \mathrm{u} & 75.4 \\ 71.0 & 0.3 & \mathrm{u} & 72.7\end{array}$

$\begin{array}{llll}69.1 & 0.5 & \mathrm{u} & 70.0\end{array}$

$\begin{array}{llll}65.9 & 0.8 & \mathrm{u} & 67.0\end{array}$

$63.2 \quad 1.0 \quad \mathrm{u} \quad 63.7$

$\begin{array}{llll}57.9 & 1.1 & \mathrm{u} & 59.0\end{array}$

$52.3 \quad 1.3 \quad \mathrm{u} \quad 53.5$

$46.5 \quad 1.5 \quad \mathrm{u} \quad 48.1$

$\begin{array}{llll}41.2 & 2.6 & \mathrm{u} & 42.3 \\ 37.8 & 3.5 & \mathrm{u} & 37.2\end{array}$

$\begin{array}{llll}37.8 & 3.5 & \mathrm{u} & 37.2\end{array}$

$32.9 \quad 4.1 \quad \mathrm{u} \quad 33.1$

29.2

$\begin{array}{llll}25.7 & 7.6 & \mathrm{u} & 25.5\end{array}$

$\begin{array}{llll}22.9 & 10.2 & \mathrm{u} & 22.7\end{array}$

$20.5 \quad 16.3 \quad \mathrm{u} \quad 20.5$

$17.4 \quad 14.7 \quad \mathrm{~m} \quad 18.5$

$16.2 \quad 17.9 \quad \mathrm{~m}$

$\begin{array}{llll}16.9 & 41.1 & \mathrm{~m} & 15.9\end{array}$

$14.1 \quad 48.5$

$11.3 \quad 56.1$ 
Sounding: GSL09

Client: USGS/NPS

Location: Great Sand Dunes National Park

Project: San Luis Valley Blue Clay

County: Saguache [Colorado]

TX loop size: $X[\mathrm{~m}] \quad 38.1 \quad \mathrm{Y}[\mathrm{m}] \quad 38.1$

$\begin{array}{cccc}\text { Model } & \text { Resistivity } & \text { Thickness } & \text { Elevation } \\ \text { Layer } & {[\text { ohm-m] }} & {[\mathrm{m}]} & {[\mathrm{m}]} \\ 1 & 268.50 & 44.7 & 2318.0 \\ 2 & 78.30 & 46.8 & 2273.2 \\ 3 & 18.63 & 57.0 & 2226.3 \\ 4 & 6.69 & -- & 2169.2\end{array}$

System: EM-47 Freq[Hz]: 285 Data Set Code: uh TX Cur[A]: 2.5 Turn Off[usec] : 2.5 RX Moment[turns-m^2]: 31.4 Gain Setting: 4

$\begin{array}{rrrrrr}\text { Time } & \text { rhoa_obs } & \text { obs_err } & \text { mask } & \begin{array}{c}\text { rhoa_cal } \\ \text { [ohm-m] }\end{array} \\ 1 & 0.00680 & 233.3 & 0.2 & \mathrm{u} & 245.7 \\ 2 & 0.00890 & 266.4 & 0.1 & \mathrm{u} & 244.4 \\ 3 & 0.01200 & 239.8 & 0.1 & \mathrm{u} & 241.1 \\ 4 & 0.01570 & 224.0 & 0.2 & \mathrm{u} & 230.8 \\ 5 & 0.02000 & 218.5 & 0.3 & \mathrm{u} & 219.9 \\ 6 & 0.02610 & 207.5 & 0.3 & \mathrm{u} & 208.3 \\ 7 & 0.03340 & 198.3 & 0.4 & \mathrm{u} & 198.8 \\ 8 & 0.04210 & 191.4 & 0.3 & \mathrm{u} & 189.0 \\ 9 & 0.05410 & 177.3 & 0.2 & \mathrm{u} & 176.6 \\ 10 & 0.06820 & 165.9 & 0.1 & \mathrm{u} & 162.6 \\ 11 & 0.08380 & 149.6 & 0.5 & \mathrm{u} & 149.2 \\ 12 & 0.10460 & 137.2 & 0.3 & \mathrm{u} & 134.9 \\ 13 & 0.13560 & 122.7 & 0.5 & \mathrm{u} & 119.7 \\ 14 & 0.17230 & 111.1 & 0.4 & \mathrm{u} & 108.1 \\ 15 & 0.21490 & 101.3 & 0.3 & \mathrm{u} & 99.1 \\ 16 & 0.27500 & 92.0 & 0.4 & \mathrm{u} & 90.6 \\ 17 & 0.34900 & 84.4 & 0.9 & \mathrm{u} & 83.2 \\ 18 & 0.43600 & 76.9 & 1.3 & \mathrm{u} & 77.0 \\ 19 & 0.55500 & 71.8 & 2.3 & \mathrm{u} & 70.7 \\ 20 & 0.70100 & 65.4 & 2.2 & \mathrm{u} & 65.4\end{array}$

Date: 09-JUN-06

UTM Coord: E[m] $438354.0 \mathrm{~N}[\mathrm{~m}] \quad 4180480.0$

Elevation $[\mathrm{m}]: 2318.0$

$\mathrm{RX}$ location: $\mathrm{X}[\mathrm{m}] \quad 0.0 \quad \mathrm{Y}[\mathrm{m}] \quad 0.0$

\section{Fit Error [\%]: 3.819}

System: EM-47 Freq[Hz]: 30 Data Set Code: hi TX $\operatorname{Cur}[A]: 2.5$ Turn Off [usec] : 2.5 RX Moment[turns-m^2]: 31.4 Gain setting: 7

Time
$[\mathrm{ms}]$
0.10000
0.12100
0.15100
0.18800
0.23100
0.29100
0.36500
0.45200
0.57000
0.71200
0.87100
1.08000
1.39000
1.75000
2.18000
2.78000
3.52000
4.39000
5.56000
7.04000

$\begin{array}{rr}\text { rhoa_obs } & \text { obs_er } \\ \text { [ohm-m] } & {[\overline{\%}]} \\ 128.7 & 0.7 \\ 120.4 & 0.9 \\ 109.9 & 1.0 \\ 98.7 & 1.2 \\ 90.4 & 1.4 \\ 79.3 & 1.8 \\ 71.8 & 2.6 \\ 64.3 & 2.9 \\ 56.9 & 4.9 \\ 49.5 & 6.6 \\ 45.2 & 8.2 \\ 39.8 & 9.2 \\ 35.0 & 10.3 \\ 30.9 & 15.5 \\ 26.7 & 18.3 \\ 23.4 & 26.1 \\ 22.6 & 41.4 \\ 21.3 & 62.0 \\ 28.9 & 100.0 \\ 22.3 & 100.0\end{array}$

mask rhoa_cal [ohm-m]

135.7

123.3

110.9

100.0

91.0

81.7

73.0

65.3

57.4

50.4

44.7

39.5

34.2

30.2

27.1

24.3

22.1

$-$ 
Sounding: GSL10

Client: USGS/NPS

Location: Great Sand Dunes National Park

Project: San Luis Valley Blue Clay

County: Alamosa [Colorado]

\begin{tabular}{|c|c|c|c|}
\hline loop & size: $\mathrm{X}[\mathrm{m}]$ & $\mathrm{Y}[\mathrm{m}]$ & 8.1 \\
\hline Model & Resistivity & Thickness & Elevation \\
\hline ayer & [ohm-m ] & {$[\mathrm{m}]$} & [m] \\
\hline 1 & 74.36 & 20.6 & 2296.7 \\
\hline 2 & 15.79 & 27.1 & 2276.0 \\
\hline 3 & 6.50 & -- & 2248.8 \\
\hline
\end{tabular}

System: EM-47 Freq[Hz]: 285 Data Set Code: uh TX Cur $[\mathrm{A}]: \quad 2.5$ Turn Off[usec]: 2.5

RX Moment [turns-m^2]: 31.4 Gain Setting: 2

$\begin{array}{rrrrrr}\text { Time } & \begin{array}{c}\text { rhoa_obs } \\ \text { [ohm-m] }\end{array} & \begin{array}{c}\text { obs_err } \\ {\left[\begin{array}{c}o \\ 0\end{array}\right.}\end{array} & \text { mask } & \begin{array}{r}\text { rhoa_cal } \\ \text { [ohm-m] }\end{array} \\ 1 & 0.00680 & 79.9 & 0.4 & \mathrm{u} & 78.6 \\ 2 & 0.00890 & 74.1 & 0.1 & \mathrm{u} & 74.0 \\ 3 & 0.01200 & 65.9 & 0.1 & \mathrm{u} & 68.2 \\ 4 & 0.01570 & 59.7 & 0.2 & \mathrm{u} & 61.6 \\ 5 & 0.02000 & 55.9 & 0.1 & \mathrm{u} & 55.6 \\ 6 & 0.02610 & 51.2 & 0.1 & \mathrm{u} & 50.0 \\ 7 & 0.03340 & 46.8 & 0.1 & \mathrm{u} & 45.6 \\ 8 & 0.04210 & 43.7 & 0.1 & \mathrm{u} & 42.2 \\ 9 & 0.05410 & 39.8 & 0.2 & \mathrm{u} & 38.8 \\ 10 & 0.06820 & 36.6 & 0.1 & \mathrm{u} & 35.9 \\ 11 & 0.08380 & 33.2 & 0.1 & \mathrm{u} & 33.4 \\ 12 & 0.10460 & 30.5 & 0.1 & \mathrm{u} & 30.7 \\ 13 & 0.13560 & 27.4 & 0.1 & \mathrm{u} & 27.6 \\ 14 & 0.17230 & 25.3 & 0.3 & \mathrm{u} & 25.1 \\ 15 & 0.21490 & 23.2 & 0.2 & \mathrm{u} & 23.0 \\ 16 & 0.27500 & 21.3 & 0.2 & \mathrm{u} & 20.9 \\ 17 & 0.34900 & 20.0 & 0.2 & \mathrm{u} & 19.3 \\ 18 & 0.43600 & 18.8 & 0.3 & \mathrm{u} & 18.1 \\ 19 & 0.55500 & 17.9 & 0.4 & \mathrm{u} & 17.1 \\ 20 & 0.70100 & 17.4 & 0.8 & \mathrm{u} & 16.4\end{array}$

Date: $10-J U N-06$

UTM Coord: $\mathrm{E}[\mathrm{m}] \quad 439727.0 \mathrm{~N}[\mathrm{~m}] \quad 4170606.0$

Elevation [m] : 2296.7

$\begin{array}{llll}\mathrm{RX} \text { location: } \mathrm{X}[\mathrm{m}] & 0.0 & \mathrm{Y}[\mathrm{m}] & 0.0\end{array}$

\section{Fit Error [\%]: 4.393}

System: EM-47 Freq[Hz]: 30 Data Set Code: hi TX $\operatorname{Cur}[A]: 2.5$ Turn Off[usec]: 2.5

RX Moment[turns-m^2]: 31.4 Gain Setting: 7

Time
$[\mathrm{ms}]$
0.10000
0.12100
0.15100
0.18800
0.23100
0.29100
0.36500
0.45200
0.57000
0.71200
0.87100
1.08000
1.39000
1.75000
2.18000
2.78000
3.52000
4.39000
5.56000
7.04000

rhoa_ob [ohm-m ]

28.9
27.1
25.0
22.9
21.1
19.2
17.7
16.2
15.0
14.1
13.1
12.1
11.1
10.7
9.9
9.3
9.1
9.9
10.4
15.8

28 .

[\%

[\%]

0.5

0.4

0.5

0.5

0.4

0.6

0.6

0.9

1.3

2. 2

3.2

4.4

14.8

13.4

24.2

51.7

100.0

15.8100 .0 mask rhoa_cal [ohm-m]

u 30.9

u $\quad 28.6$

u $\quad 23.5$

$\mathrm{u} \quad 21.5$

19.5
17.7

16.3

14.9

13.9

13.0

12.2

11.4

10.9

10.4

10.0

9.7

9.6 
Sounding: GSL11

Client: USGS/NPS

Location: Great Sand Dunes National Park

Project: San Luis Valley Blue Clay

County: Alamosa [Colorado]

\begin{tabular}{|c|c|c|c|}
\hline loop & size: $x[m]$ & $\mathrm{Y}[\mathrm{m}]$ & 8.1 \\
\hline Model & Resistivity & Thickness & Elevation \\
\hline Layer & [ohm-m ] & {$[\mathrm{m}]$} & {$[\mathrm{m}]$} \\
\hline 1 & 237.00 & 5.1 & 2293.6 \\
\hline 2 & 28.19 & 40.3 & 2288.4 \\
\hline 3 & 9.97 & 29.0 & 2248.0 \\
\hline 4 & 5.69 & -- & 2219.0 \\
\hline
\end{tabular}

System: EM-47 Freq[Hz]: 285 Data Set Code: uh TX $\operatorname{Cur}[A]: 2.5$ Turn Off[usec] : 2.5 $\mathrm{RX}$ Moment[turns-m^2]: 31.4 Gain Setting: 1

$\begin{array}{rrrrrr}\text { Time } & \begin{array}{c}\text { rhoa_obs } \\ \text { [ohm-m] }\end{array} & \begin{array}{c}\text { obs_err } \\ \text { [\%] }\end{array} & \text { mask } & \begin{array}{c}\text { rhoa_cal } \\ \text { [ohm-m] }\end{array} \\ 1 & 0.00680 & 54.0 & 0.6 & \mathrm{u} & 54.8 \\ 2 & 0.00890 & 49.9 & 0.2 & \mathrm{u} & 48.8 \\ 3 & 0.01200 & 45.1 & 0.1 & \mathrm{u} & 45.0 \\ 4 & 0.01570 & 42.0 & 0.2 & \mathrm{u} & 42.4 \\ 5 & 0.02000 & 40.8 & 0.1 & \mathrm{u} & 40.6 \\ 6 & 0.02610 & 39.0 & 0.1 & \mathrm{u} & 39.2 \\ 7 & 0.03340 & 37.8 & 0.2 & \mathrm{u} & 38.2 \\ 8 & 0.04210 & 37.4 & 0.1 & \mathrm{u} & 37.4 \\ 9 & 0.05410 & 36.4 & 0.2 & \mathrm{u} & 36.3 \\ 10 & 0.06820 & 36.0 & 0.1 & \mathrm{u} & 35.1 \\ 11 & 0.08380 & 34.3 & 0.2 & \mathrm{u} & 33.8 \\ 12 & 0.10460 & 33.2 & 0.2 & \mathrm{u} & 32.3 \\ 13 & 0.13560 & 31.2 & 0.2 & \mathrm{u} & 30.4 \\ 14 & 0.17230 & 29.3 & 0.2 & \mathrm{u} & 28.5 \\ 15 & 0.21490 & 27.4 & 0.1 & \mathrm{u} & 26.8 \\ 16 & 0.27500 & 25.5 & 0.2 & \mathrm{u} & 25.0 \\ 17 & 0.34900 & 23.9 & 0.4 & \mathrm{u} & 23.4 \\ 18 & 0.43600 & 22.4 & 0.3 & \mathrm{u} & 22.0 \\ 19 & 0.55500 & 21.2 & 0.6 & \mathrm{u} & 20.7 \\ 20 & 0.70100 & 20.4 & 1.3 & \mathrm{u} & 19.8\end{array}$

Date: $10-J U N-06$

UTM Coord: E[m] 435143.0 N[m] 4170651.0

Elevation $[\mathrm{m}]$ : 2293.6

RX location: $\mathrm{X}[\mathrm{m}] \quad 0.0 \quad \mathrm{Y}[\mathrm{m}] \quad 0.0$

\section{Fit Error [\%]: 3.124}

System: EM-47 Freq[Hz]: 30 Data Set Code: hi TX $\operatorname{Cur}[A]: 2.5$ Turn Off [usec] : 2.5

RX Moment[turns-m^2]: 31.4 Gain setting: 7

Time
$[\mathrm{ms}]$
0.10000
0.12100
0.15100
0.18800
0.23100
0.29100
0.36500
0.45200
0.57000
0.71200
0.87100
1.08000
1.39000
1.75000
2.18000
2.78000
3.52000
4.39000
5.56000
7.04000

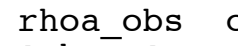

obs_er

mask rhoa cal

[ohm-m] [\%]

[ohm-m]

$\begin{array}{llll}39.9 & 0.4 & \mathrm{u} & 32.4 \\ 29.9 & \mathrm{u} & 30.8\end{array}$

$\begin{array}{llll}28.5 & 0.4 & \mathrm{u} & 29.0\end{array}$

$\begin{array}{llll}26.5 & 0.5 & \mathrm{u} & 27.1\end{array}$

$\begin{array}{llll}24.9 & 0.4 & \mathrm{u} & 25.3\end{array}$

$\begin{array}{llll}22.8 & 0.4 & \mathrm{u} & 23.3\end{array}$

$\begin{array}{llll}20.9 & 0.5 & \mathrm{u} & 21.3\end{array}$

$\begin{array}{llll}19.2 & 0.7 & \mathrm{u} & 19.6\end{array}$

$\begin{array}{llll}17.5 & 0.7 & \mathrm{u} & 17.9\end{array}$

$\begin{array}{llll}16.3 & 1.0 & \mathrm{u} & 16.4\end{array}$

$\begin{array}{llll}14.9 & 1.2 & \mathrm{u} & 15.2\end{array}$

$13.8 \quad 1.9 \quad \mathrm{u} \quad 14.0$

$12.6 \quad 2.4 \quad \mathrm{u} \quad 12.9$

$\begin{array}{llll}11.9 & 3.2 & \mathrm{u} & 12.0\end{array}$

$\begin{array}{llll}11.2 & 5.5 & \mathrm{u} & 11.3\end{array}$

$\begin{array}{llll}10.9 & 8.4 & \mathrm{u} & 10.7\end{array}$

$\begin{array}{llll}10.6 & 13.7 & \mathrm{u} & 10.2\end{array}$

$\begin{array}{llll}9.8 & 16.4 & \mathrm{u} & 9.9\end{array}$

$13.1 \quad 40.7$

$11.0 \quad 44.7$ 
Sounding: GSL12

Client: USGS/NPS

Location: Great Sand Dunes National Park

Project: San Luis Valley Blue Clay

County: Alamosa [Colorado]

TX loop size: $X[\mathrm{~m}] \quad 38.1 \quad \mathrm{Y}[\mathrm{m}] \quad 38.1$

$\begin{array}{cccc}\text { Model } & \text { Resistivity } & \text { Thickness } & \text { Elevation } \\ \text { Layer } & {[\text { ohm-m] }} & {[\mathrm{m}]} & {[\mathrm{m}]} \\ 1 & 682.00 & 12.4 & 2295.8 \\ 2 & 43.59 & 47.9 & 2283.3 \\ 3 & 14.58 & 28.8 & 2235.3 \\ 4 & 7.23 & -- & 2206.5\end{array}$

System: EM-47 Freq[Hz]: 315 Data Set Code: uh TX Cur[A]: 2.5 Turn off[usec]: 2.5 $\mathrm{RX}$ Moment[turns-m^2]: 31.4 Gain Setting: 3

$\begin{array}{rrrrrr}\text { Time } & \text { rhoa_obs } & \text { obs_err } & \text { mask } & \begin{array}{c}\text { rhoa_cal } \\ \text { [ohm-m] }\end{array} \\ 1 & 0.00680 & 117.5 & 0.1 & \mathrm{u} & 119.6 \\ 2 & 0.00890 & 107.7 & 0.2 & \mathrm{u} & 104.6 \\ 3 & 0.01200 & 94.3 & 0.2 & \mathrm{u} & 94.1 \\ 4 & 0.01570 & 85.9 & 0.2 & \mathrm{u} & 86.8 \\ 5 & 0.02000 & 81.7 & 0.1 & \mathrm{u} & 81.5 \\ 6 & 0.02610 & 76.6 & 0.1 & \mathrm{u} & 77.0 \\ 7 & 0.03340 & 73.3 & 0.2 & \mathrm{u} & 73.8 \\ 8 & 0.04210 & 71.4 & 0.1 & \mathrm{u} & 71.0 \\ 9 & 0.05410 & 68.1 & 0.1 & \mathrm{u} & 67.9 \\ 10 & 0.06820 & 66.1 & 0.1 & \mathrm{u} & 64.8 \\ 11 & 0.08380 & 62.7 & 0.2 & \mathrm{u} & 61.8 \\ 12 & 0.10460 & 59.5 & 0.2 & \mathrm{u} & 58.5 \\ 13 & 0.13560 & 55.0 & 0.2 & \mathrm{u} & 54.3 \\ 14 & 0.17230 & 51.0 & 0.1 & \mathrm{u} & 50.4 \\ 15 & 0.21490 & 47.2 & 0.3 & \mathrm{u} & 46.8 \\ 16 & 0.27500 & 43.3 & 0.2 & \mathrm{u} & 42.8 \\ 17 & 0.34900 & 39.8 & 0.4 & \mathrm{u} & 39.2 \\ 18 & 0.43600 & 36.8 & 0.6 & \mathrm{u} & 36.3 \\ 19 & 0.55500 & 34.2 & 0.8 & \mathrm{u} & 33.7 \\ 20 & 0.70100 & 31.6 & 1.0 & \mathrm{u} & 31.8\end{array}$

Date: $10-J U N-06$

UTM Coord: $\mathrm{E}[\mathrm{m}]$

Elevation $[\mathrm{m}]$ : 2295.8

\section{$34360.0 \quad \mathrm{~N}[\mathrm{~m}] \quad 4176318.0$}

$\mathrm{RX}$ location: $\mathrm{X}[\mathrm{m}]$

$0.0 \quad \mathrm{Y}[\mathrm{m}]$

0.0

\section{Fit Error [\%]: 2.643}

System: EM-47 Freq[Hz]: 30 Data Set Code: hi TX Cur[A]: 2.5 Turn Off[usec]: 2.5

RX Moment[turns-m^2]: 31.4 Gain setting: 7

Time
$[\mathrm{ms}]$
0.10000
0.12100
0.15100
0.18800
0.23100
0.29100
0.36500
0.45200
0.57000
0.71200
0.87100
1.08000
1.39000
1.75000
2.18000
2.78000
3.52000
4.39000
5.56000
7.04000

rhoa obs

[ohm-m]

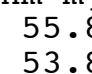

53.8

50.5

46.3

42.9

38.5

34.7

31.3

27.9

25.2

22.5

20.4

18.7

17.2

16.1

15.4

13.9

14.5

15.7

17.0 obs er

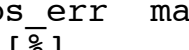

[\%]

0.5
0.5

0.5

0.8

0.5

0.7

0.8

1.3

1.3

2.6

2.3

3.3

4.2

8.6

7.0

15.1

16.0

37.2

50.3

94.0 mask rhoa_cal

[ohm-m]

$\begin{array}{ll}\mathrm{u} & 58.4 \\ \mathrm{u} & 55.1\end{array}$

55.1

47.0

43.0

38.7

34.7

31.3

27.9

25.1

22.9

20.9

18.9

17.4

16.2

15.1

14.3

13.8
13.4 
Sounding: GSL13

Client: USGS/NPS

Location: Great Sand Dunes National Park

Project: San Luis Valley Blue Clay

County: Saguache [Colorado]

TX loop size: $X[\mathrm{~m}] \quad 38.1 \quad \mathrm{Y}[\mathrm{m}] \quad 38.1$

$\begin{array}{cccc}\text { Model } & \text { Resistivity } & \text { Thickness } & \text { Elevation } \\ \text { Layer } & {[\text { ohm-m] }} & {[\mathrm{m}]} & {[\mathrm{m}]} \\ 1 & 84.15 & 15.1 & 2302.8 \\ 2 & 28.90 & 24.5 & 2287.6 \\ 3 & 9.93 & 59.7 & 2263.0 \\ 4 & 8.22 & -- & 2203.3\end{array}$

System: EM-47 Freq[Hz]: 315 Data Set Code: uh TX Cur[A]: 2.5 Turn off[usec]: 2.5 $\mathrm{RX}$ Moment[turns-m^2]: 31.4 Gain Setting: 2

\begin{tabular}{|c|c|c|c|c|c|}
\hline & $\begin{array}{l}\text { Time } \\
\text { [ms ] }\end{array}$ & $\begin{array}{l}\text { rhoa_obs } \\
\text { [ohm-m] }\end{array}$ & $\begin{array}{c}\text { obs_err } \\
{\left[\frac{\circ}{\circ}\right]}\end{array}$ & mask & $\begin{array}{l}\text { rhoa_cal } \\
{[\text { ohm-m] }}\end{array}$ \\
\hline 1 & 0.00680 & 75.7 & 0.4 & $\mathrm{u}$ & 76.4 \\
\hline 2 & 0.00890 & 71.2 & 0.2 & $\mathrm{u}$ & 69.5 \\
\hline 3 & 0.01200 & 64.4 & 0.1 & $\mathrm{u}$ & 64.6 \\
\hline 4 & 0.01570 & 59.7 & 0.1 & $\mathrm{u}$ & 60.8 \\
\hline 5 & 0.02000 & 57.7 & 0.0 & $\mathrm{u}$ & 57.8 \\
\hline 6 & 0.02610 & 54.3 & 0.1 & $\mathrm{u}$ & 54.6 \\
\hline 7 & 0.03340 & 51.0 & 0.2 & $\mathrm{u}$ & 51.5 \\
\hline 8 & 0.04210 & 48.5 & 0.1 & $\mathrm{u}$ & 48.0 \\
\hline 9 & 0.05410 & 44.5 & 0.2 & $\mathrm{u}$ & 44.1 \\
\hline 10 & 0.06820 & 41.7 & 0.2 & $\mathrm{u}$ & 40.2 \\
\hline 11 & 0.08380 & 38.1 & 0.2 & $\mathrm{u}$ & 37.0 \\
\hline 12 & 0.10460 & 34.9 & 0.2 & $\mathrm{u}$ & 33.7 \\
\hline 13 & 0.13560 & 31.0 & 0.2 & $\mathrm{u}$ & 30.4 \\
\hline 14 & 0.17230 & 28.1 & 0.1 & $\mathrm{u}$ & 27.8 \\
\hline 15 & 0.21490 & 25.9 & 0.3 & $\mathrm{u}$ & 25.8 \\
\hline 16 & 0.27500 & 24.0 & 0.4 & $\mathrm{u}$ & 23.9 \\
\hline 17 & 0.34900 & 22.9 & 0.4 & $\mathrm{u}$ & 22.6 \\
\hline 18 & 0.43600 & 22.0 & 0.8 & $\mathrm{u}$ & 21.6 \\
\hline 19 & 0.55500 & 21.4 & 1.6 & $\mathrm{u}$ & 20.9 \\
\hline 20 & 0.70100 & 21.6 & 1.8 & $\mathrm{u}$ & 20.5 \\
\hline
\end{tabular}

Date: 11-JUN-06

UTM Coord: $\mathrm{E}[\mathrm{m}] \quad 420232.0 \mathrm{~N}[\mathrm{~m}] \quad 4178294.0$

Elevation $[\mathrm{m}]$ : 2302.8

RX location: $\mathrm{X}[\mathrm{m}] \quad 0.0 \quad \mathrm{Y}[\mathrm{m}] \quad 0.0$

\section{Fit Error [\%]: 4.390}

System: EM-47 Freq[Hz]: 30 Data Set Code: hi TX Cur[A]: 2.5 Turn Off[usec]: 2.5

RX Moment[turns-m^2]: 31.4 Gain setting: 7

Time
$[\mathrm{ms}]$
0.10000
0.12100
0.15100
0.18800
0.23100
0.29100
0.36500
0.45200
0.57000
0.71200
0.87100
1.08000
1.39000
1.75000
2.18000
2.78000
3.52000
4.39000
5.56000
7.04000

rhoa obs [ohm-m] obs

$30.5 \quad 0.2$

$27.9 \quad 0.2$

25.20 .2

23.4

21.7

20.3

19.1

18.0

17.6

16.5

15.6

14.4

13.8

12.7

11.9

12.

12.6

13.1

23.5
0.3

0.3

0.4

0.5

0.8

1.1

1.5

7.2

8.1

13.0

20.6

35.2

64.3

100.0 mask rhoa_cal

[ohm-m]

34.0

31.3

28.6

26.2

24.2

22.3

20.8

19.4

18.2

17.1

16.2

15.4

14.5

13.8

13.3

12.8

12.5

12.3

12.2 
Sounding: GSL14

Client: USGS/NPS

Location: Great Sand Dunes National Park

Project: San Luis Valley Blue Clay

County: Alamosa [Colorado]

TX loop size: $X[\mathrm{~m}] \quad 38.1 \quad \mathrm{Y}[\mathrm{m}] \quad 38.1$

$\begin{array}{cccc}\text { Model } & \text { Resistivity } & \text { Thickness } & \text { Elevation } \\ \text { Layer } & {[\text { ohm-m] }} & {[\mathrm{m}]} & {[\mathrm{m}]} \\ 1 & 56.80 & 32.3 & 2295.1 \\ 2 & 28.96 & 39.1 & 2262.7 \\ 3 & 6.99 & -- & 2223.5\end{array}$

System: EM-47 Freq[Hz]: 285 Data Set Code: uh TX $\operatorname{Cur}[\mathrm{A}]: \quad 2.5$ Turn Off[usec]: 2.5

RX Moment[turns-m^2]: 31.4 Gain Setting: 1

\begin{tabular}{|c|c|c|c|c|}
\hline $\begin{array}{l}\text { Time } \\
\text { [ms ] }\end{array}$ & $\begin{array}{l}\text { rhoa_obs } \\
{[\text { ohm-m] }}\end{array}$ & obs_err & mask & $\begin{array}{l}\text { rhoa_cal } \\
\text { [ohm-m] }\end{array}$ \\
\hline 0.00680 & 58.8 & 0.4 & $\mathrm{u}$ & 58.4 \\
\hline 0.00890 & 58.9 & 0.0 & $\mathrm{u}$ & 57.1 \\
\hline 0.01200 & 57.4 & 0.2 & $\mathrm{u}$ & 57.8 \\
\hline 0.01570 & 56.1 & 0.2 & $\mathrm{u}$ & 58.0 \\
\hline 0.02000 & 56.9 & 0.2 & $\mathrm{u}$ & 57.6 \\
\hline 0.02610 & 55.8 & 0.1 & $\mathrm{u}$ & 56.5 \\
\hline 0.03340 & 55.1 & 0.1 & $\mathrm{u}$ & 55.0 \\
\hline 0.04210 & 55.1 & 0.1 & $\mathrm{u}$ & 53.7 \\
\hline 0.05410 & 53.8 & 0.3 & $\mathrm{u}$ & 52.5 \\
\hline 0.06820 & 53.5 & 0.4 & $\mathrm{u}$ & 51.5 \\
\hline 0.08380 & 50.9 & 0.2 & $\mathrm{u}$ & 50.6 \\
\hline 0.10460 & 49.8 & 0.2 & $\mathrm{u}$ & 49.1 \\
\hline 0.13560 & 47.3 & 0.3 & $\mathrm{u}$ & 46.5 \\
\hline 0.17230 & 44.5 & 0.5 & $\mathrm{u}$ & 43.4 \\
\hline 0.21490 & 41.1 & 0.5 & $\mathrm{u}$ & 40.1 \\
\hline 0.27500 & 38.2 & 0.9 & $\mathrm{u}$ & 36.5 \\
\hline 0.34900 & 34.7 & 1.8 & $\mathrm{u}$ & 33.2 \\
\hline 0.43600 & 32.0 & 2.3 & $\mathrm{u}$ & 30.6 \\
\hline 5500 & 29.3 & 3.2 & $\mathrm{u}$ & 28.2 \\
\hline 0100 & 28.7 & 6.2 & $\mathrm{~d}$ & - \\
\hline
\end{tabular}

Date: $12-\mathrm{JUN}-06$

UTM Coord: $\mathrm{E}[\mathrm{m}]$

Elevation [m] : 2295.

$31247.0 \quad \mathrm{~N}[\mathrm{~m}] \quad 4176321.0$

RX location: $\mathrm{X}[\mathrm{m}]$

$0.0 \quad \mathrm{Y}[\mathrm{m}]$

0.0

\section{Fit Error[\%]: 4.446}

System: EM-47 Freq[Hz]: 30 Data Set Code: hi TX Cur[A]: 2.5 Turn Off[usec]: 2.5

RX Moment[turns-m^2]: 31.4 Gain Setting: 7

\begin{tabular}{|c|c|c|c|c|c|}
\hline & $\begin{array}{l}\text { Time } \\
\text { [ms ] }\end{array}$ & $\begin{array}{l}\text { rhoa_obs } \\
\text { [ohm-m] }\end{array}$ & $\begin{array}{c}\text { obs_err } \\
{\left[\frac{\%}{\circ}\right]}\end{array}$ & mask & $\begin{array}{l}\text { rhoa_cal } \\
\text { [ohm-m] }\end{array}$ \\
\hline 1 & 0.10000 & 45.7 & 0.4 & $\mathrm{u}$ & 48.9 \\
\hline 2 & 0.12100 & 45.0 & 0.4 & $\mathrm{u}$ & 47.0 \\
\hline 3 & 0.15100 & 42.9 & 0.3 & $\mathrm{u}$ & 44.1 \\
\hline 4 & 0.18800 & 39.8 & 0.4 & $\mathrm{u}$ & 40.6 \\
\hline 5 & 0.23100 & 36.8 & 0.4 & $\mathrm{u}$ & 37.2 \\
\hline 6 & 0.29100 & 33.0 & 0.5 & $\mathrm{u}$ & 33.4 \\
\hline 7 & 0.36500 & 29.6 & 0.7 & $\mathrm{u}$ & 29.8 \\
\hline 8 & 0.45200 & 26.2 & 1.0 & $\mathrm{u}$ & 26.9 \\
\hline 9 & 0.57000 & 23.3 & 0.9 & $\mathrm{u}$ & 24.0 \\
\hline 10 & 0.71200 & 21.3 & 1.8 & $\mathrm{u}$ & 21.7 \\
\hline 11 & 0.87100 & 19.3 & 2.0 & $\mathrm{u}$ & 19.9 \\
\hline 12 & 1.08000 & 17.6 & 2.4 & $\mathrm{u}$ & 18.3 \\
\hline 13 & 1.39000 & 16.2 & 2.7 & $\mathrm{u}$ & 16.6 \\
\hline 14 & 1.75000 & 15.1 & 4.5 & $\mathrm{u}$ & 15.4 \\
\hline 15 & 2.18000 & 14.4 & 6.6 & $\mathrm{u}$ & 14.4 \\
\hline 16 & 2.78000 & 13.6 & 9.2 & $\mathrm{u}$ & 13.6 \\
\hline 17 & 3.52000 & 13.5 & 13.9 & $\mathrm{u}$ & 12.9 \\
\hline 18 & 4.39000 & 12.9 & 32.0 & $\mathrm{u}$ & 12.5 \\
\hline 19 & 5.56000 & 14.4 & 40.6 & d & - \\
\hline 20 & 7.04000 & 14.4 & 88.5 & $d$ & - \\
\hline
\end{tabular}


Sounding: GSL15

Client: USGS/NPS

Location: Great Sand Dunes National Park

Project: San Luis Valley Blue Clay

County: Saguache [Colorado]

TX loop size: $X[\mathrm{~m}] \quad 38.1 \quad \mathrm{Y}[\mathrm{m}] \quad 38.1$

$\begin{array}{cccc}\text { Model } & \text { Resistivity } & \text { Thickness } & \text { Elevation } \\ \text { Layer } & \text { [ohm-m] } & {[\mathrm{m}]} & {[\mathrm{m}]} \\ 1 & 132.20 & 3.5 & 2296.7 \\ 2 & 38.42 & 4.7 & 2293.1 \\ 3 & 28.83 & 59.7 & 2288.4 \\ 4 & 12.48 & 19.9 & 2228.7 \\ 5 & 7.47 & -- & 2208.8\end{array}$

System: EM-47 Freq[Hz]: 315 Data Set Code: uh TX $\operatorname{Cur}[\mathrm{A}]: 2.5$ Turn Off[usec] : 2.5 RX Moment[turns-m^2]: $\quad 31.4 \quad$ Gain Setting: 1

\begin{tabular}{|c|c|c|c|c|}
\hline $\begin{array}{l}\text { Time } \\
{[\mathrm{ms}]}\end{array}$ & $\begin{array}{l}\text { rhoa_obs } \\
\text { [ohm-m] }\end{array}$ & $\begin{array}{c}\text { obs_err } \\
{\left[\frac{\mathrm{o}}{\mathrm{o}}\right]}\end{array}$ & mask & $\begin{array}{l}\text { rhoa_cal } \\
\text { [ohm-m] }\end{array}$ \\
\hline 0.00680 & 52.6 & 0.2 & $\mathrm{u}$ & 51.4 \\
\hline 0.00890 & 48.1 & 0.1 & $\mathrm{u}$ & 46.4 \\
\hline 0.01200 & 42.7 & 0.2 & $\mathrm{u}$ & 43.2 \\
\hline 0.01570 & 39.3 & 0.2 & $\mathrm{u}$ & 41.0 \\
\hline 0.02000 & 38.0 & 0.2 & $\mathrm{u}$ & 39.2 \\
\hline 0.02610 & 36.4 & 0.2 & $\mathrm{u}$ & 37.6 \\
\hline 0.03340 & 36.0 & 0.3 & $\mathrm{u}$ & 36.4 \\
\hline 0.04210 & 35.9 & 0.2 & $\mathrm{u}$ & 35.5 \\
\hline 0.05410 & 35.4 & 0.4 & $\mathrm{u}$ & 34.8 \\
\hline 0.06820 & 36.3 & 0.7 & $\mathrm{u}$ & 34.4 \\
\hline 0.08380 & 34.0 & 0.1 & $\mathrm{u}$ & 34.3 \\
\hline 0.10460 & 37.0 & 0.1 & $\mathrm{u}$ & 34.1 \\
\hline 0.13560 & 33.1 & 0.1 & $\mathrm{u}$ & 33.9 \\
\hline 0.17230 & 41.6 & 0.3 & $\mathrm{~m}$ & 33.5 \\
\hline 0.21490 & 42.7 & 0.7 & $\mathrm{~m}$ & 32.9 \\
\hline 0.27500 & 33.1 & 0.8 & $\mathrm{~m}$ & 31.8 \\
\hline 0.34900 & 28.3 & 0.7 & $\mathrm{~m}$ & 30.5 \\
\hline 0.43600 & 37.5 & 2.1 & $\mathrm{~m}$ & 29.3 \\
\hline 0.55500 & 29.2 & 3.2 & $\mathrm{~m}$ & 28.1 \\
\hline 0.70100 & 30.9 & 4.5 & $\mathrm{~d}$ & - \\
\hline
\end{tabular}

Date: $12-J U N-06$

UTM Coord: E[m] $425480.0 \mathrm{~N}[\mathrm{~m}] \quad 4183103.0$

Elevation $[\mathrm{m}]$ : 2296.7

$\mathrm{RX}$ location: $\mathrm{X}[\mathrm{m}] \quad 0.0 \quad \mathrm{Y}[\mathrm{m}] \quad 0.0$

Fit Error $[\%]: \quad 5.326$

System: EM-47 Freq[Hz]: 30 Data Set Code: hi TX Cur[A]: 2.5 Turn Off[usec]: 2.5

RX Moment[turns-m^2]: 31.4 Gain Setting: 7

$\begin{array}{ccccc}\begin{array}{c}\text { Time } \\ \text { [ms] }\end{array} & \begin{array}{c}\text { rhoa_obs } \\ \text { [ohm-m] }\end{array} & \begin{array}{c}\text { obs_err } \\ \text { [\%] }\end{array} & \text { mask } & \begin{array}{c}\text { rhoa_cal } \\ \text { [ohm-m] }\end{array} \\ 0.10000 & 33.0 & 0.4 & \mathrm{u} & 33.9 \\ 0.12100 & 33.1 & 0.4 & \mathrm{u} & 33.6 \\ 0.15100 & 31.5 & 0.4 & \mathrm{u} & 33.1 \\ 0.18800 & 40.9 & 0.6 & \mathrm{~m} & 32.4 \\ 0.23100 & 40.7 & 0.6 & \mathrm{~m} & 31.3 \\ 0.29100 & 29.1 & 0.5 & \mathrm{~m} & 29.6 \\ 0.36500 & 25.4 & 0.7 & \mathrm{~m} & 27.8 \\ 0.45200 & 30.8 & 1.2 & \mathrm{~m} & 25.8 \\ 0.57000 & 23.1 & 1.2 & \mathrm{u} & 23.8 \\ 0.71200 & 23.6 & 1.9 & \mathrm{u} & 21.9 \\ 0.87100 & 20.0 & 2.1 & \mathrm{u} & 20.3 \\ 1.08000 & 18.5 & 2.2 & \mathrm{u} & 18.8 \\ 1.39000 & 17.0 & 3.5 & \mathrm{u} & 17.3 \\ 1.75000 & 15.9 & 6.6 & \mathrm{u} & 16.1 \\ 2.18000 & 14.8 & 5.7 & \mathrm{u} & 15.2 \\ 2.78000 & 14.8 & 13.4 & \mathrm{u} & 14.3 \\ 3.52000 & 14.7 & 27.4 & \mathrm{~m} & 13.7 \\ 4.39000 & 15.1 & 35.0 & \mathrm{~m} & 13.2 \\ 5.56000 & 22.7 & 100.0 & \mathrm{~d} & - \\ 7.04000 & 30.9 & 100.0 & \mathrm{~d} & -\end{array}$


Sounding: GSL16

Client: USGS/NPS

Location: Great Sand Dunes National Park

Project: San Luis Valley Blue Clay

County: Colorado

\begin{tabular}{|c|c|c|c|}
\hline loop & size: $X[\mathrm{~m}]$ & $\mathrm{Y}[\mathrm{m}]$ & 8.1 \\
\hline Model & Resistivity & Thickness & Elevatior \\
\hline ayer & [ohm-m ] & [m ] & {$[\mathrm{m}]$} \\
\hline 1 & 477.60 & 9.3 & 2325.6 \\
\hline 2 & 91.65 & 62.1 & 2316.2 \\
\hline 3 & 6.87 & -- & 2254.1 \\
\hline
\end{tabular}

System: EM-47 Freq[Hz]: 315 Data Set Code: uh TX Cur[A]: 2.5 Turn Off[usec]: 2.5

RX Moment[turns-m^2]: 31.4 Gain Setting: 3

$\begin{array}{rrrrrr}\text { Time } & \begin{array}{c}\text { rhoa_obs } \\ \text { [ohm-m] }\end{array} & \begin{array}{c}\text { obs_err } \\ \text { [o] }\end{array} & \text { mask } & \begin{array}{r}\text { rhoa_cal } \\ \text { [ohm-m] }\end{array} \\ 1 & 0.00680 & 125.7 & 0.3 & \mathrm{~m} & 139.3 \\ 2 & 0.00890 & 129.2 & 0.3 & \mathrm{u} & 130.5 \\ 3 & 0.01200 & 127.6 & 0.3 & \mathrm{u} & 127.0 \\ 4 & 0.01570 & 127.6 & 0.2 & \mathrm{u} & 125.6 \\ 5 & 0.02000 & 132.2 & 0.5 & \mathrm{u} & 126.2 \\ 6 & 0.02610 & 136.2 & 0.4 & \mathrm{u} & 128.8 \\ 7 & 0.03340 & 134.7 & 0.7 & \mathrm{u} & 131.5 \\ 8 & 0.04210 & 134.7 & 1.8 & \mathrm{u} & 131.9 \\ 9 & 0.05410 & 118.9 & 2.0 & \mathrm{u} & 127.4 \\ 10 & 0.06820 & 104.1 & 2.9 & \mathrm{u} & 117.9 \\ 11 & 0.08380 & 104.9 & 5.8 & \mathrm{u} & 106.5 \\ 12 & 0.10460 & 88.0 & 3.9 & \mathrm{u} & 93.2 \\ 13 & 0.13560 & 81.4 & 5.5 & \mathrm{u} & 78.5 \\ 14 & 0.17230 & 72.9 & 6.5 & \mathrm{u} & 66.9 \\ 15 & 0.21490 & 52.4 & 18.7 & \mathrm{u} & 58.0 \\ 16 & 0.27500 & 54.3 & 31.9 & \mathrm{u} & 49.9 \\ 17 & 0.34900 & 45.1 & 44.8 & \mathrm{u} & 43.8 \\ 18 & 0.43600 & 38.2 & 55.5 & \mathrm{u} & 39.2 \\ 19 & 0.55500 & 51.9 & 100.0 & \mathrm{u} & 35.4 \\ 20 & 0.70100 & 28.7 & 55.2 & \mathrm{u} & 32.7\end{array}$

Date: $12-J U N-06$

UTM Coord: E[m] $444083.0 \mathrm{~N}[\mathrm{~m}] \quad 4176509.0$

Elevation $[\mathrm{m}]$ : 2325.6

$\begin{array}{llll}\mathrm{RX} \text { location: } \mathrm{X}[\mathrm{m}] & 0.0 & \mathrm{Y}[\mathrm{m}] & 0.0\end{array}$

Fit Error [\%]: 15.385

System: EM-47 Freq[Hz]: 30 Data Set Code: hi TX $\operatorname{Cur}[\mathrm{A}]: \quad 2.5$ Turn Off[usec] : 2.5

RX Moment[turns-m^2]: 31.4 Gain Setting: 7

$\begin{array}{ccccc}\begin{array}{c}\text { Time } \\ \text { [ms ] }\end{array} & \begin{array}{c}\text { rhoa_obs } \\ \text { [ohm-m] }\end{array} & \begin{array}{c}\text { obs_err } \\ \text { [\%] }\end{array} & \text { mask } & \begin{array}{c}\text { rhoa_cal } \\ \text { [ohm-m] }\end{array} \\ 0.10000 & 84.3 & 2.2 & \mathrm{u} & 93.3 \\ 0.12100 & 79.0 & 2.5 & \mathrm{u} & 81.7 \\ 0.15100 & 69.6 & 3.8 & \mathrm{u} & 69.7 \\ 0.18800 & 60.1 & 5.9 & \mathrm{u} & 59.5 \\ 0.23100 & 50.0 & 6.5 & \mathrm{u} & 51.4 \\ 0.29100 & 44.1 & 9.6 & \mathrm{u} & 43.8 \\ 0.36500 & 39.8 & 12.1 & \mathrm{u} & 37.7 \\ 0.45200 & 32.9 & 12.0 & \mathrm{u} & 33.0 \\ 0.57000 & 30.3 & 20.8 & \mathrm{u} & 28.8 \\ 0.71200 & 23.1 & 24.2 & \mathrm{u} & 25.5 \\ 0.87100 & 23.0 & 32.7 & \mathrm{u} & 23.0 \\ 1.08000 & 22.3 & 49.0 & \mathrm{u} & 20.7 \\ 1.39000 & 17.9 & 32.7 & \mathrm{u} & 18.6 \\ 1.75000 & 18.3 & 46.0 & \mathrm{u} & 17.0 \\ 2.18000 & 12.6 & 69.9 & \mathrm{u} & 15.8 \\ 2.78000 & 13.3 & 93.4 & \mathrm{u} & 14.7 \\ 3.52000 & 15.1 & 100.0 & \mathrm{u} & 13.9 \\ 4.39000 & 28.9 & 100.0 & \mathrm{~d} & - \\ 5.56000 & 13.7 & 100.0 & \mathrm{~m} & 12.9 \\ 7.04000 & 52.0 & 100.0 & \mathrm{~d} & -\end{array}$


Sounding: GSL17

Client: USGS/NPS

Location: Great Sand Dunes National Park

Project: San Luis Valley Blue Clay

County: Saguache [Colorado]

TX loop size: $X[\mathrm{~m}] \quad 38.1 \quad \mathrm{Y}[\mathrm{m}] \quad 38.1$

$\begin{array}{cccc}\text { Model } & \text { Resistivity } & \text { Thickness } & \text { Elevation } \\ \text { Layer } & \text { [ohm-m] } & {[\mathrm{m}]} & {[\mathrm{m}]} \\ 1 & 421.80 & 7.2 & 2337.8 \\ 2 & 141.30 & 77.1 & 2330.5 \\ 3 & 10.62 & -- & 2253.4\end{array}$

System: EM-47 Freq[Hz]: 315 Data Set Code: uh TX Cur[A]: 2.5 Turn Off[usec]: 2.5

RX Moment[turns-m^2]: 31.4 Gain Setting: 3

$\begin{array}{ccccr}\begin{array}{c}\text { Time } \\ \text { [ms] }\end{array} & \begin{array}{r}\text { rhoa_obs } \\ \text { [ohm-m] }\end{array} & \begin{array}{c}\text { obs_err } \\ \text { [\%] }\end{array} & \text { mask } & \begin{array}{r}\text { rhoa_cal } \\ \text { [ohm-m] }\end{array} \\ 0.00680 & 160.8 & 0.1 & \mathrm{u} & 165.7 \\ 0.00890 & 171.0 & 0.1 & \mathrm{u} & 160.9 \\ 0.01200 & 164.8 & 0.2 & \mathrm{u} & 161.7 \\ 0.01570 & 154.0 & 0.2 & \mathrm{u} & 163.9 \\ 0.02000 & 170.0 & 0.3 & \mathrm{u} & 167.9 \\ 0.02610 & 160.6 & 0.6 & \mathrm{u} & 174.2 \\ 0.03340 & 181.3 & 1.1 & \mathrm{u} & 179.9 \\ 0.04210 & 215.8 & 1.9 & \mathrm{u} & 181.6 \\ 0.05410 & 142.6 & 2.1 & \mathrm{u} & 176.1 \\ 0.06820 & 146.9 & 4.5 & \mathrm{u} & 163.3 \\ 0.08380 & 206.5 & 18.9 & \mathrm{u} & 147.8 \\ 0.10460 & 120.8 & 13.1 & \mathrm{u} & 129.7 \\ 0.13560 & 127.5 & 14.8 & \mathrm{u} & 109.7 \\ 0.17230 & 99.5 & 27.2 & \mathrm{u} & 93.9 \\ 0.21490 & 73.5 & 8.6 & \mathrm{u} & 81.7 \\ 0.27500 & 83.1 & 41.3 & \mathrm{u} & 70.7 \\ 0.34900 & 58.2 & 24.3 & \mathrm{u} & 62.3 \\ 0.43600 & 55.0 & 29.7 & \mathrm{u} & 56.0 \\ 0.55500 & 44.3 & 31.0 & \mathrm{u} & 50.9 \\ 0.70100 & 32.9 & 79.1 & \mathrm{u} & 47.2\end{array}$

Date: $12-\mathrm{JUN}-06$

UTM Coord: $\mathrm{E}[\mathrm{m}] \quad 444403.0 \mathrm{~N}[\mathrm{~m}] \quad 4180568.0$

Elevation $[\mathrm{m}]: 2337.8$

RX location: X[m] $0.0 \quad \mathrm{Y}[\mathrm{m}] \quad 0.0$

Fit Error $[\%]: 21.706$

System: EM-47 Freq[Hz]: 30 Data Set Code: hi TX Cur[A]: 2.5 Turn Off[usec]: 2.5

RX Moment[turns-m^2]: 31.4 Gain Setting: 7

$\begin{array}{ccccc}\begin{array}{c}\text { Time } \\ \text { [ms ] }\end{array} & \begin{array}{r}\text { rhoa_obs } \\ \text { [ohm-m] }\end{array} & \begin{array}{r}\text { obs_err } \\ \text { [\%] }\end{array} & \text { mask } & \begin{array}{r}\text { rhoa_cal } \\ \text { [ohm-m] }\end{array} \\ 0.10000 & 133.3 & 3.6 & \mathrm{u} & 130.0 \\ 0.12100 & 103.1 & 3.6 & \mathrm{u} & 114.2 \\ 0.15100 & 110.2 & 10.4 & \mathrm{u} & 97.9 \\ 0.18800 & 93.6 & 11.1 & \mathrm{u} & 83.9 \\ 0.23100 & 67.5 & 9.4 & \mathrm{u} & 72.8 \\ 0.29100 & 59.4 & 14.0 & \mathrm{u} & 62.4 \\ 0.36500 & 54.0 & 18.3 & \mathrm{u} & 54.0 \\ 0.45200 & 45.9 & 21.9 & \mathrm{u} & 47.5 \\ 0.57000 & 38.4 & 18.8 & \mathrm{u} & 41.6 \\ 0.71200 & 38.8 & 29.2 & \mathrm{u} & 37.0 \\ 0.87100 & 33.3 & 40.7 & \mathrm{u} & 33.5 \\ 1.08000 & 32.2 & 48.5 & \mathrm{u} & 30.4 \\ 1.39000 & 25.9 & 59.0 & \mathrm{u} & 27.4 \\ 1.75000 & 26.4 & 100.0 & \mathrm{u} & 25.1 \\ 2.18000 & 33.0 & 100.0 & \mathrm{u} & 23.4 \\ 2.78000 & 19.4 & 100.0 & \mathrm{u} & 21.8 \\ 3.52000 & 21.9 & 100.0 & \mathrm{u} & 20.7 \\ 4.39000 & 37.7 & 100.0 & \mathrm{~d} & - \\ 5.56000 & 12.8 & 100.0 & \mathrm{~d} & - \\ 7.04000 & 18.5 & 100.0 & \mathrm{~d} & -\end{array}$




\section{Appendix E. TEM Sounding Plots and Descriptions}

Plots of the measured apparent resistivity, calculated apparent resistivity for the inversion model, and the inversion estimated resistivity-depth function are given below along with a description of the results.

The number of transients used in the data averages was nominally set at seven for the first five soundings (GSD01 through GSD05), while for the remaining 12 soundings 21 transients were averaged. For this second group of soundings the sounding name was changed from GSDnn to GSLnn to indicated that more data were averaged.

In most of the soundings the channel 2 data appeared to be biased upwards and were not used in the inversion, but preserved in the plots (masked). The masked data points are plotted as solid diamonds ( $)$.

\section{Sounding GSD01}

A four-layer model with decreasing resistivity in the first three layers followed by a slight increase in the fourth layer resistivity gave a voltage misfit error of 2.74 percent. The channel 2 datum was masked. Attempts to fit the data with a three-layer model resulted in misfit error of 3.84 percent.

\section{Sounding GSD02}

A four-layer model with decreasing resistivity produced a very good fit to the data (3.12 percent). Dropping the bottom layer and reinverting the data could not give as good a fit ( 6.88 percent). The channel 2 datum was masked.

\section{Sounding GSD03}

The four-layer model starts with a very high near surface resistivity that drops to a minimum in layer three, followed by an increase in fourth layer resistivity. Channel 1 was dropped from the inversion resulting in a final misfit error of 3.75 percent. Including channel 1 in the inversion increased the misfit to 4.39 percent.

\section{Sounding GSD04}

A three-layer model was chosen for the data after masking the channel 1 datum. The last two data (2.18 and $2.78 \mathrm{~ms}$ ) were also masked. If these two points were included, the model required a poorly determined high resistivity $(150 \mathrm{ohm}-\mathrm{m})$ basement, which is not geologically reasonable. Misfit error is 4.49 percent.

\section{Sounding GSD05}

Interpreted resistivity decreases from a high of $130 \mathrm{ohm}-\mathrm{m}$ at the surface to around $5 \mathrm{ohm}-\mathrm{m}$ at depth. While there is some sort of very small irregularity in the first two channels, masking either channels 1, 2, or both did not significantly alter the misfit error or the first-layer resistivity and thickness. Accordingly all early channels were retained in the inversion. Misfit error was 3.34 percent. Data at times greater than 2.18 ms were masked.

\section{Sounding GSD06 (GSL06)}

Better fits to the data were obtained by masking the channel 1 datum. The best fit (5.05 percent) was obtained with a four-layer model whose resistivity decreases with depth. The high first-layer resistivity $(650 \mathrm{ohm}-\mathrm{m})$ is poorly determined, while the other layer resistivities and thicknesses are well constrained.

\section{Sounding GSD07 (GSL07)}

The data are fit with a four-layer model that becomes less resistive with depth. Channel 1 was masked. Most model parameters are well resolved, however, the transition from the first to the third layer is ambiguous, that is, there are any number of models that fit the transition equally well. Misfit error is 4.36 percent.

\section{Sounding GSD08 (GSL08)}

A four-layer model fits the data well with resistivity decreasing with depth. Data points at times greater than $2.18 \mathrm{~ms}$ were masked. Misfit error was 3.00 percent. Aside from the transition between the second and fourth layer, the layers are fairly well resolved. 


\section{Sounding GSD09 (GSL09)}

The data are modeled with a four-layer model with decreasing resistivity with depth. Data points up to 3.52 ms were used. Misfit error was 3.82 percent. All layer are fairly well resolved.

\section{Sounding GSD10 (GSL10)}

A three-layer model does a good job of fitting the data. Resistivities decrease with depth, and aside from the depth of the transition between the second and third layer the model is well resolved. Data points at times greater than 2.18 ms were masked. The misfit error was 4.39 percent.

\section{Sounding GSD11 (GSL11)}

A three-layer model was used for these data. Resistivities decrease with depth. The thickness of the fist layer is the least well resolved parameter. The misfit error was 4.34. percent.

\section{Sounding GSD12 (GSL12)}

A three-layer model with resistivity decreasing with depth fits the data very well. All model parameters are well resolved. The data point at time $5.56 \mathrm{~ms}$ was masked. The misfit error was 4.29 percent.

\section{Sounding GSD13 (GSL13)}

A four-layer model gives the best results for this sounding. The layer resistivities decrease with depth. The transition from the first layer to the third layer is moderately well constrained. The fourth layer resistivity is only 30 percent less than that of the third layer. The misfit error was 4.39 percent. Trying to use a three-layer model increased the misfit error to 4.99 percent.

\section{Sounding GSD14 (GSL14)}

The data are modeled with a three-layer model with layer resistivity decreasing with depth. The first layer resistivity is very well determined. The transition depth between the first and second layer is the least well determined feature of the sounding. The misfit error was 4.45 percent.

\section{Sounding GSD15 (GSL15)}

A three-layer model was used to fit this noisy sounding. Layer resistivity decreases with depth. The high noise level between 0.17 and $0.56 \mathrm{~ms}$ is caused by an unidentified metal object near the site. Masking these noisy points, resistivity of the second layer is well determined. The resistivity and thickness of the first layer is not well determined. This misfit error was 5.96 percent. Without masking data in the time range indicated, the misfit error increased to 14.6 percent.

\section{Sounding GSD16 (GSL16)}

A three-layer model provides a model fit to this sounding. The data are corrupted by noise from a nearby electric fence. Layer resistivity is found to decrease with depth. The second and third layer are fairly well determined, while the near surface layer is not well resolved. The misfit error is 15.7 percent.

\section{Sounding GSD17 (GSL17)}

This sounding also exhibits noise from a nearby electric fence. The three-layer model resistivity decreases with depth. The second layer is pretty well determined. The first-layer resistivity and thickness are not well determined. The misfit error is 21.7 percent. 
GSD01

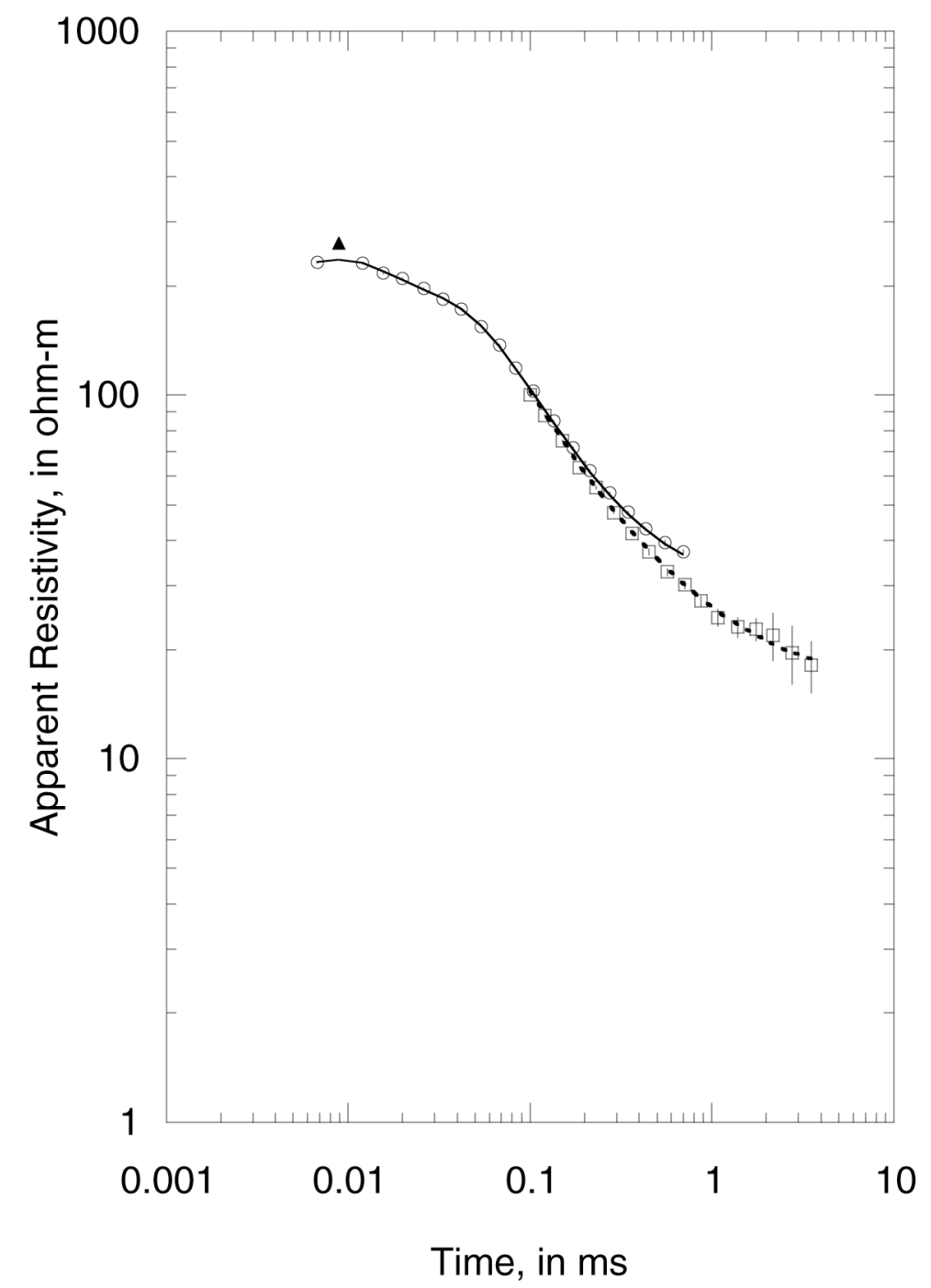

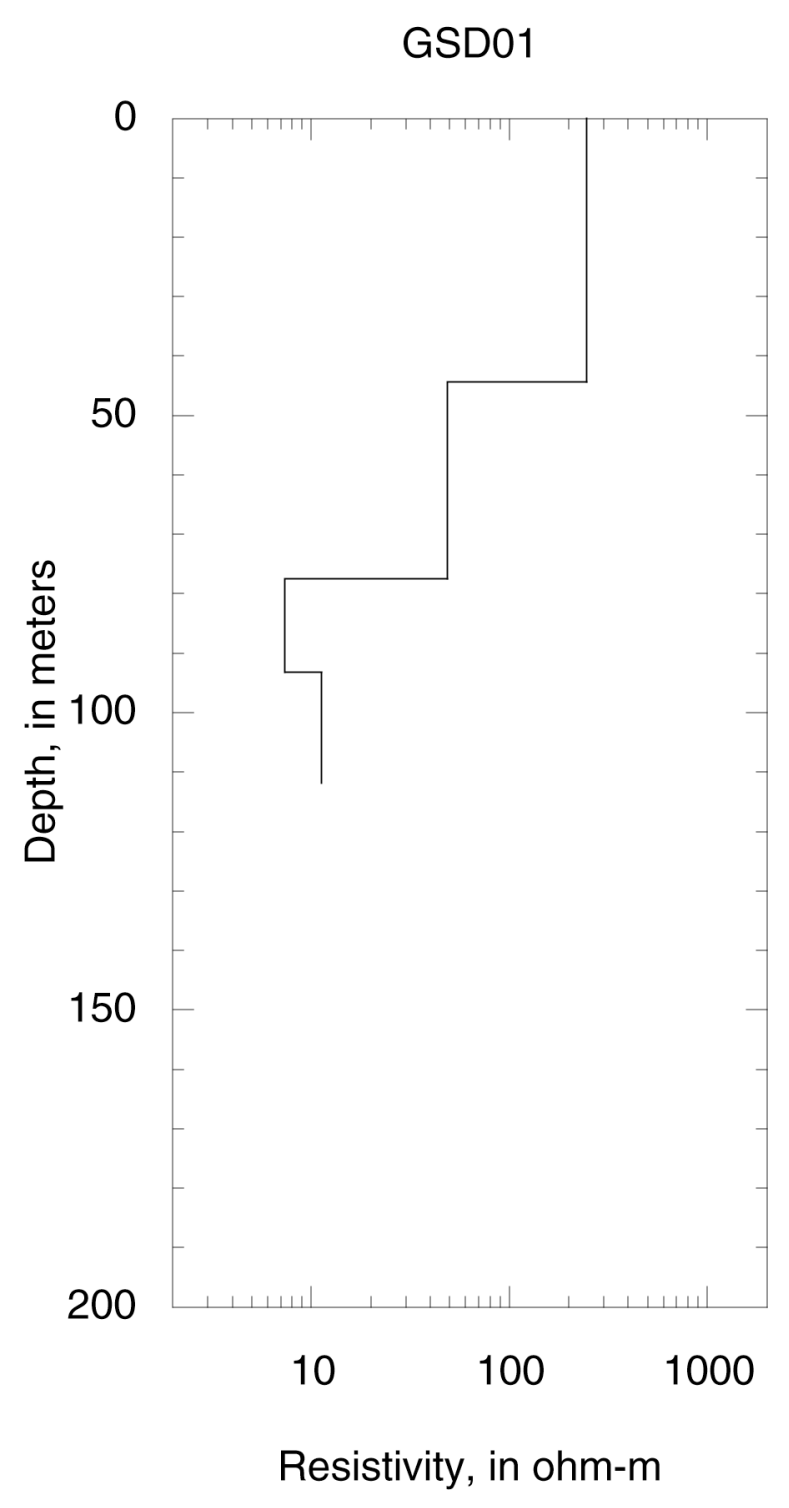

Figure E-1. Sounding GSD01 
GSD02

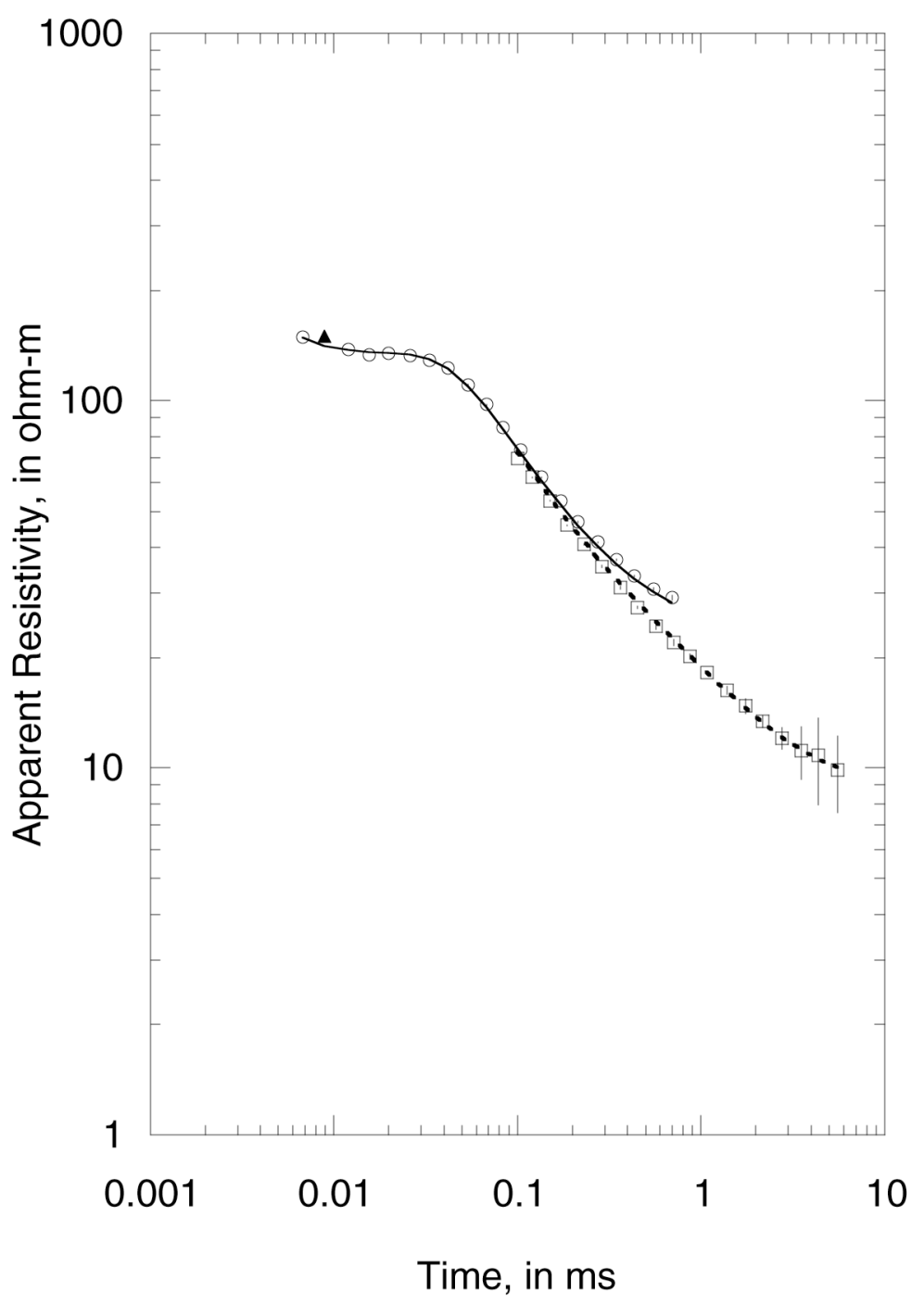

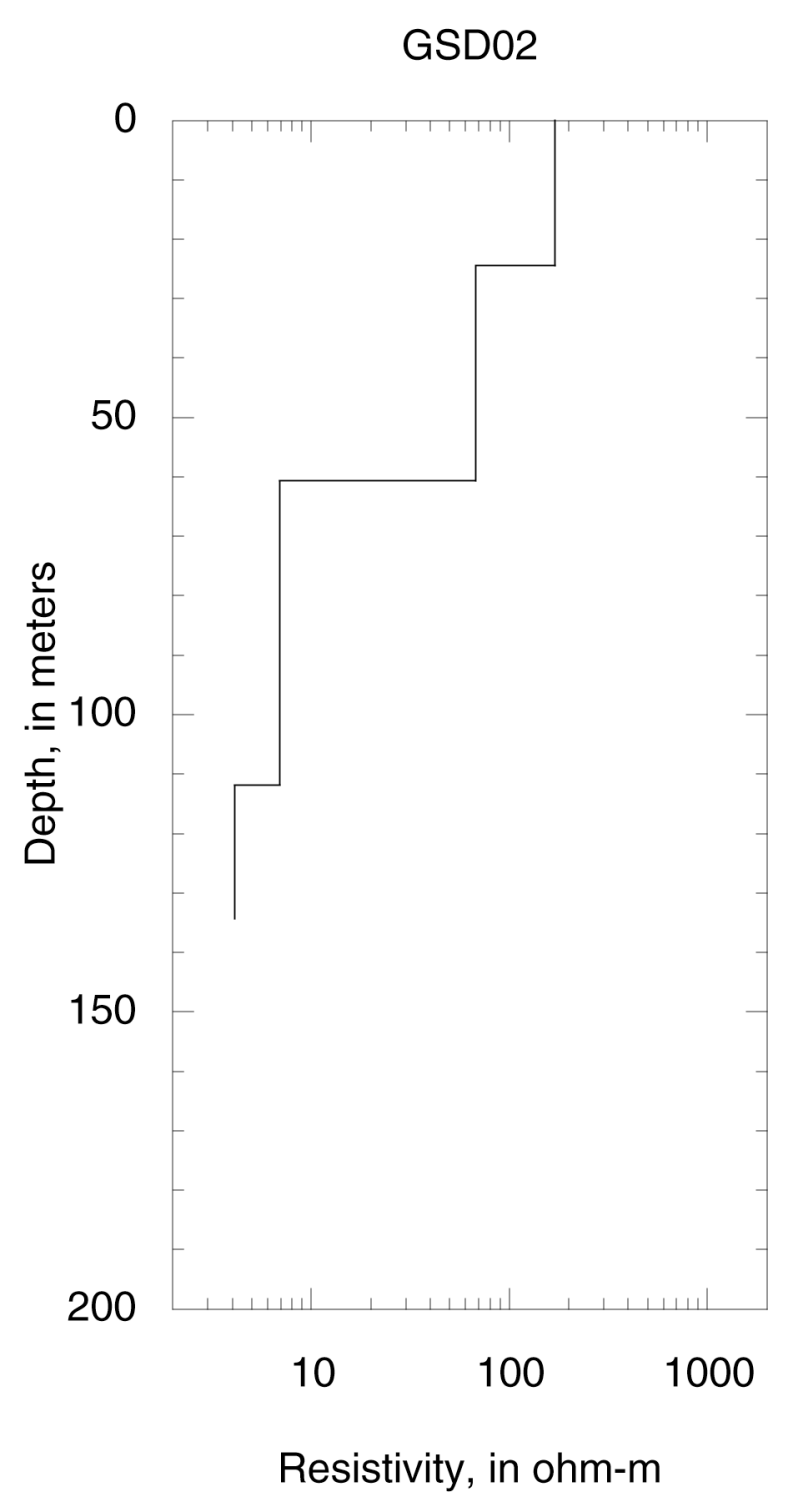

Figure E-2. Sounding GSD02 
GSD03

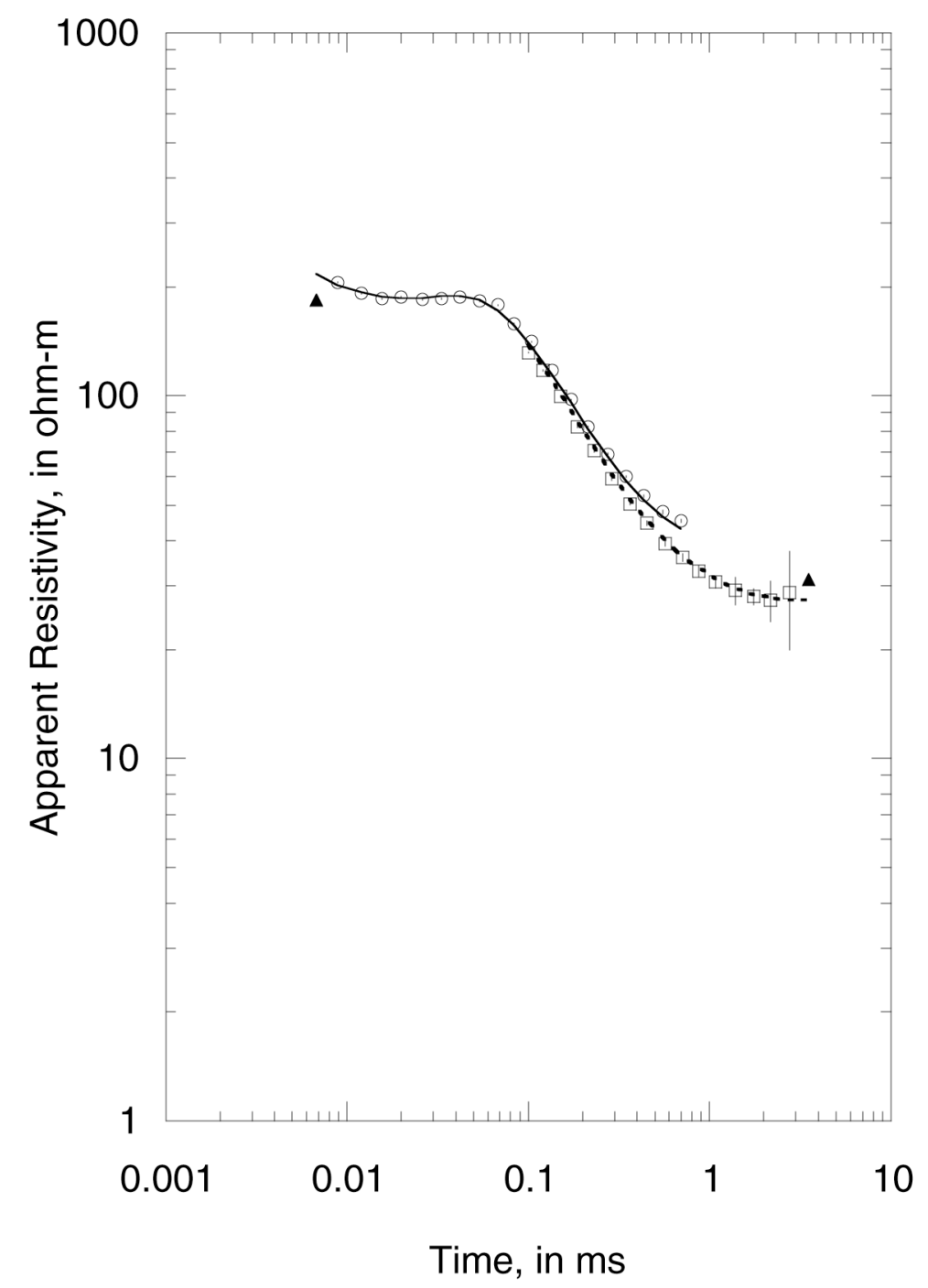

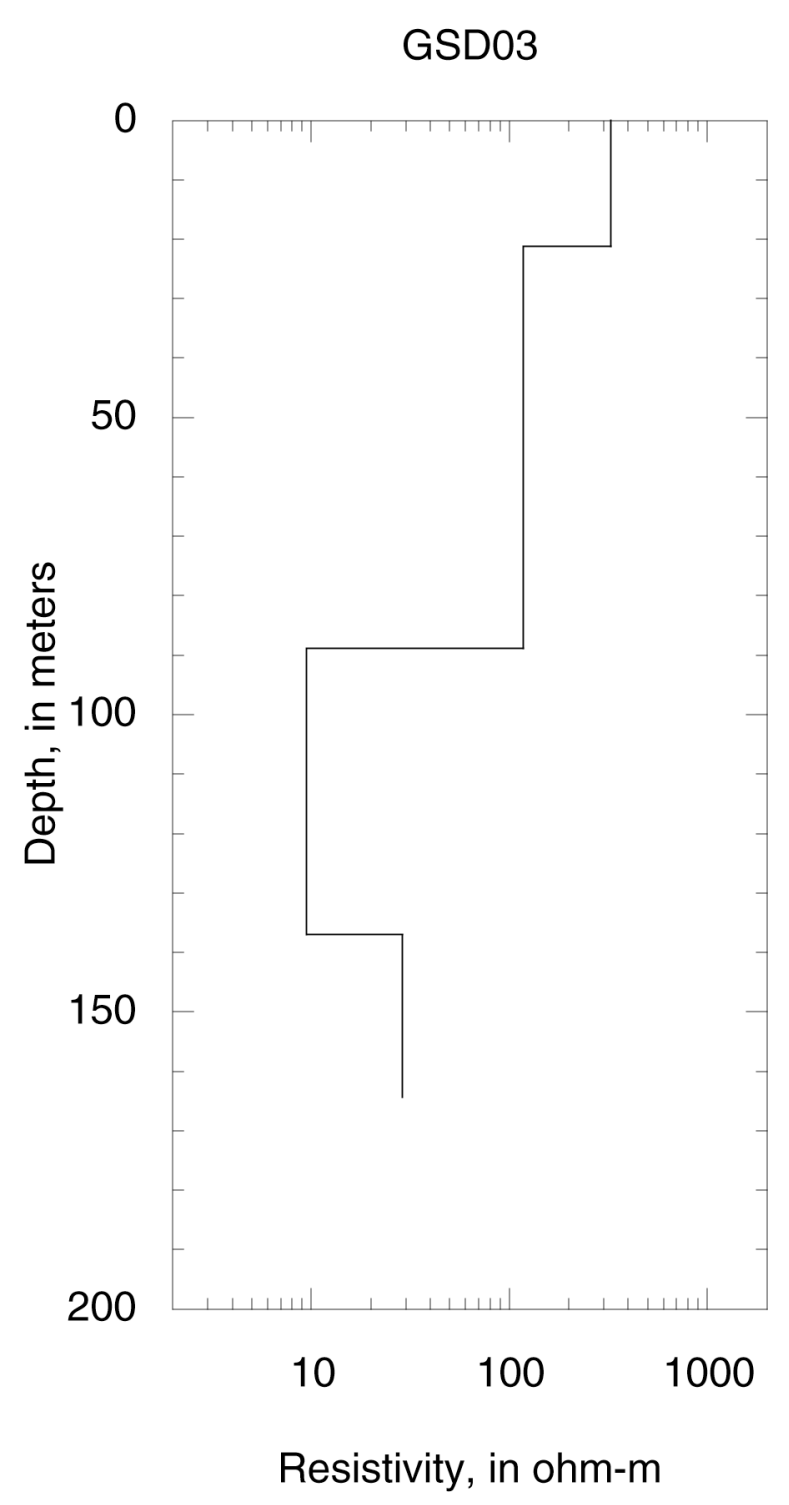

Figure E-3. Sounding GSD03 
GSD04

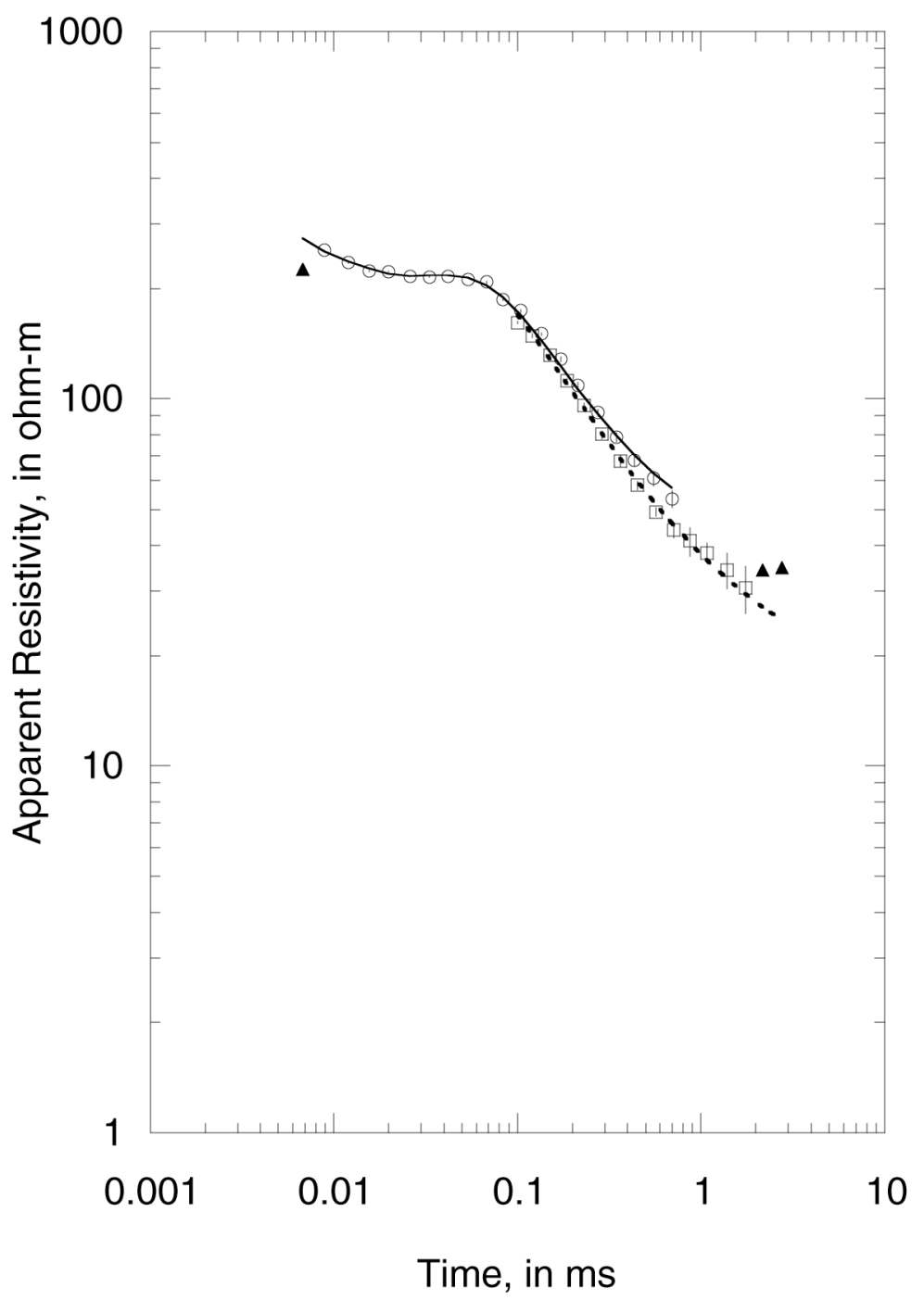

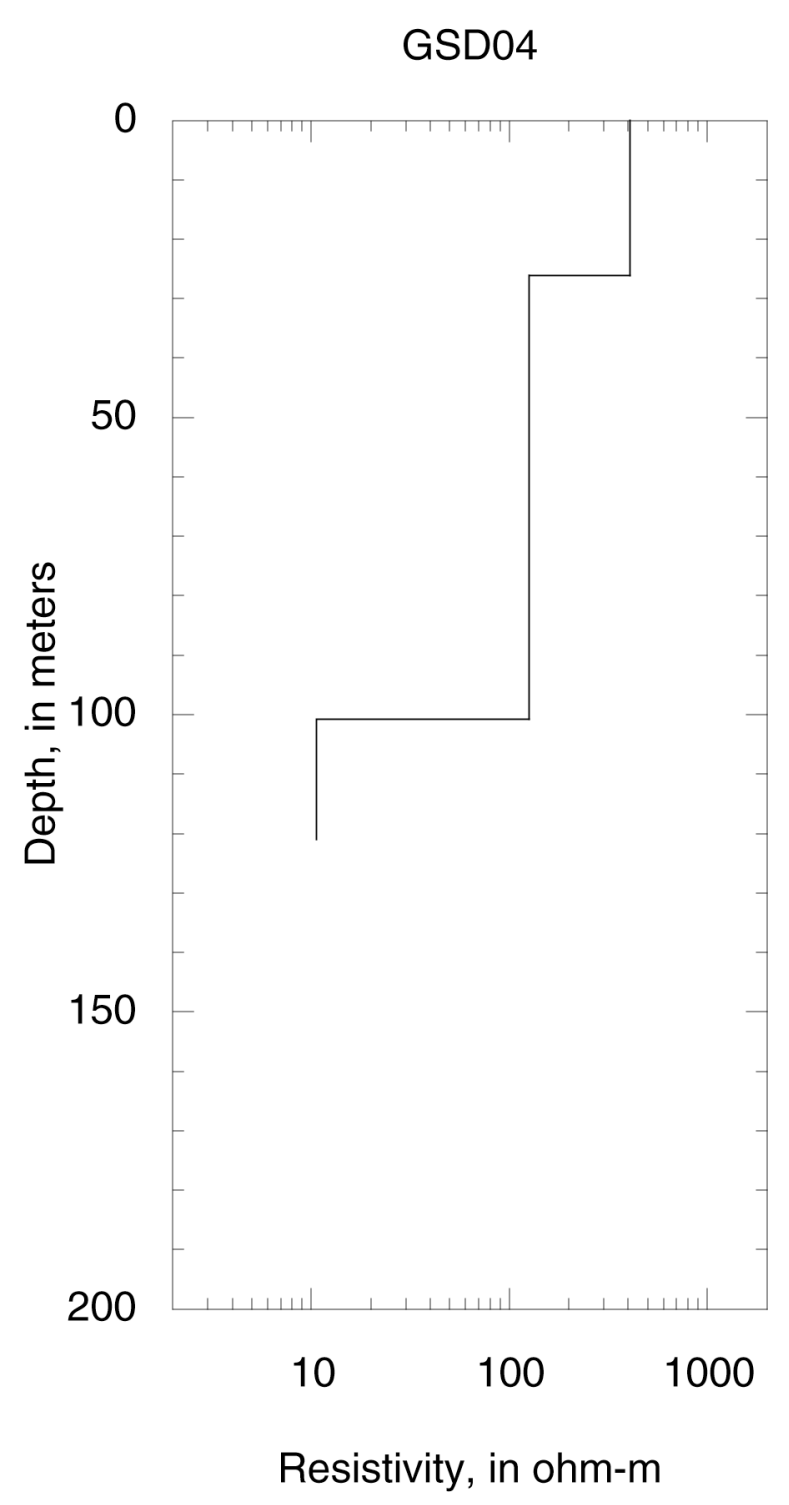

Figure E-4. Sounding GSD04 
GSD05

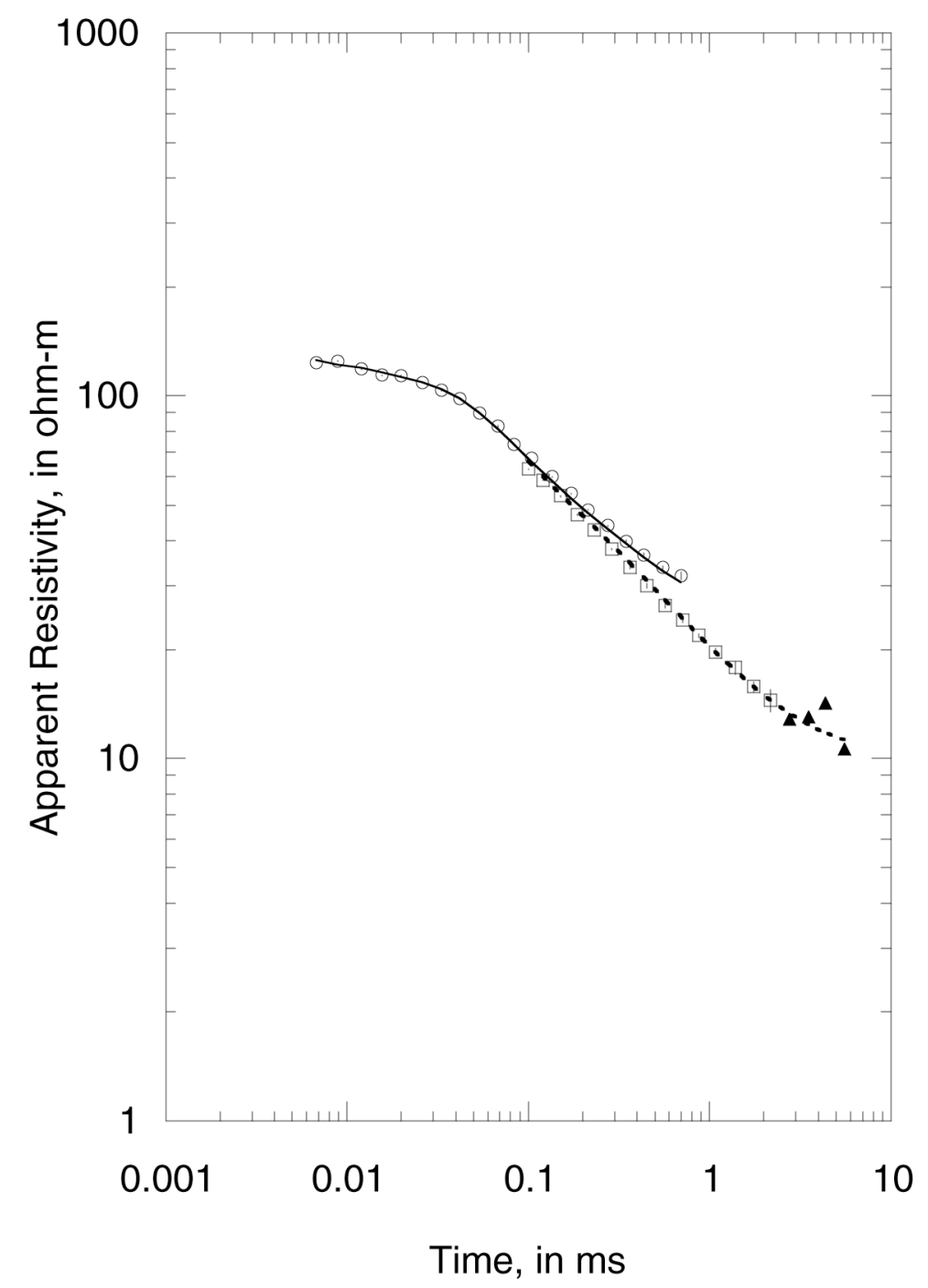

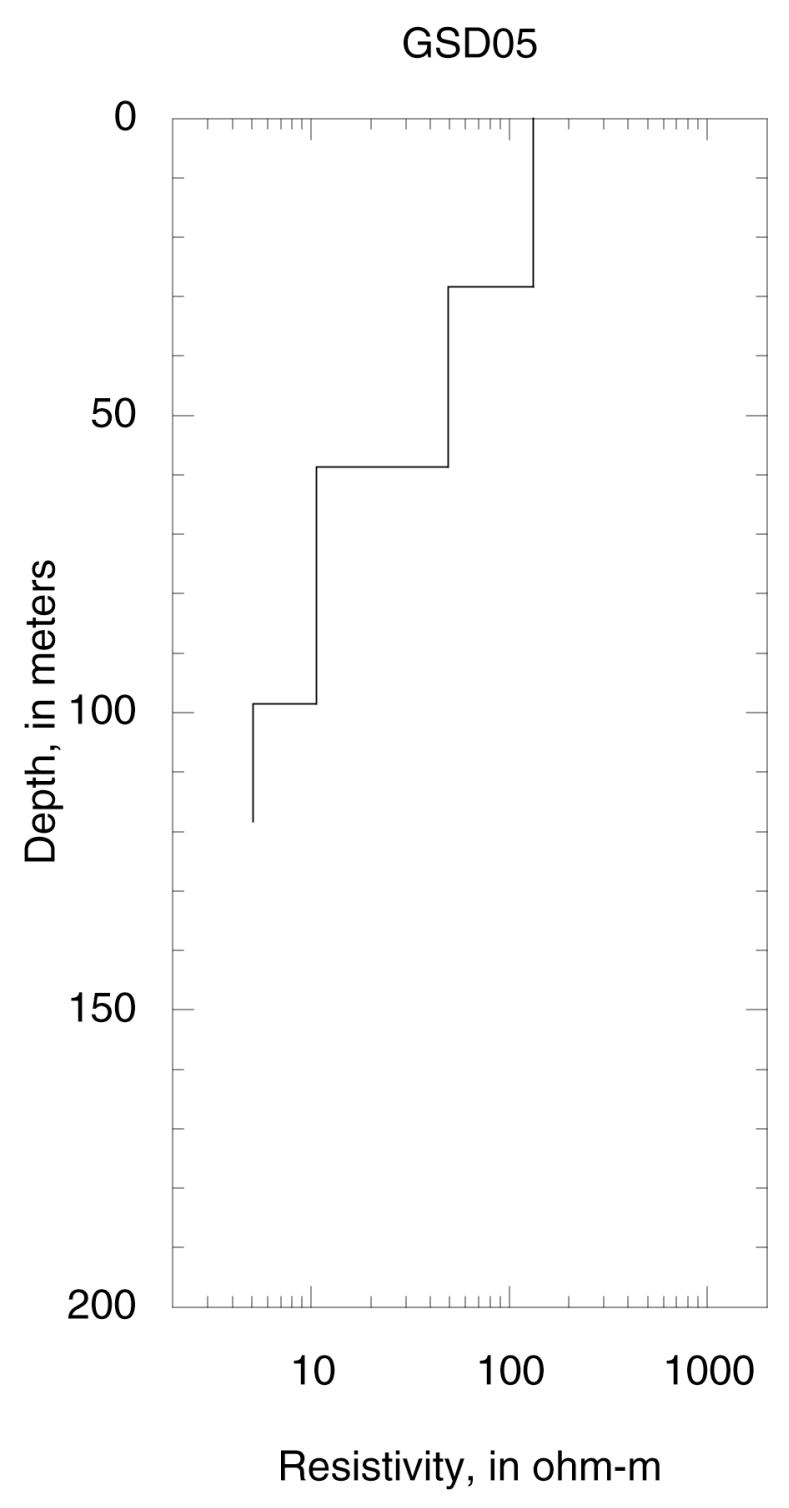

Figure E-5. Sounding GSD05 
GSL06

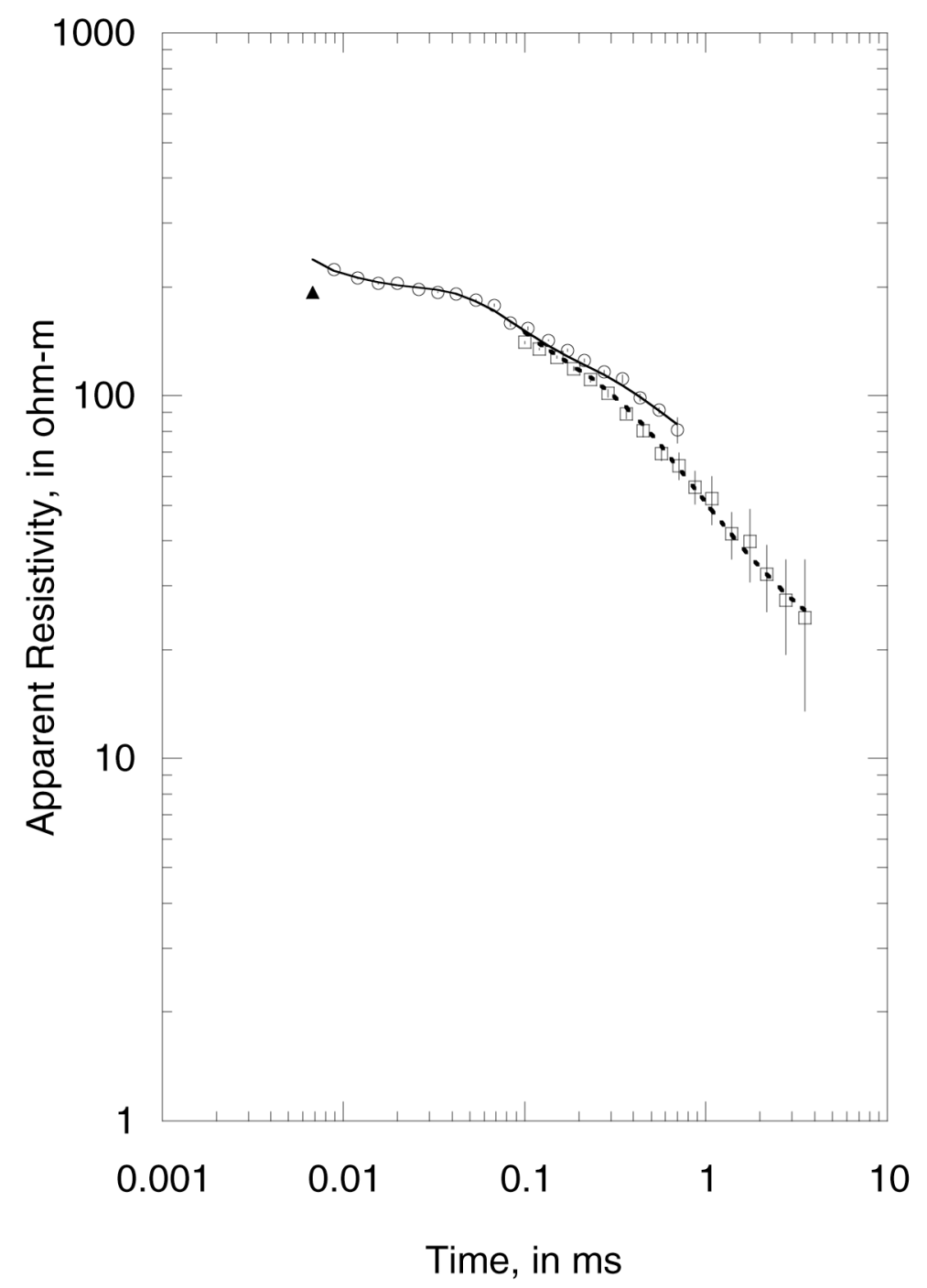

GSL06

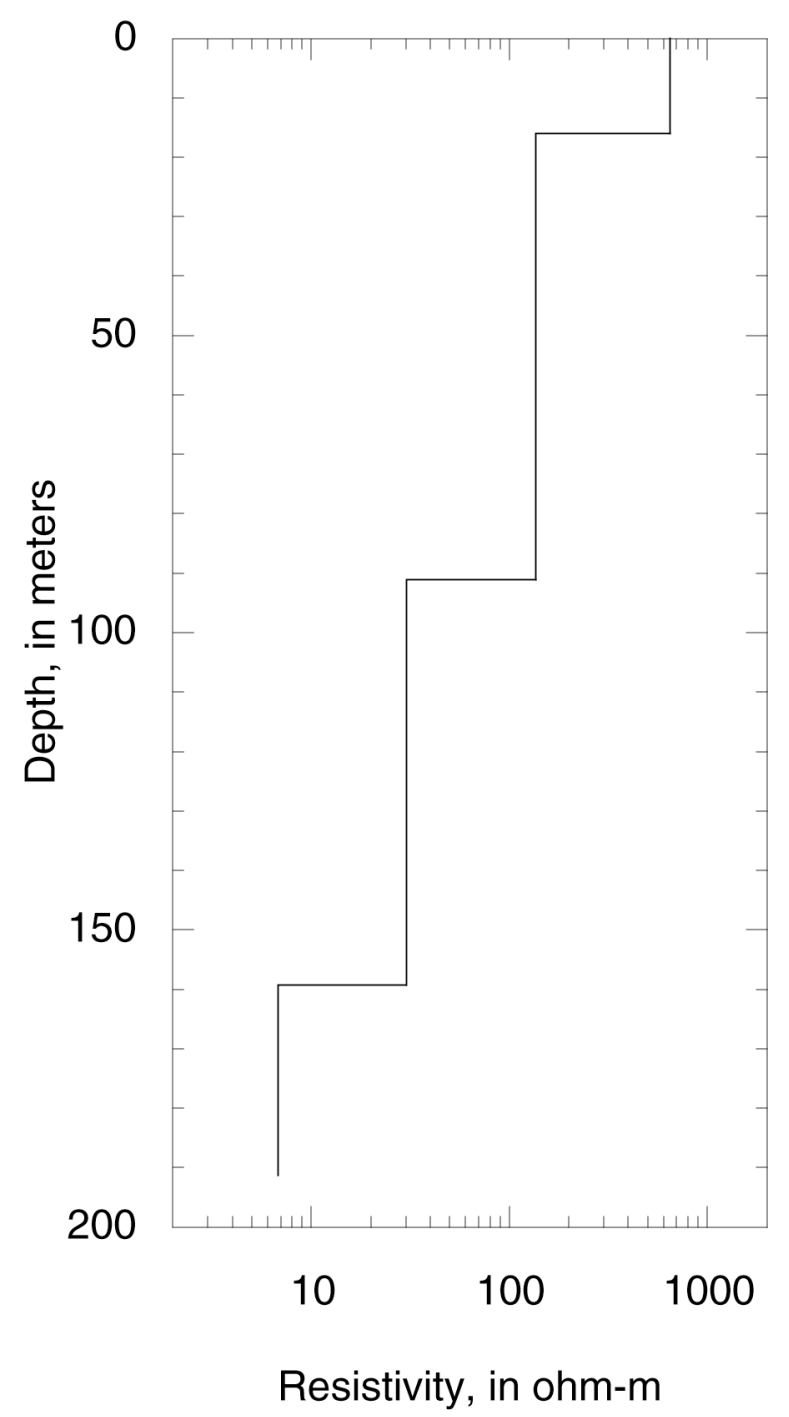

Figure E-6. Sounding GSD06 (GSL06) 


\section{GSL07}

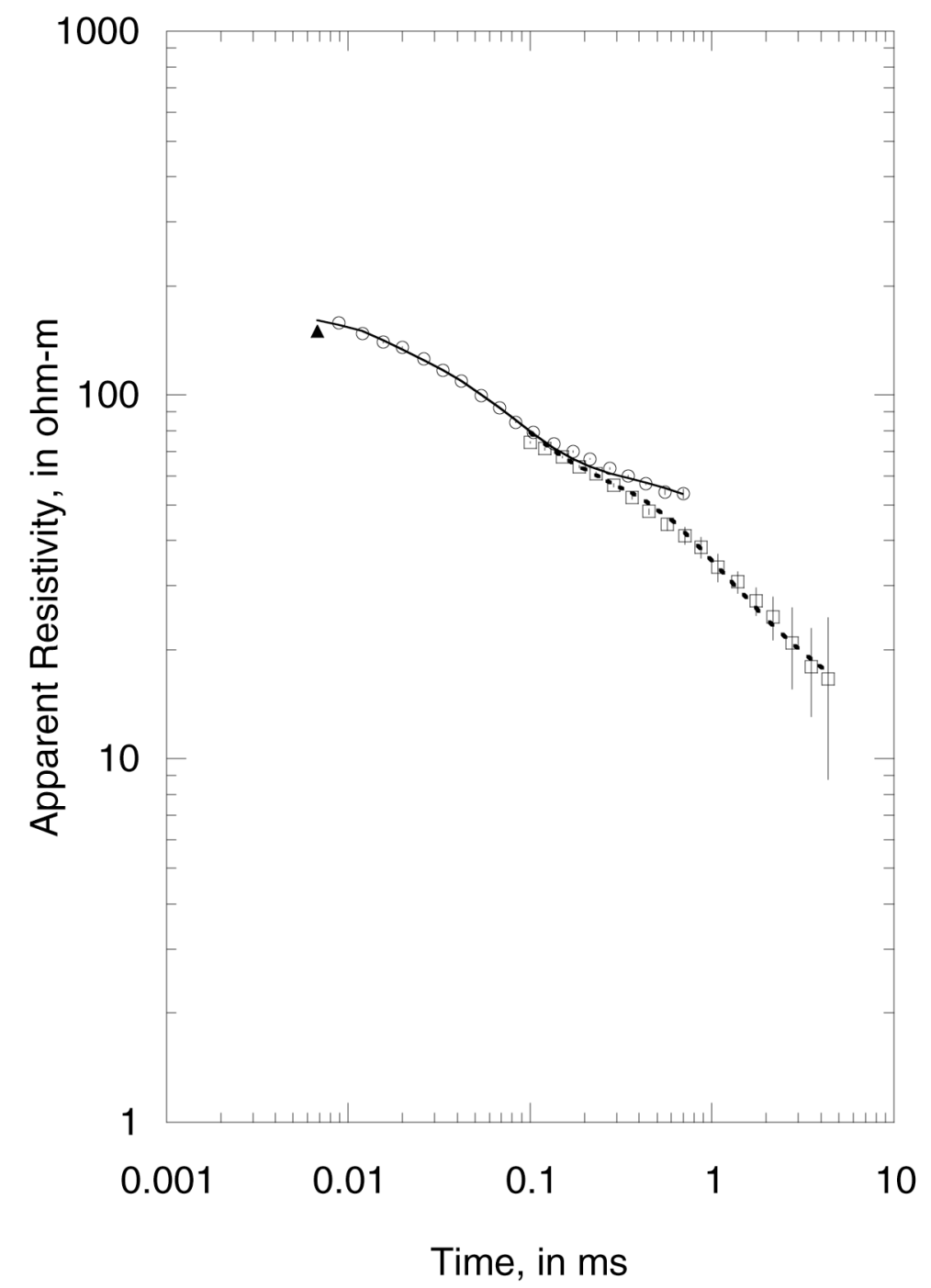

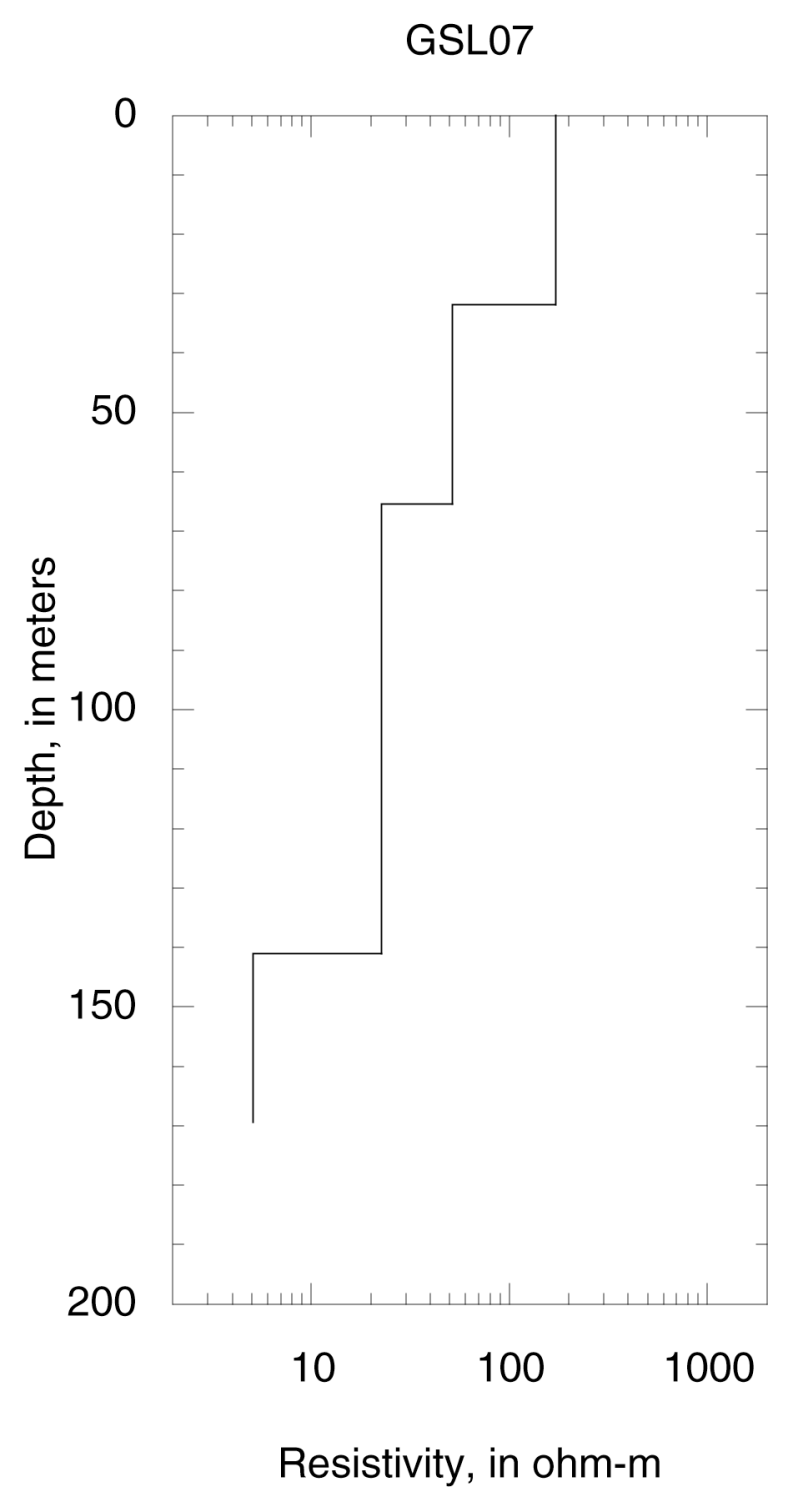

Figure E-7. Sounding GSD07 (GSL07) 


\section{GSL08}

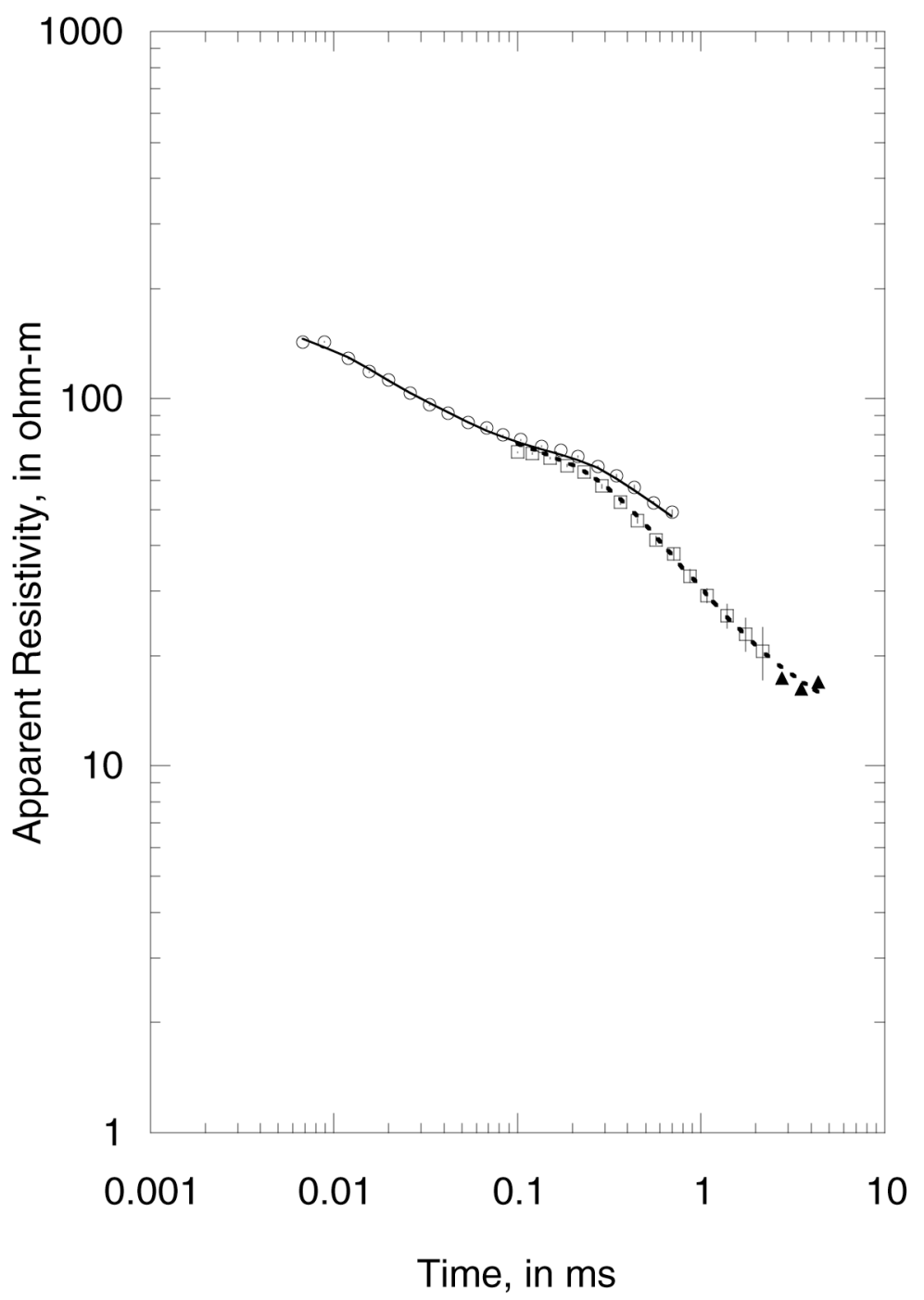

\section{GSL08}

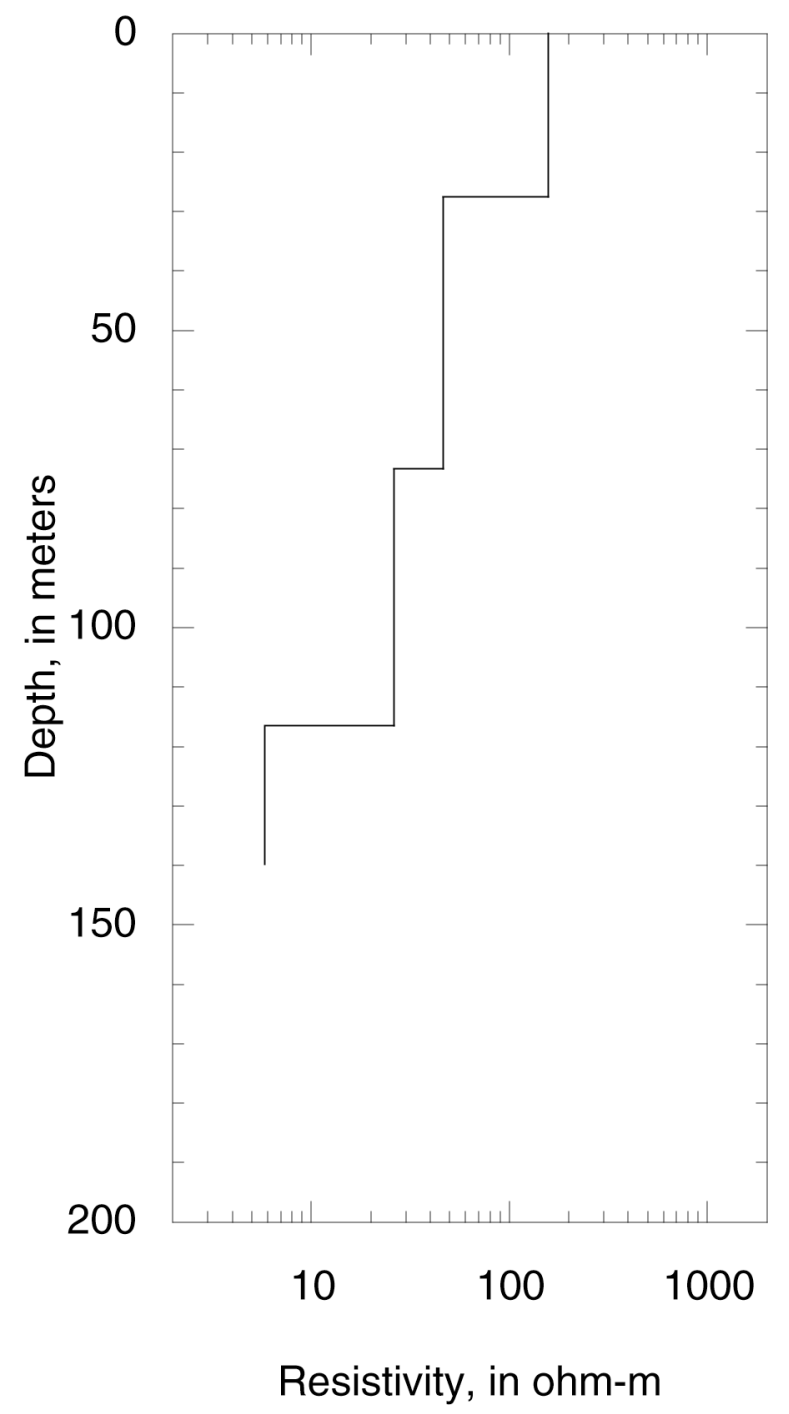

Figure E-8. Sounding GSD08 (GSL08) 


\section{GSL09}

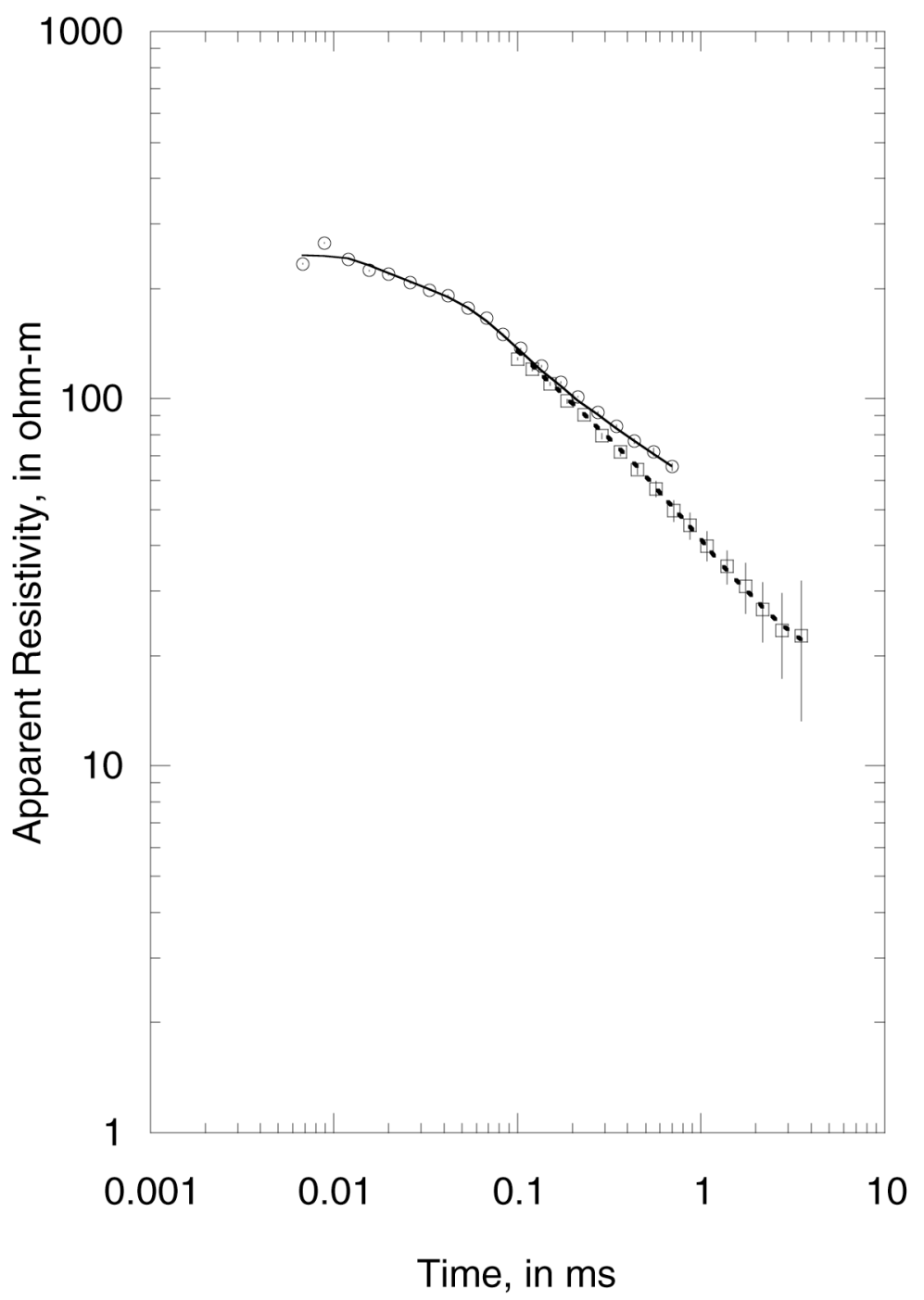

\section{GSL09}

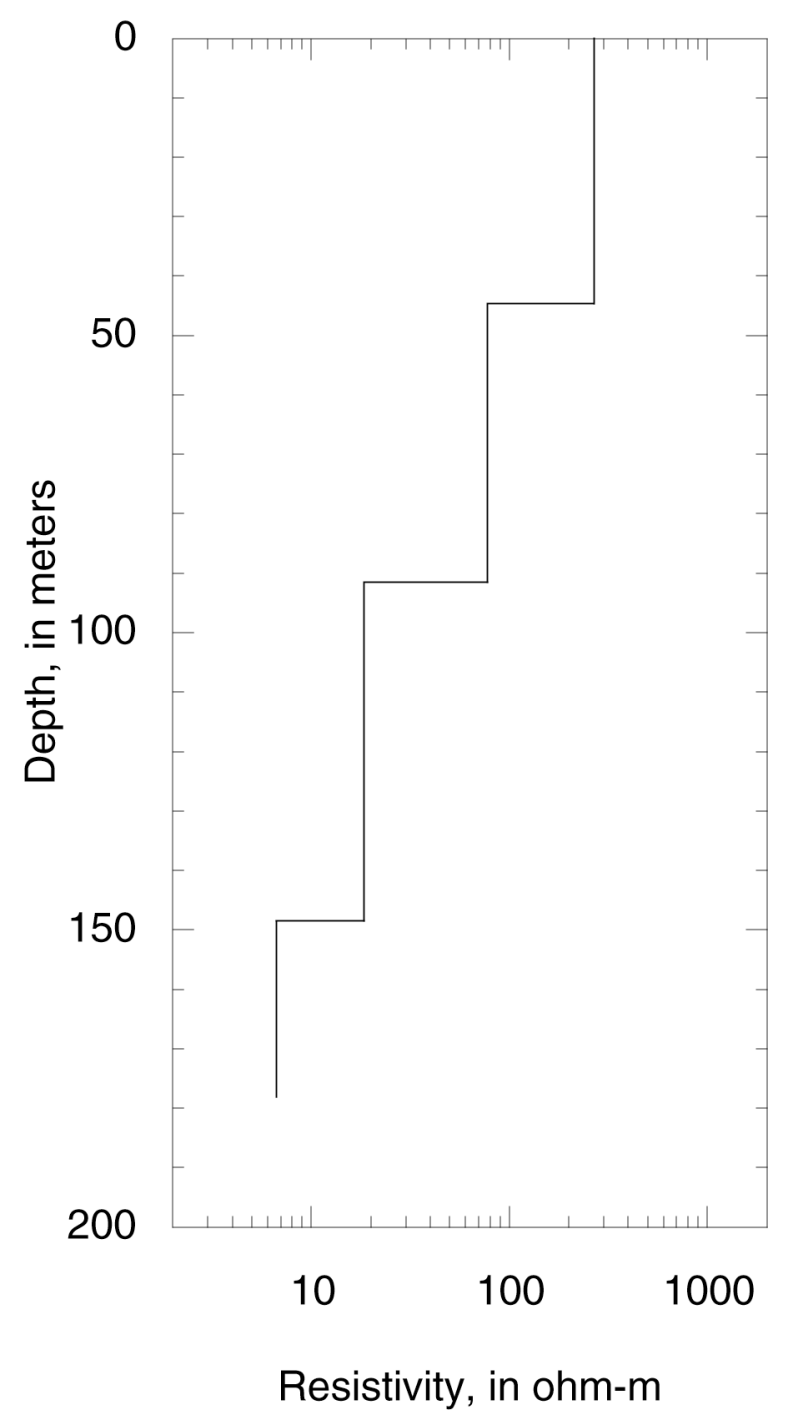

Figure E-9. Sounding GSD09 (GSL09) 
GSL10

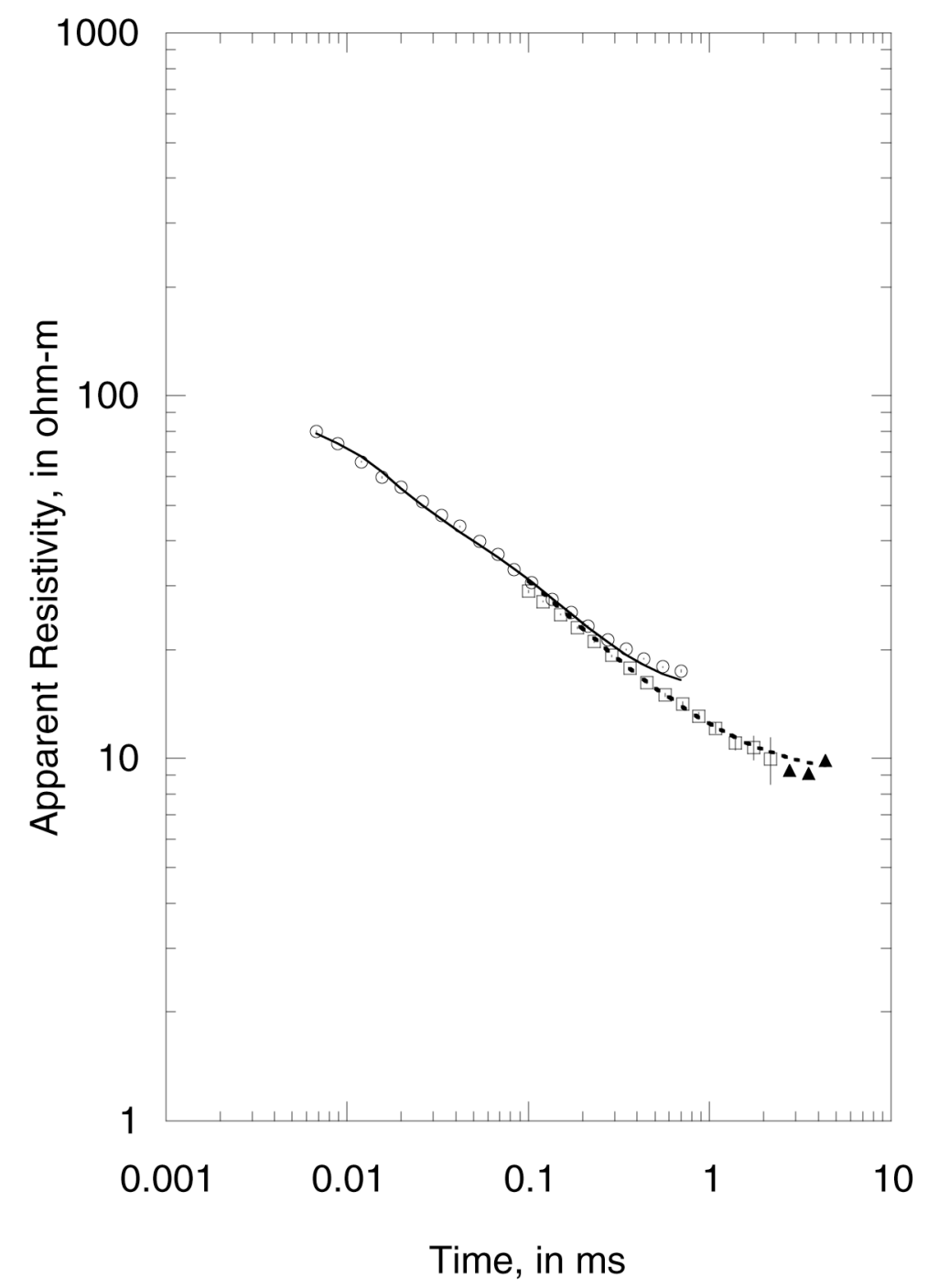

GSL10

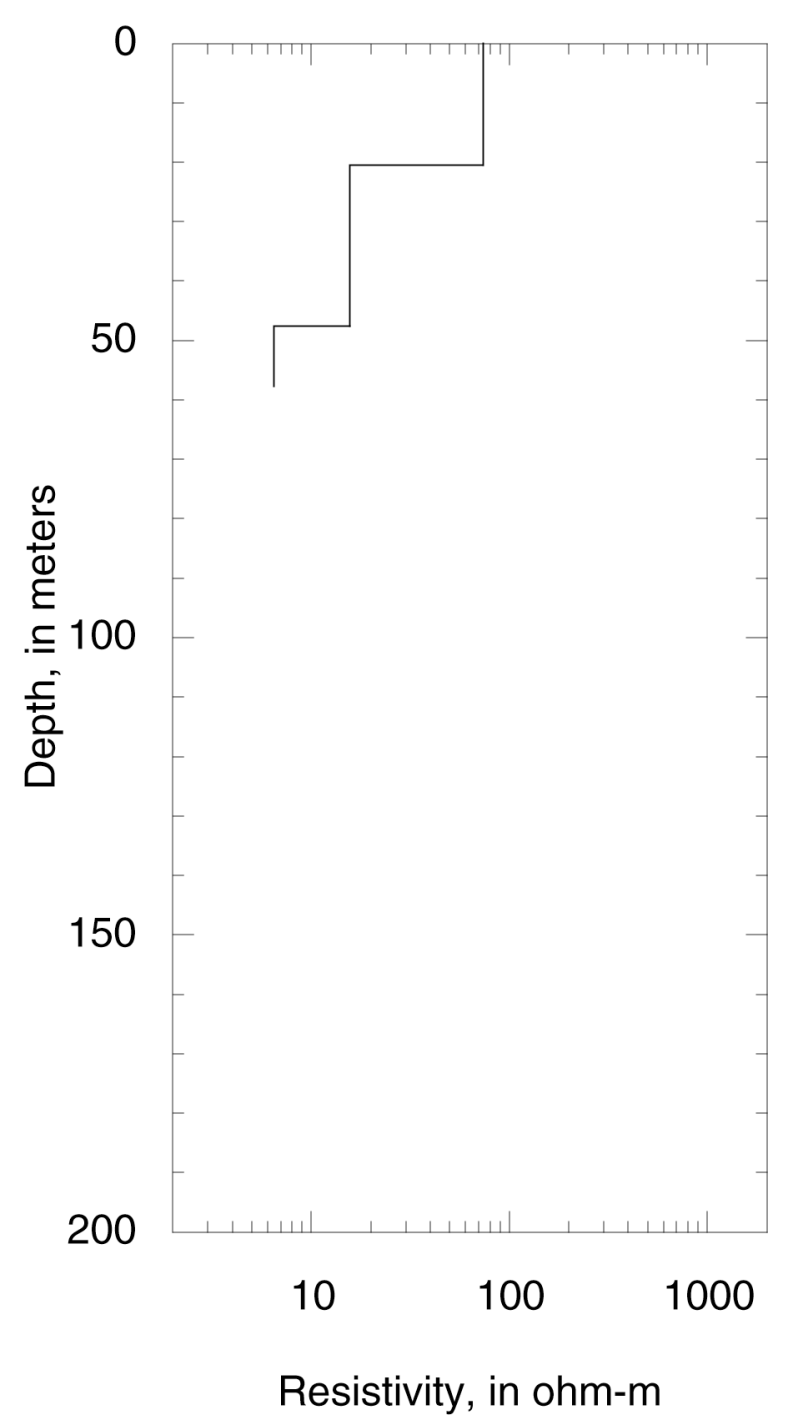

Figure E-10. Sounding GSD10 (GSL10) 
GSL11

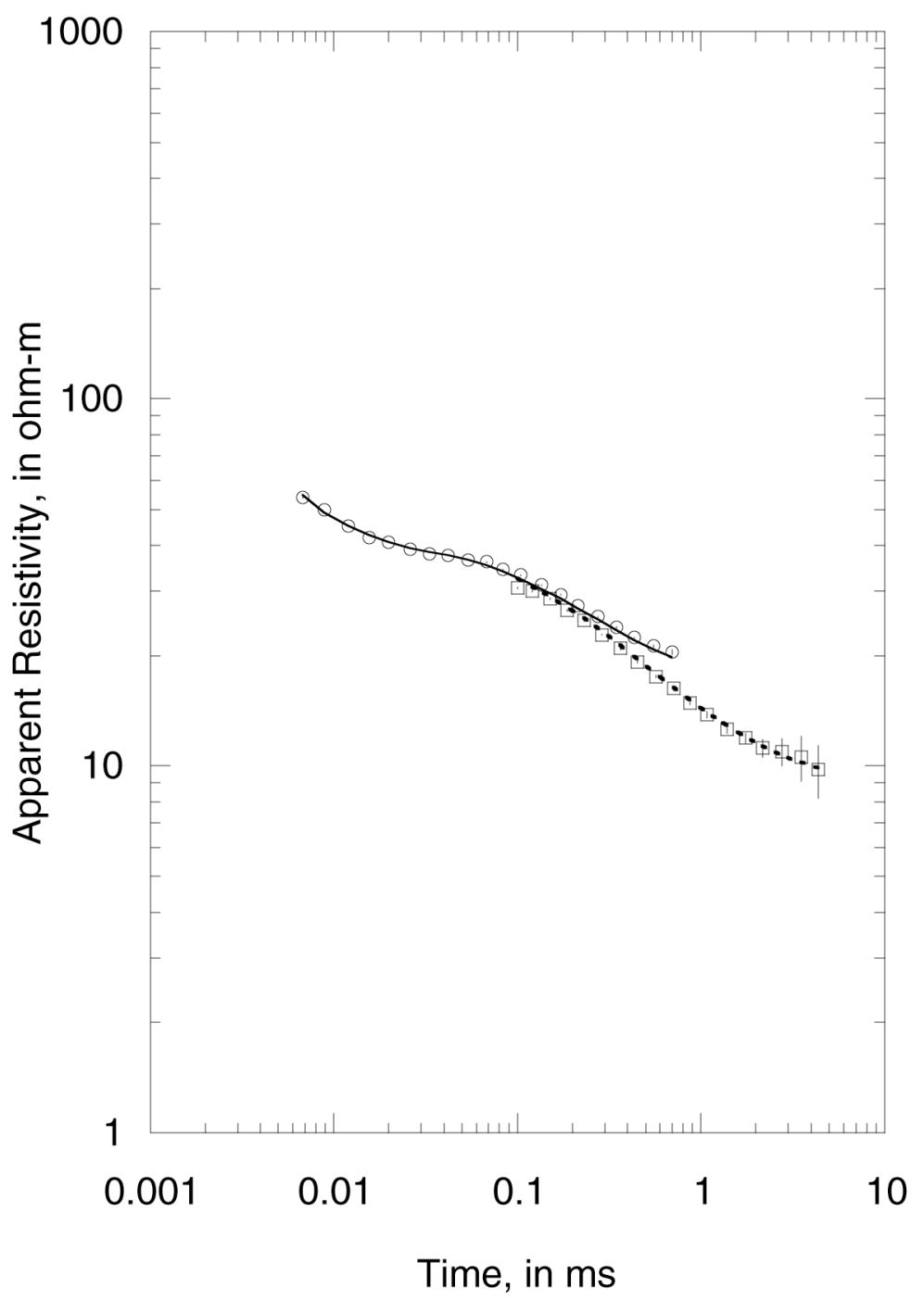

GSL11

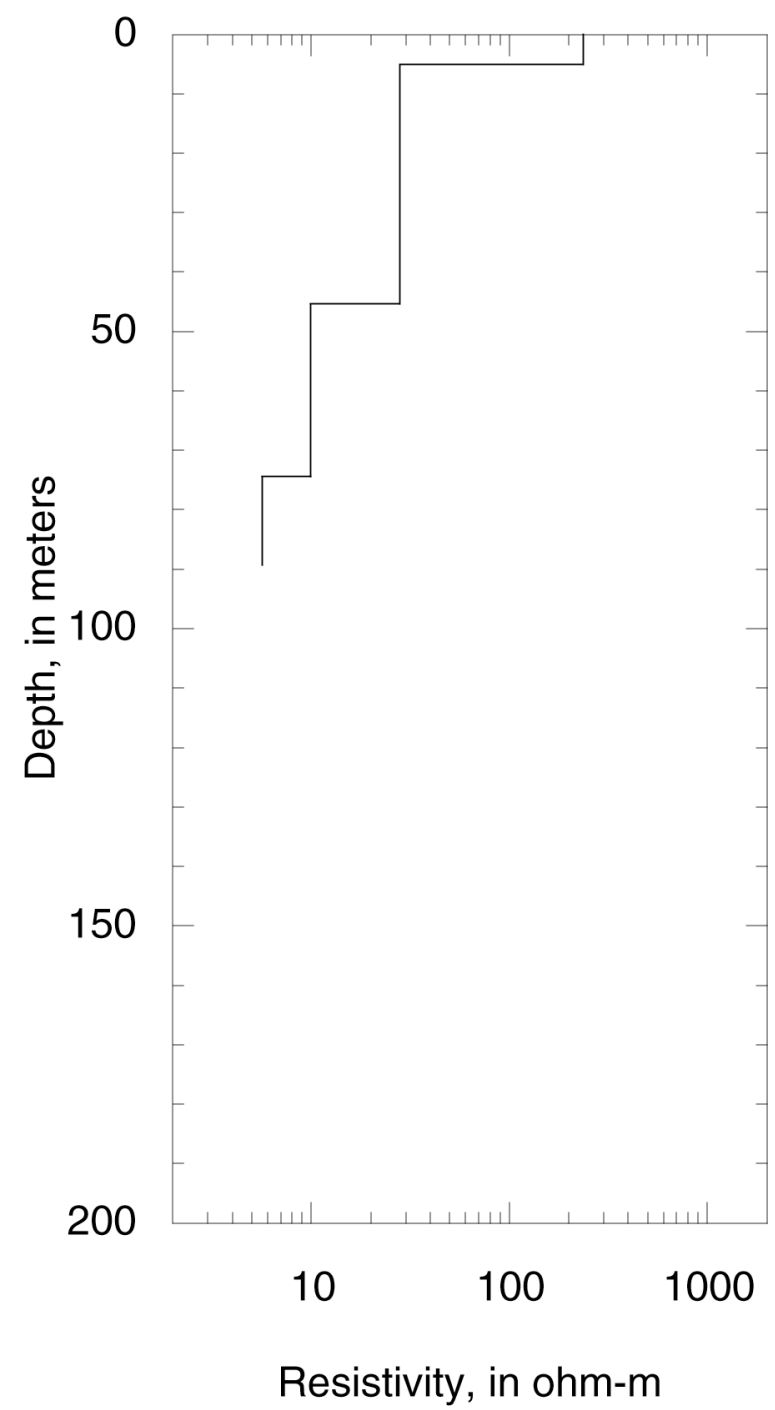

Figure E-11. Sounding GSD11 (GSL11) 
GSL12

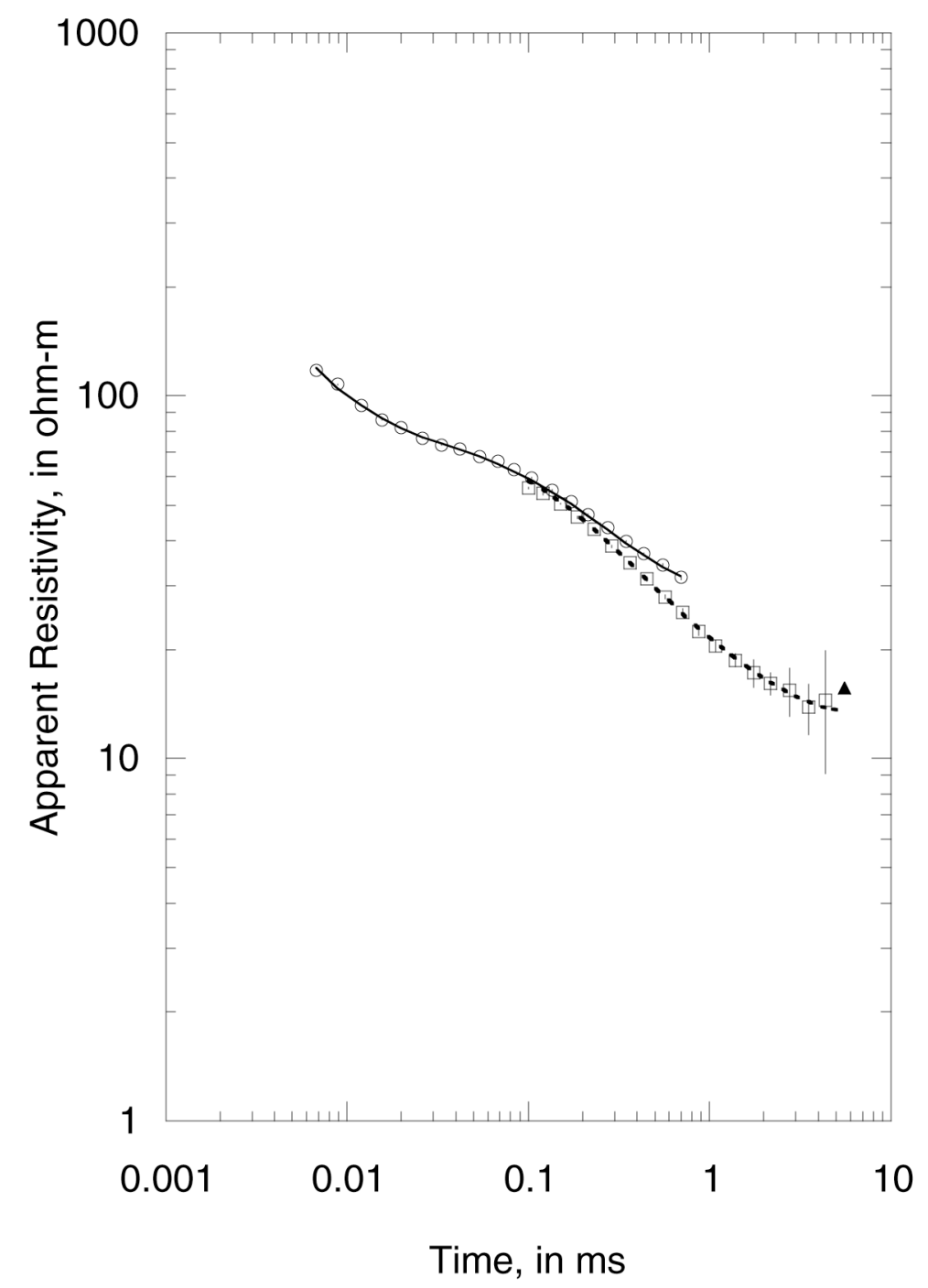

GSL12

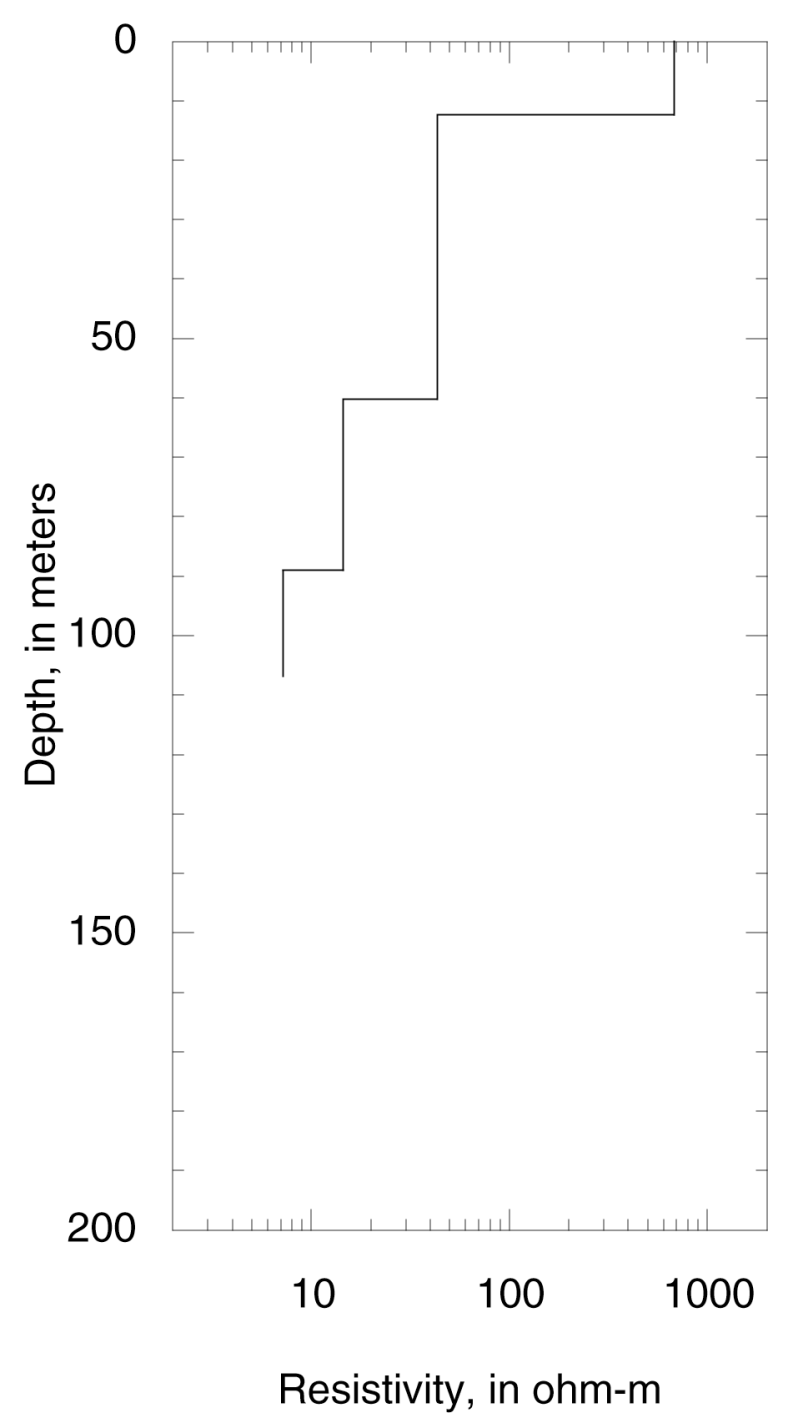

Figure E-12. Sounding GSD12 (GSL12) 
GSL13

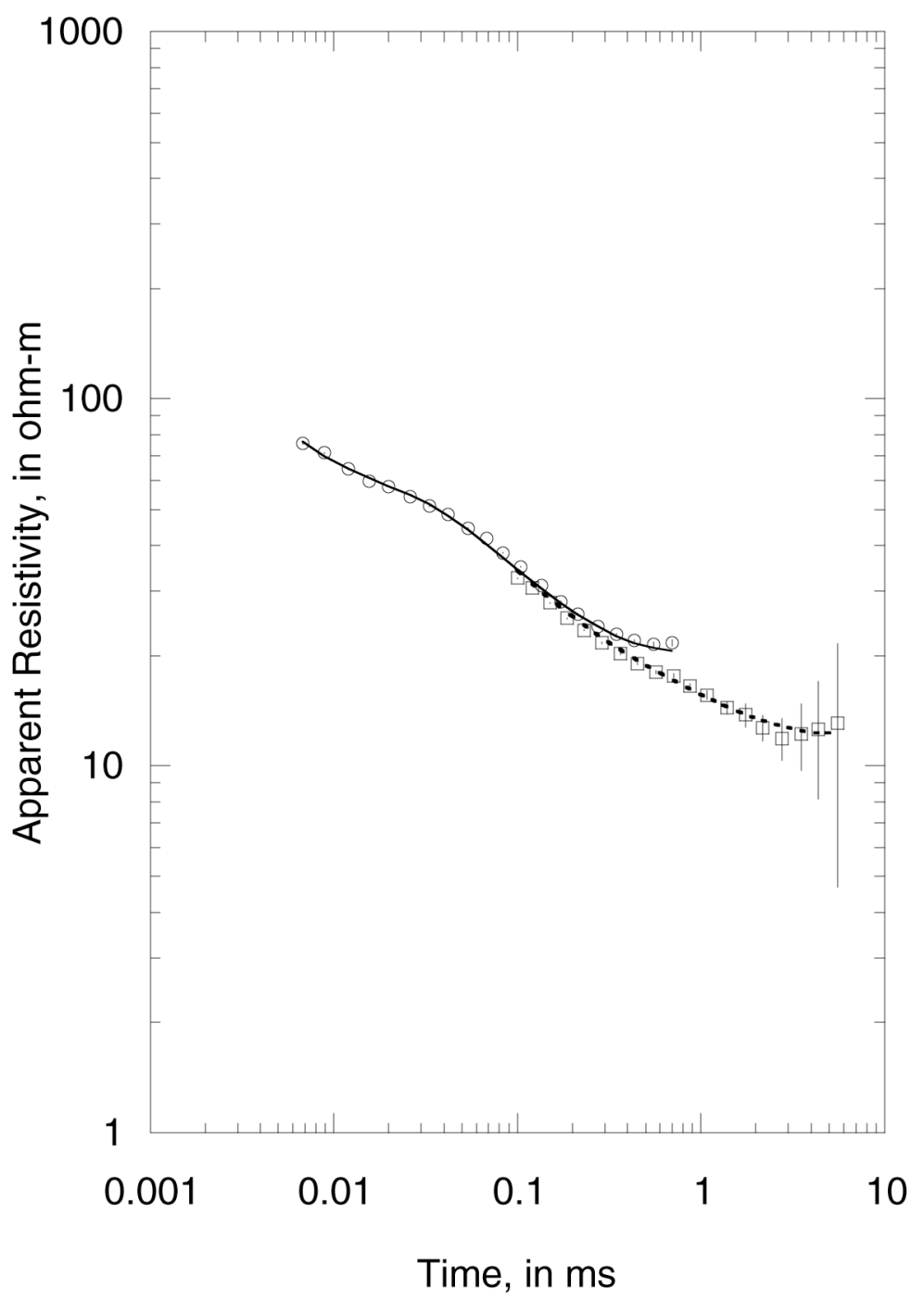

GSL13

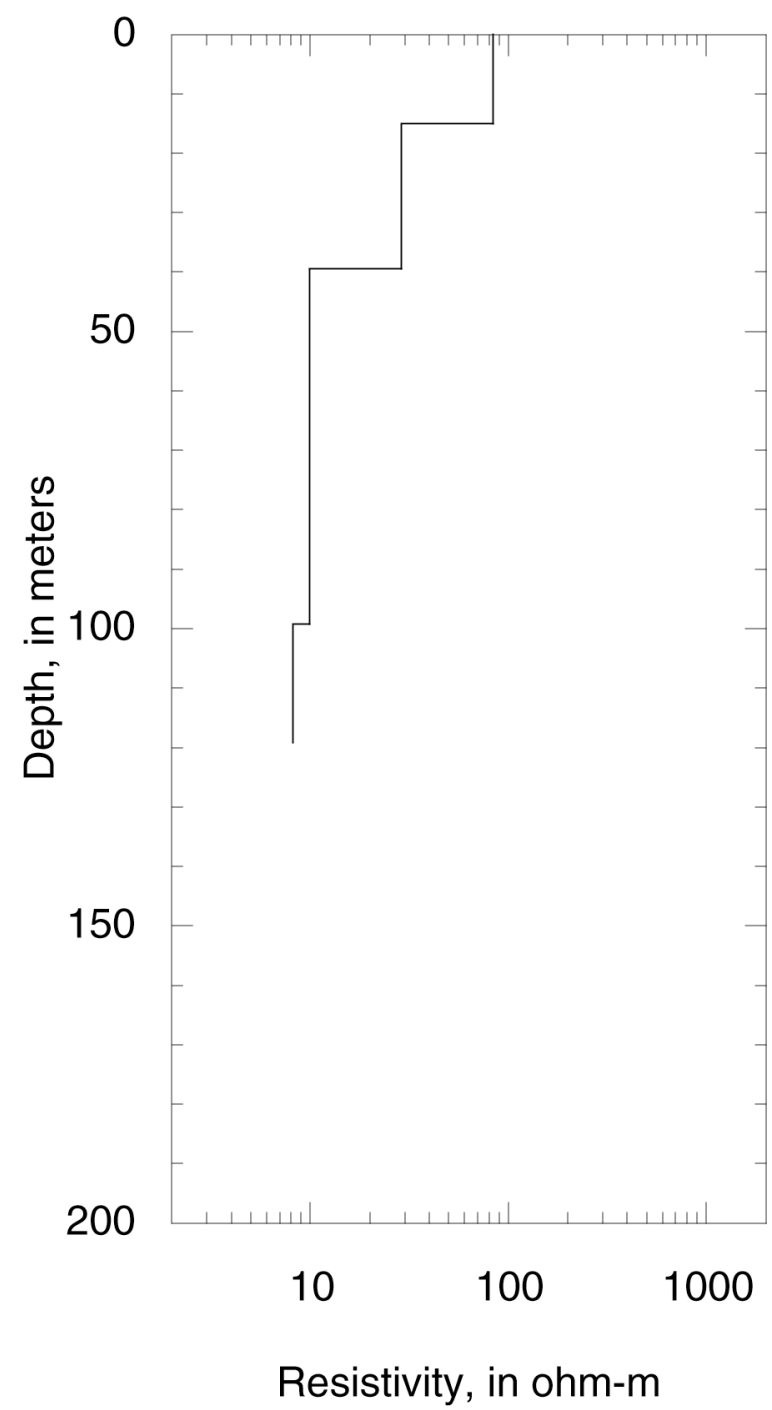

Figure E-13. Sounding GSD13 (GSL13) 
GSL14

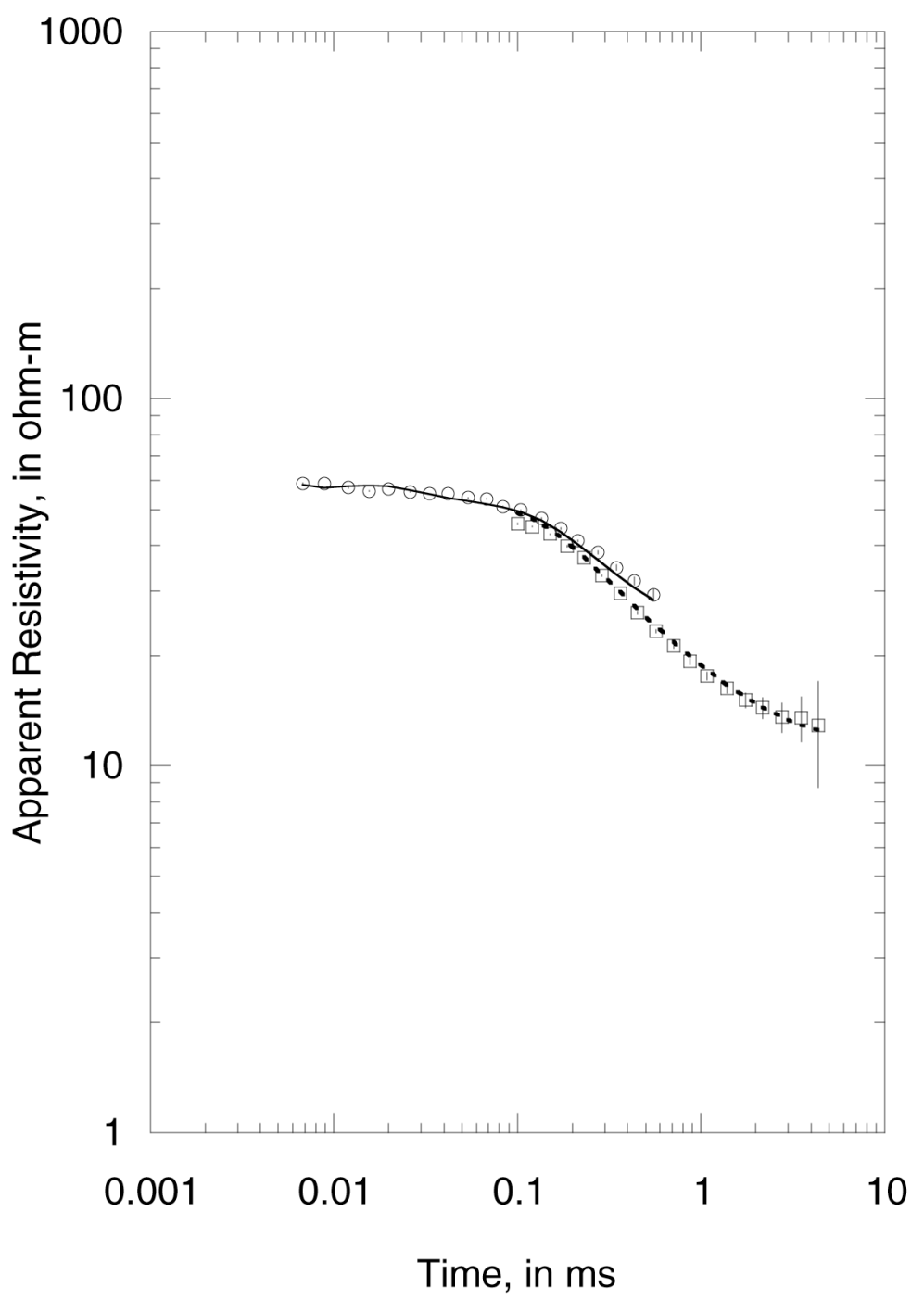

GSL14

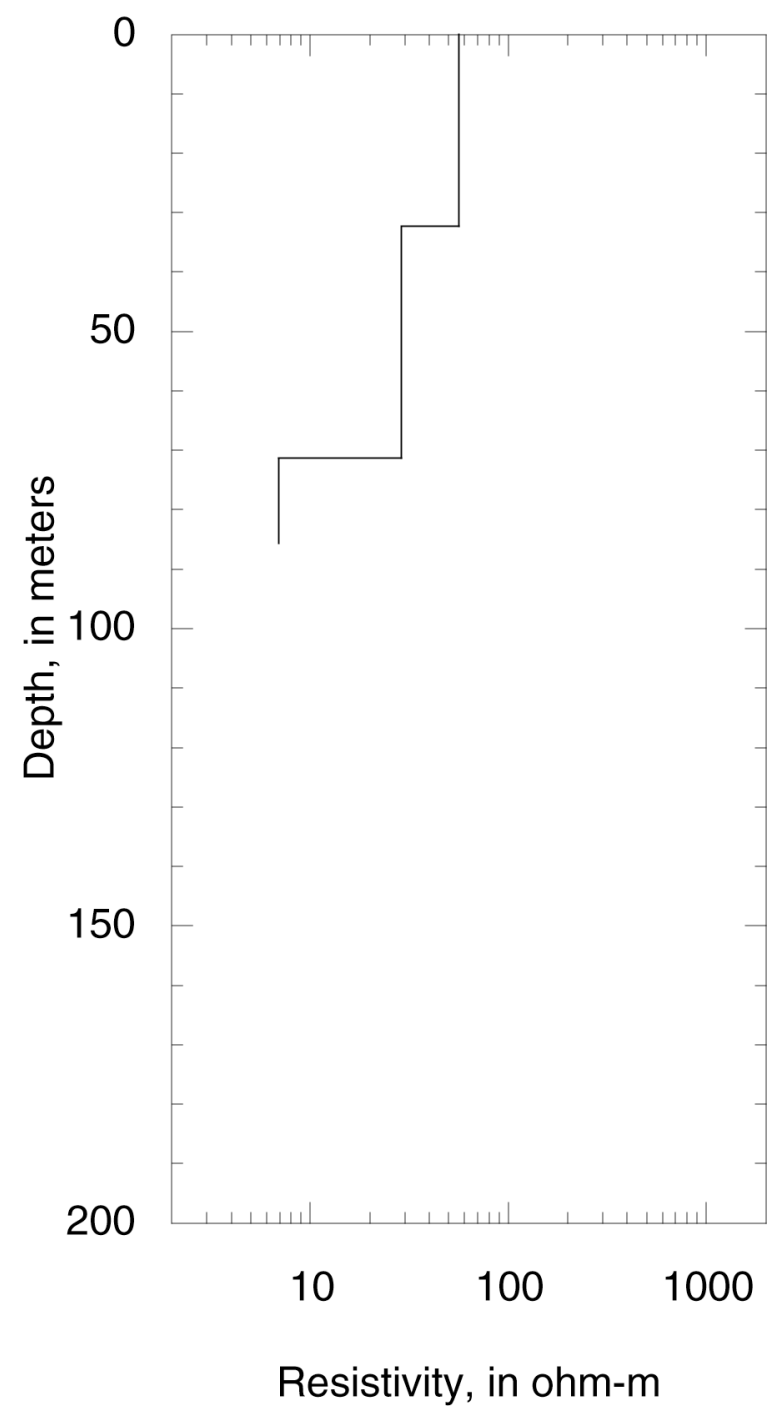

Figure E-14. Sounding GSD14 (GSL14) 
GSL15

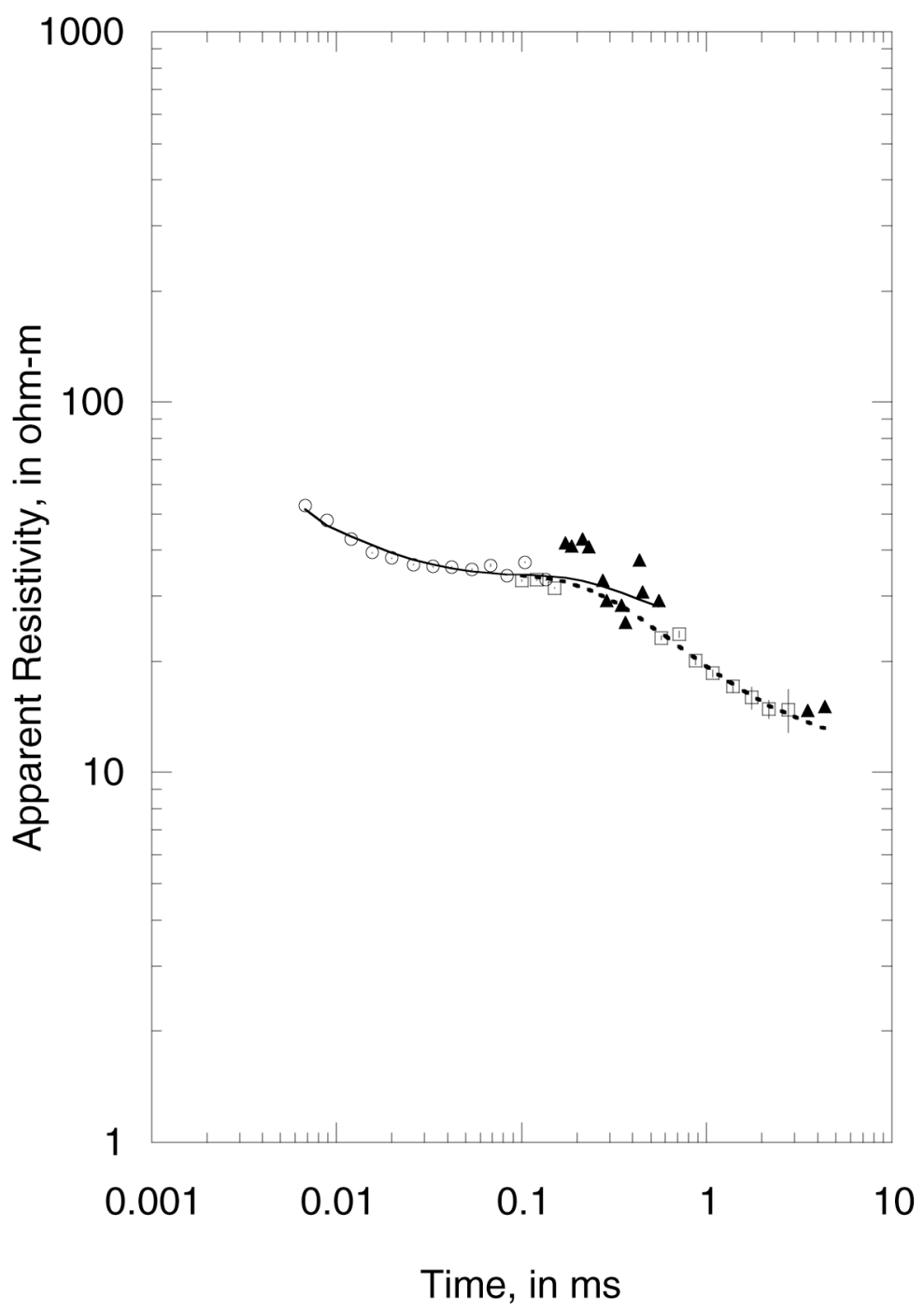

GSL15

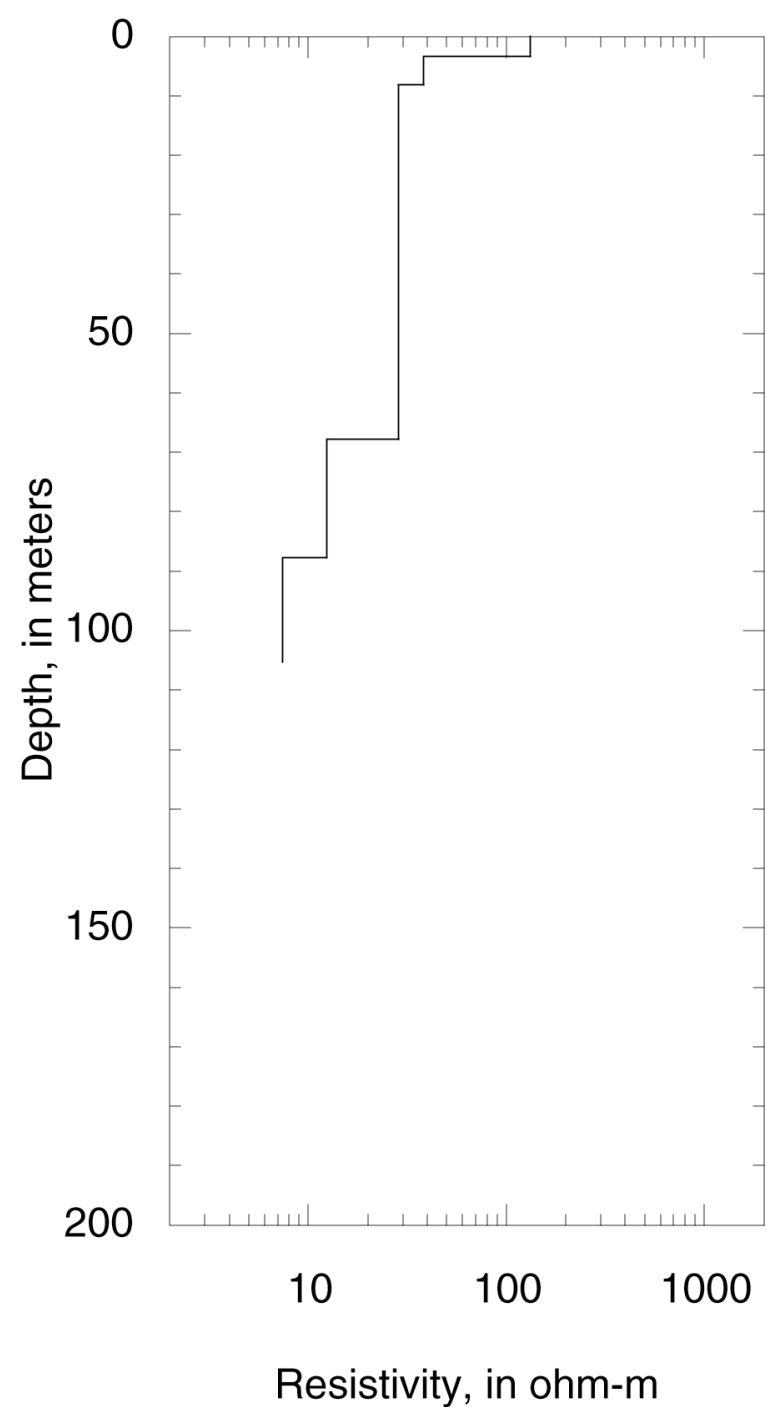

Figure E-15. Sounding GSD15 (GSL15) 
GSL16

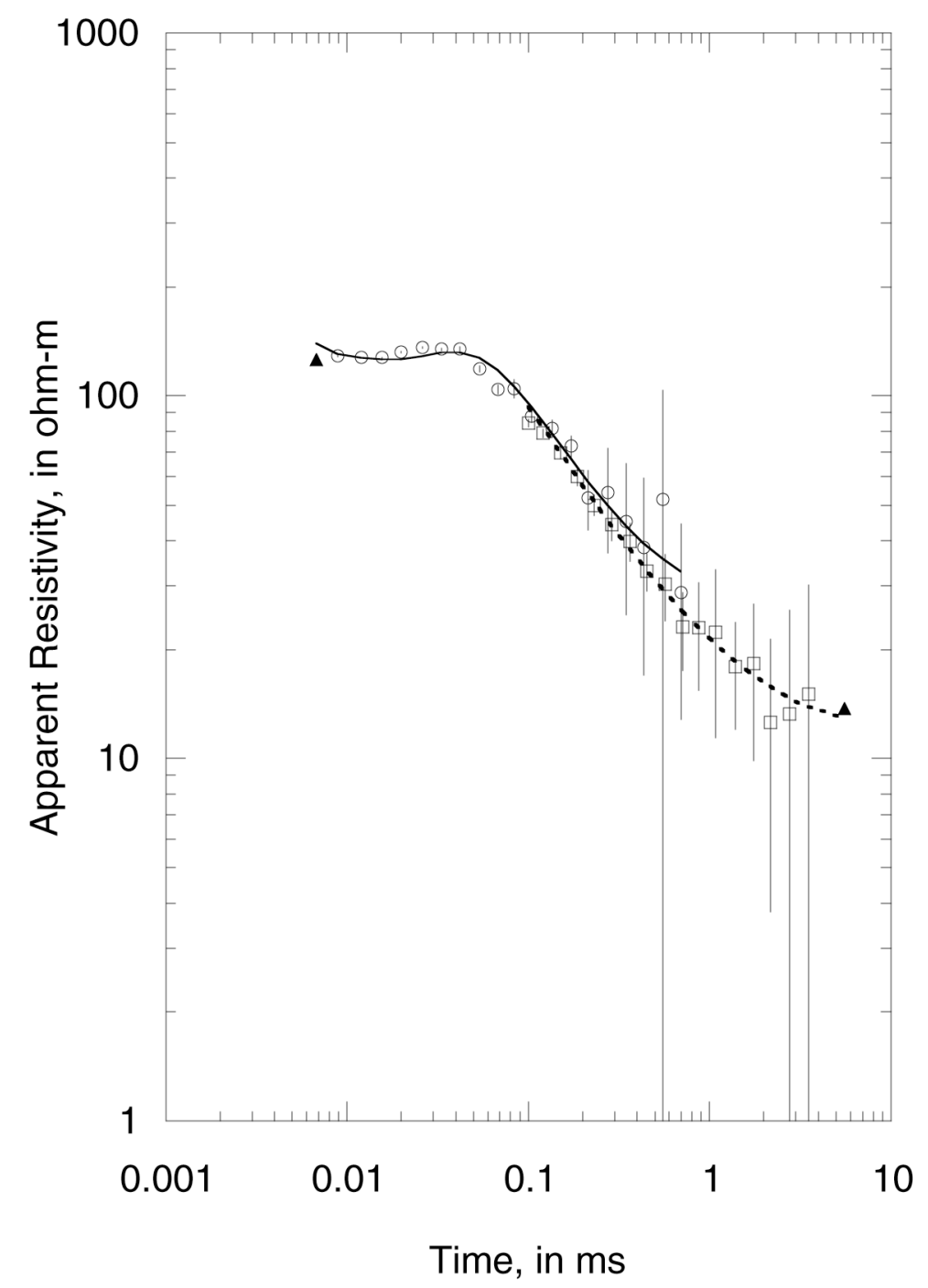

GSL16

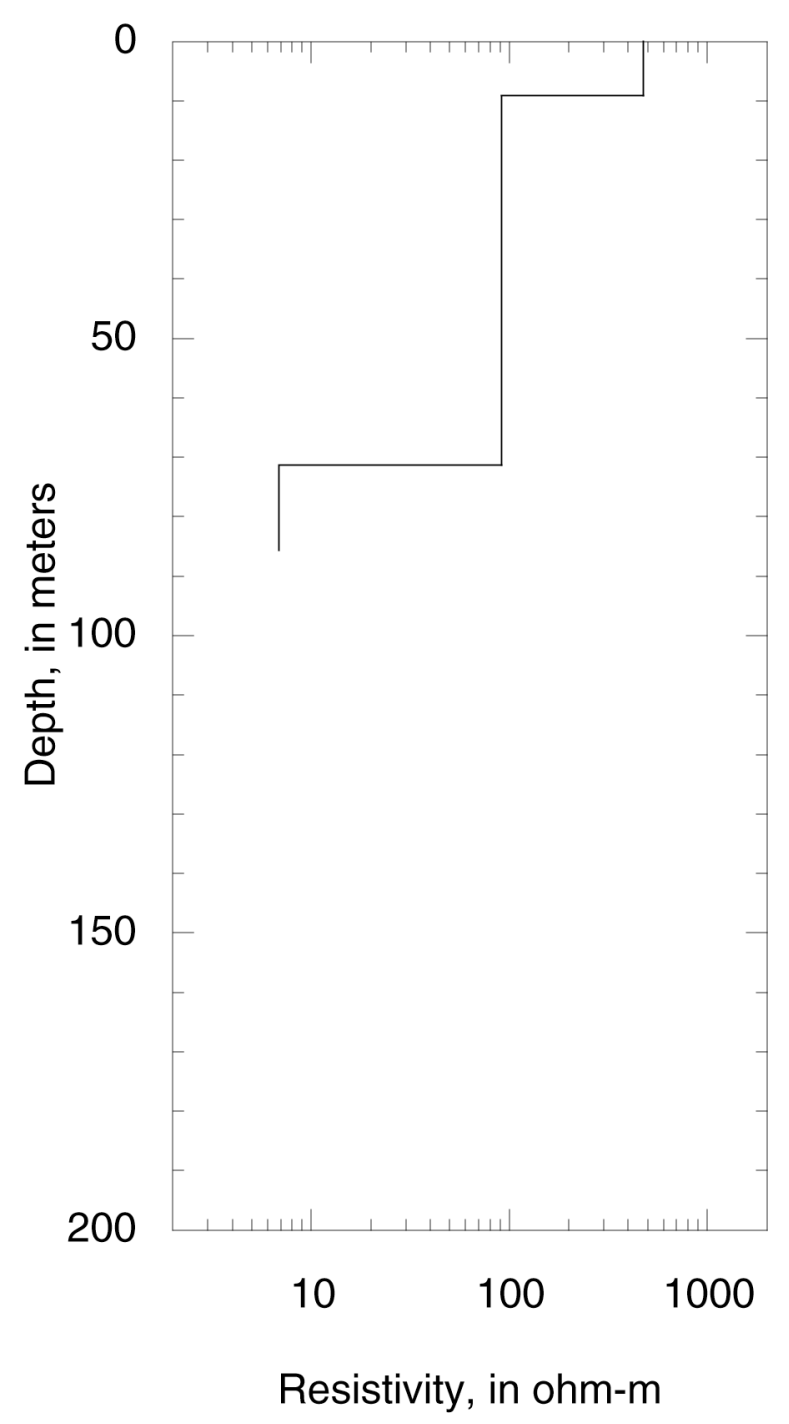

Figure E-16. Sounding GSD16 (GSL16) 


\section{GSL17}

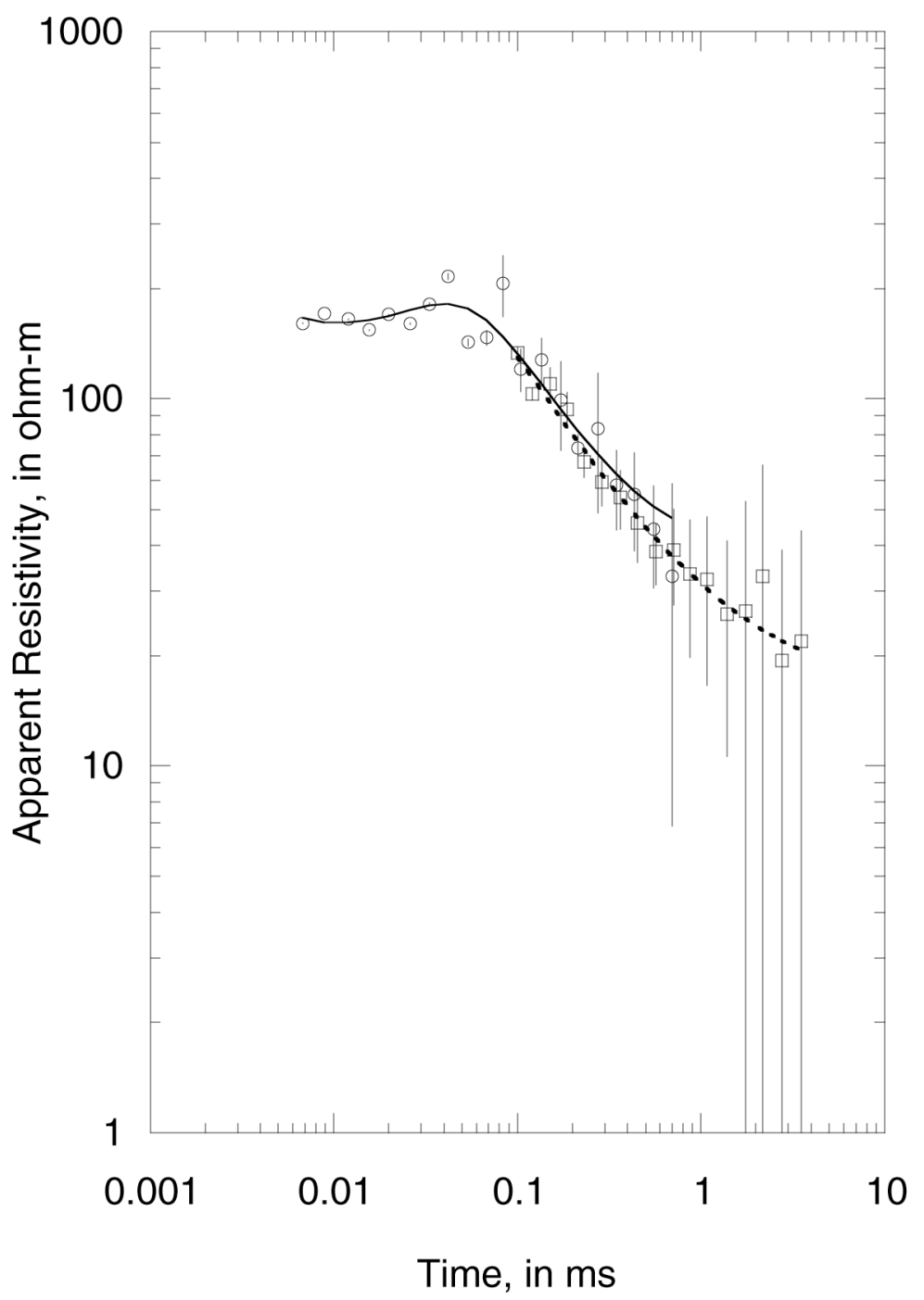

GSL17

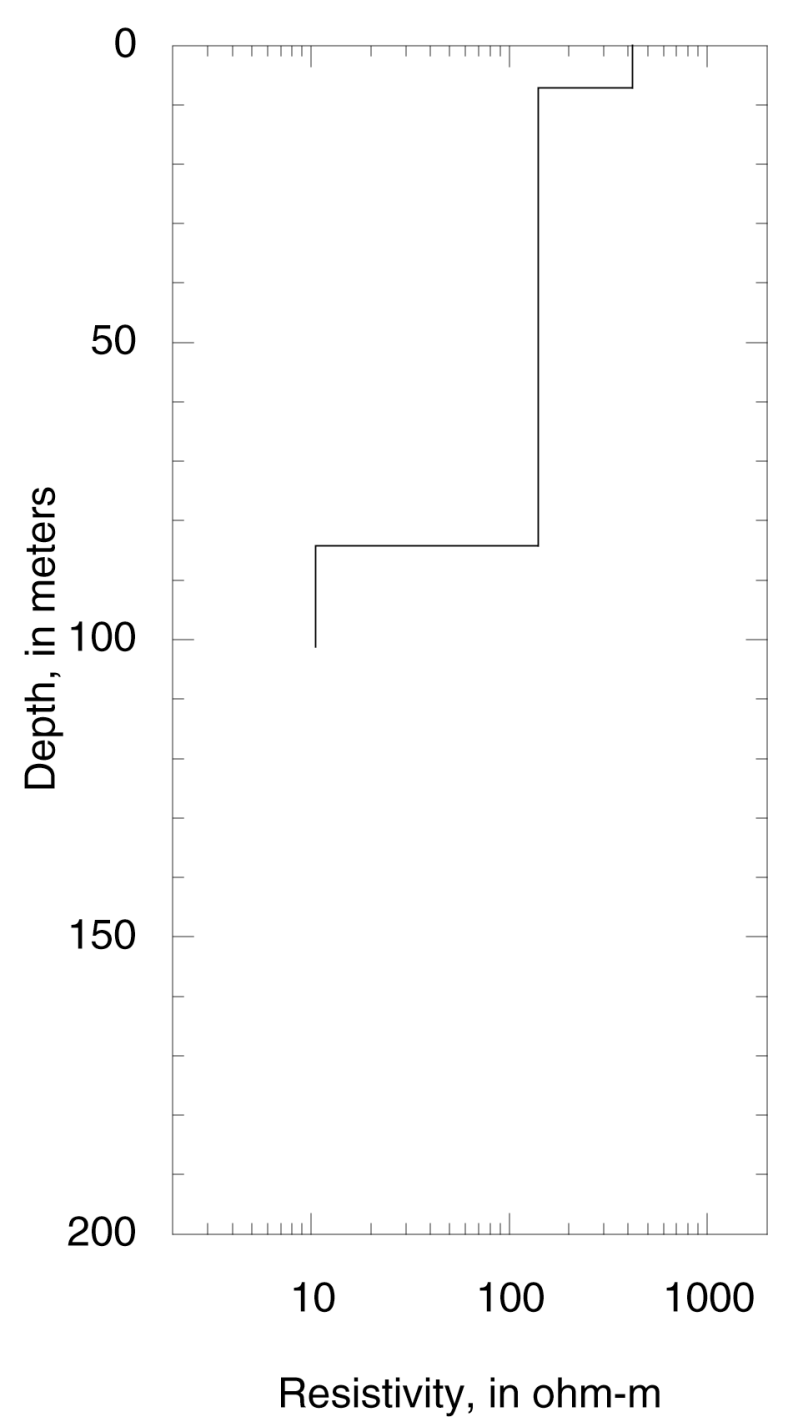

Figure E-17. Sounding GSD17 (GSL17) 